\title{
Bond Premium Cyclicality and Liquidity Traps*
}

\author{
Nicolas Caramp ${ }^{\dagger}$ \\ Sanjay R. Singh \\ University of California, Davis \\ University of California, Davis
}

February 2020

\begin{abstract}
Safe asset shortages can expose an economy to liquidity traps. The nature of these traps is determined by the cyclicality of the bond premium. A counter-cyclical bond premium opens the possibility of self-fulfilling liquidity traps. Small issuances of government debt crowd out private debt and exacerbate these pessimismdriven recessions. In contrast, government debt is expansionary in fundamental liquidity traps. In the data, we find evidence of a counter-cyclical bond premium. We propose robust policies that prevent the emergence of self-fulfilling traps and are expansionary in fundamental traps, but they require sufficient fiscal capacity. In a quantitative model calibrated to the Great Recession, a promise to increase the government debt-to-GDP ratio by 16 percentage points precludes the possibility of self-fulfilling traps.
\end{abstract}

Keywords: bond premium, safe assets, liquidity trap

JEL Classification: E0, E1, E5, E32, E52

*We thank James Cloyne, Gauti Eggertsson, Òscar Jordà, Bulat Gafarov, Athanasios Geromichalos, Pierre-Olivier Gourinchas, Veronica Guerrieri, Arvind Krishnamurthy, Alan Taylor, and seminar participants at UC Davis for comments and discussions. All remaining errors are our own. First Draft: January 2020.

${ }^{\dagger}$ Department of Economics, University of California, Davis. Email: ncaramp@ucdavis.edu

${ }_{\ddagger}^{\ddagger}$ Department of Economics, University of California, Davis. Email: sjrsingh@ucdavis.edu 


\section{Introduction}

A prominent narrative about the origins of the Great Recession is that the crisis was triggered by a collapse of the supply of safe assets. A combination of factors, such as the sudden realization that mortgage-related assets (e.g., agency and private label MBSs and CDOs) could no longer be considered safe, the deterioration of the creditworthiness of several European countries, and a global flight-to-quality, generated a scarcity of safe assets that put downward pressure on short-term nominal rates and marked the beginning of the deepest recession in the post-war era.

With conventional monetary policy constrained by the zero lower bound (ZLB) on the short-term nominal interest rate, an important body of literature advocated for an increase in the supply of (safe) U.S. government bonds in order to compensate for the private safe asset shortage. ${ }^{1}$ The idea is simple but powerful: if the crisis was caused by a drop in the supply of private safe assets, an increase in the supply of safe government bonds can at least partially offset the decline, stimulating the economy relative to laissez-faire. In this paper, we show that this policy prescription is not robust. Whether issuances of public safe assets are expansionary or not depends on the nature of the shock that hit the economy and the cyclical properties of asset prices.

We develop a theory of the macroeconomic consequences of safe asset scarcity. Our theory puts at the forefront the bond premium; that is, the premium households pay to hold assets that provide non-pecuniary benefits. The main theoretical result of the paper shows that, depending on the cyclicality of the bond premium, the economy admits two different kinds of liquidity trap equilibria, both of which feature zero nominal interest rates, a high bond premium and below-potential output. We label them fundamental and self-fulfilling liquidity traps (FLTs and SFLTs, respectively), following the seminal work of Eggertsson and Woodford (2003) and Benhabib, Schmitt-Grohé and Uribe (2001b). Unfortunately for policy makers, these two types of liquidity trap equilibria have similar observable dynamics of output, inflation and private assets but conflicting policy implications. This means that policy makers can end up in situations in which they do not know what type of trap they are facing and, therefore, have little guidance about the right policies to implement. In this paper, we show that there exist robust policies that, if credibly implemented, preclude the existence of an SFLT and stimulate the economy under an FLT.

Our model has three main ingredients. First, households are willing to pay a premium for assets that provide safety or liquidity services. In the model, this willingness arises from

\footnotetext{
${ }^{1}$ See, e.g., Caballero and Farhi (2017); Caballero, Farhi and Gourinchas (2015, 2016); Kiyotaki and Moore (2019); Del Negro, Eggertsson, Ferrero and Kiyotaki (2017b).
} 
workers' retirement concerns. Second, the supply of safe assets is endogenous and varies with the state of the economy. Production is undertaken by firms that face a constraint on their capacity to issue safe debt. We assume that debt is safe if and only if it is free from roll-over risk, that is, if it can be fully repaid using internal funds. This safety constraint gives rise to a pro-cyclical supply of safe assets. Third, the economy features nominal rigidities and a monetary policy that follows a Taylor-type interest rate rule subject to a ZLB constraint. The rich set of interactions between the demand and the supply of assets and the non-linear interest rate rule allows us to obtain novel results about the nature of recessions and their implications for policy.

A key statistic determining the type of liquidity trap the economy is exposed to is the cyclicality of the bond premium, that is, the response of the bond premium to changes in aggregate output. Our main analytical result shows that SFLTs are associated with a counter-cyclical bond premium, whereas FLTs co-exist with a pro-cyclical premium. The counter-cyclicality of the bond premium gives rise to SFLTs because expectations of low output imply a higher bond premium and a lower short-term nominal interest rate. If the bond premium is sufficiently high, the presence of the ZLB constrains the central bank in its ability to stabilize the economy, leading to a drop in employment and output, which justifies agents' pessimism. In contrast, with a pro-cyclical bond premium, expectations of low output imply a low bond premium and, hence, a high interest rate. However, according to the Taylor rule, high interest rates are not consistent with low levels of output, so SFLTs are not possible in this case. When the bond premium is pro-cyclical, only exogenous reductions in the natural rate of interest may lead the economy to a liquidity trap equilibrium.

To determine the plausibility of an SFLT, we turn to the data and estimate the response of the bond premium to cyclical movements in GDP. We find strong evidence of a countercyclical bond premium for various measures of the premium and the cycle. Our baseline specification uses monthly data from 1948 to 2011. We use the Baa-Aaa corporate bond spread as the measure of the bond premium and the annual growth rate of the industrial production index to proxy for the cycle. Following recent work by Krishnamurthy and Vissing-Jorgensen (2012) and Nagel (2016), we control for the federal funds rate and the supply of Treasury bills, as well as for the VIX as a measure of uncertainty. Our results are robust to using various measures of the output gap (Hamilton (2018) filter, band-pass filter, monthly growth rate of the industrial production index, a polynomial filter, unemployment rate, the Chicago Fed National Activity Index), and the bond premium (Baa-Aaa spread, Aaa-Treasury spread, three-month banker's acceptance rates and Treasury spread, threemonth high-grade commercial paper and Treasury spread, three-month certificate of deposit rates and Treasury spread, and spread between lower-grade commercial paper and Treasury). 
Our theoretical results also show that the cyclical properties of the bond premium depend on the relative elasticity of the demand and the supply of safe assets to aggregate output. In particular, we show that when the supply of safe assets is more (less) elastic to changes in output than the demand, the bond premium is counter-cyclical (pro-cyclical). Thus, we check the data to ascertain whether the counter-cyclicality of the bond premium is (at least in part) driven by a pro-cyclical safe asset supply. We measure private safe assets following Gorton, Lewellen and Metrick (2012)'s classification of the US financial accounts data. Crosscorrelations of total private safe assets and its sub-categories with various measures of the cycle provide suggestive evidence of a pro-cyclical supply of private safe assets, justifying our modeling assumptions.

Finally, we analyze the effects of policy intervention. We show that the issuance of (safe) government debt in small quantities is contractionary in SFLTs, while it is expansionary in FLTs. However, a sufficiently large increase in government debt can eliminate the SFLT. We interpret this result as a variation of Krugman (2014)'s timidity trap. Krugman coined the term "timidity trap" in the context of policy discussions around the Great Recession. He defined it as "(...) the consistent tendency of policy makers who have the right ideas in principle to go for half-measures in practice, and the way this timidity ends up backfiring, politically and even economically." In our setup, a small increase in government debt is contractionary in an SFLT. Instead, if the government were to credibly commit to implementing a sufficiently large-scale intervention, an SFLT scenario would cease to exist. Moreover, such a commitment would also improve the outcomes under an FLT. Thus, it is the implementation of discrete rather than incremental policies that can robustly lift the economy out of a slump. We also show that increases in government spending can have similar effects, but that they are dominated by bond issuances in terms of welfare.

An important aspect of these policy interventions is that they need to be credible. In our model, credibility has two dimensions. First, agents in the economy need to believe that if the economy finds itself in a liquidity trap, the government will be willing to intervene as promised. While this promise is an off-equilibrium outcome with respect to SFLTs (i.e., agents' anticipation of a government intervention rules out the possibility of an SFLT as an equilibrium), it can be an equilibrium outcome under FLTs. Thus, in order to rule out SFLTs, the government needs to show its commitment by implementing large-scale interventions in FLTs. Second, this "willingness" needs to be paired with a fiscal capacity to take the necessary measures. As in He, Krishnamurthy and Milbradt (2019), we constrain the government's ability to provide safe assets with a roll-over risk constraint. If the government cannot guarantee the safety of the bonds it is issuing, then the intervention will not have the desired effects. In a quantitative model calibrated to replicate a Great Recession scenario, we 
find that a commitment to increase government debt-to-GDP ratio by 16 percentage points eliminates the possibility of SFLTs.

Literature review. This paper is related to several strands of the literature. First, it is related to the literature on safe-asset shortages and credit market disruptions that lead to liquidity traps. $^{2}$ Caballero and Farhi (2017) and Caballero, Farhi and Gourinchas (2016) build models in which liquidity trap equilibria arise as the result of a shock that reduces the supply of safe assets and increases the bond premium. Similarly, Eggertsson and Krugman (2012) and Guerrieri and Lorenzoni (2017) focus on the role of debt-deleveraging in generating a liquidity trap; Curdia and Woodford (2011) and Del Negro et al. (2017b) formalize liquidity traps with financial market disruptions that cause credit spreads to rise. All these papers study FLTs, and the public provision of debt is expansionary and welfare improving (see also Gourinchas and Jeanne 2013). Acharya and Dogra (2018) study a liquidity trap episode in which increases in public debt crowd out capital investment but improve welfare. We contribute to this literature by modeling a rich interaction between the demand and supply of safe assets. We formalize a scenario in which a small increase in the provision of public debt reduces welfare. ${ }^{3}$

Our paper is also related to the literature examining expectations-driven liquidity traps. These papers show that the non-linearity of the Taylor rule can give rise to multiple steady states. Persistent pessimism about inflation, productivity growth or unemployment can shift the economy from a full employment equilibrium to an unintended steady state featuring low inflation, low growth or high unemployment, and a binding ZLB on nominal interest rates (see Benhabib et al. 2001b; Benhabib, Schmitt-Grohé and Uribe 2002 for early formalizations of these ideas). Among these, our paper is closest to Schmitt-Grohé and Uribe (2017), Benigno and Fornaro (2018) and Heathcote and Perri (2018). Schmitt-Grohé and Uribe (2017) present a model in which a pessimistic confidence shock can generate a liquidity trap featuring an initial fall in growth and a subsequent jobless recovery in which the output growth rate goes back to trend but employment is permanently lower. Benigno and Fornaro (2018) study a New Keynesian model featuring endogenous growth in which an expectations shock can permanently reduce the growth rate of the economy. Heathcote and Perri (2018) formalize the susceptibility of an economy to an expectations-driven trap due to a counter-cyclical demand for liquidity. Agents face state-contingent unemployment risk and use safe assets as a self-insurance mechanism. We rely on pro-cyclical asset demand to obtain a unified

\footnotetext{
${ }^{2}$ Bernanke (2005) and Caballero (2006) identified the role of shortage of safe assets in global imbalances and capital flows.

${ }^{3}$ In a recent paper, Mian, Straub and Sufi (2019) formalize a debt trap due to excessive debt in the economy and show that increases in public debt can reduce the level of output.
} 
framework that can generate fundamental and self-fulfilling liquidity traps. We identify the cyclicality of the bond premium as a crucial variable determining the type of recessions an economy is exposed to. Bilbiie (2018) is a recent paper that studies FLTs and SFLTs in a unified framework. Our paper differs from it in two main ways. First, we study economies that feature a state-contingent bond premium. Second, we study robust policies that can be beneficial independently of the type of trap affecting the economy. Benigno and Fornaro (2018) share our finding that sufficiently large interventions can rule out self-fulfilling traps. Our contributions are to show that discrete interventions can be robust to the type of trap and analyze the implications for the government's fiscal capacity. ${ }^{4}$

Finally, our paper contributes to the recent literature documenting the properties of the convenience yield of various safe assets. Beyond the papers already noted, our paper is related to the important contributions by Barro and Mollerus (2014), Sunderam (2015), Greenwood, Hanson and Stein (2015), Krishnamurthy and Vissing-Jorgensen (2015) and Del Negro, Giannone, Giannoni and Tambalotti (2017a). Like us, Jiang, Krishnamurthy and Lustig (2019) model pro-cyclical asset supply to analyze the global implications of US dollardenominated assets. We show the conditions under which a pro-cyclical supply of assets makes the economy vulnerable to pessimism-driven recessions and find empirical support for the two main ingredients of our model.

The paper proceeds as follows. Section 2 presents a bare-bones model formalizing our key insights. We build on the analytical device of Caballero et al. (2016) to identify the role of bond-premium cyclicality in generating contrasting policy prescriptions. We also show empirical evidence consistent with the conditions for self-fulfilling liquidity traps arising in equilibrium. Section 3 shows the mechanisms through the lens of a microfounded infinite horizon model. Section 4 studies the implications for policy and presents the robust policies. Section 5 develops a quantitative model, which allows us to show the transitional dynamics of the economy to a liquidity trap as well as to quantify the magnitudes of robust policies. Section 6 concludes.

\section{Safe Asset Scarcity: A Simple Theory and Empirics}

In this section, we outline the main ingredients of our theory in a simple log-linearized model in the spirit of Caballero et al. (2016). The main takeaway of the model is that the cyclicality of the bond premium, which depends on the output elasticity of safe asset supply relative to demand, is a key statistic determining the equilibrium properties of the

\footnotetext{
${ }^{4}$ See Obstfeld (2013) for a discussion of the importance of fiscal capacity for attenuating the aftermaths of financial crises, and Jordà, Schularick and Taylor (2016) and Romer and Romer (2018) for empirical support.
} 
economy and its policy implications. The empirical evidence suggests the plausibility of an expectations-driven scarcity of safe assets as an equilibrium outcome.

\section{$2.1 \quad$ Log-linearized model}

Consider a stationary equilibrium of an economy with permanently fixed prices. Agents prefer to hold certain financial assets because of their non-pecuniary benefits (e.g., liquidity or safety). We label them safe assets. ${ }^{5}$ A representative firm produces the consumption good and issues safe assets. The central bank sets the nominal interest rate on safe assets following a Taylor-type rule with the objective of keeping output at its natural level. We consider a cashless limit of the economy but include a zero lower bound (ZLB) constraint on the nominal interest rate. The model can be characterized by the following equations:

$$
\begin{gathered}
i^{s}=\max \left\{0, r^{s}+\phi(y-\bar{y})\right\} ; \quad \phi>1 \\
s^{d}=\psi_{i} i^{s}+\psi_{y} y-\psi_{\Delta}\left(i-i^{s}\right)+\lambda \\
s^{s}=b^{g}+\eta_{y} y \\
s^{d}=s^{s}
\end{gathered}
$$

Equation (TR) is the monetary rule of a central bank that sets the nominal interest rate on safe assets, $i^{s}$, in order to stabilize the output gap, $y-\bar{y}$, subject to the ZLB constraint. We denote the natural rate of interest (that is, the interest rate consistent with a zero output gap) by $r^{s}$. Equation (D-SA) is the safe asset demand. The demand for safe assets, $s^{d}$, is increasing in the return on safe assets $\left(\psi_{i}>0\right)$. The parameter $\psi_{y}$ captures the cyclicality of the safe asset demand. Intertemporal consumption smoothing may imply a pro-cyclical demand for safe assets $\psi_{y}>0$, while a precautionary savings motive can generate a countercyclical demand $\psi_{y}<0$. The demand for safe assets also depends on the bond premium, $i-i^{s}$, where $i$ is the rate of return of an asset that does not provide safety services, and $\psi_{\Delta}>0$ is the sensitivity of the demand to the premium. The variable $\lambda$ represents an exogenous demand shifter. Equation (S-SA) is the supply of safe assets. We assume that the supply is pro-cyclical, i.e., $\eta_{y}>0$. Borrowing constraints tied to the firms' profits can generate a pro-cyclical supply. ${ }^{6}$ Finally, $b^{g}$ denotes the provision of safe assets by the government. Equation $\left(\mathrm{SA}^{*}\right)$ clears the safe asset market. An equilibrium is characterized by these four equations.

\footnotetext{
${ }^{5}$ See Geromichalos, Herrenbrueck and Lee (2018) for an analysis of the differences between safety and liquidity.

${ }^{6}$ In the model of Section 3, we assume that in order for a financial asset to be safe, it has to be free of roll-over risk, providing a microfoundation for $\eta_{y}>0$.
} 
Figure 1: TR-SA representation
(a) $\eta_{y}-\psi_{y}<0$
(b) $\eta_{y}-\psi_{y}>0$
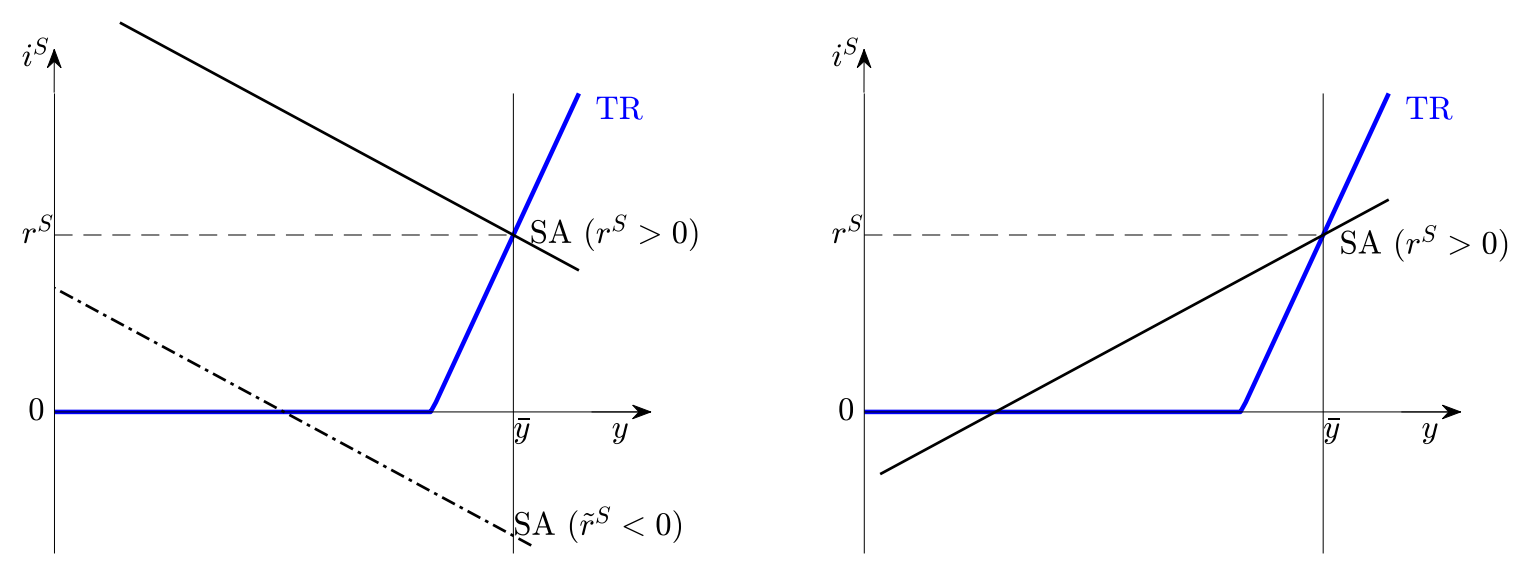

Combining equations (D-SA), (S-SA) and (SA*), we can write a system of two equations (SA) - (TR) and two endogenous variables $\left(y, i^{s}\right)$, given $r^{s}, i, b^{g}$ and $\lambda .{ }^{7}$ The safe asset (SA) equilibrium is given by

$$
\left(\eta_{y}-\psi_{y}\right) y=\psi_{i} i^{s}+\left(\lambda-b^{g}\right)-\psi_{\Delta}\left(i-i^{s}\right)
$$

In Caballero et al. (2016), $\eta_{y}=0$ and $\psi_{y}>0$, so that $\eta_{y}-\psi_{y}<0$. Here, we assume that $\eta_{y}>0$ and $\psi_{y}$ can be positive or negative, so the economy can feature $\eta_{y}-\psi_{y}>0$. Relative to Caballero et al. (2016), equation (SA) allows more flexibility in the sign of $\eta_{y}-\psi_{y}$, which represents the difference between the elasticity with respect to output of the supply and the demand of safe assets. This extension allows us to identify a new theory of safety traps.

\subsection{TR-SA representation and the bond premium}

Figure 1 plots the system (TR)-(SA). In Panel (a), we plot the equation (SA) when $\eta_{y}-\psi_{y}<$ 0 , which implies a negative relation between the return on safe assets and the output gap. We assume that the economy starts with a positive natural interest rate and the central bank keeps output at its potential. The economy is then hit by a shock that increases the demand for safe assets (e.g., an increase in $\lambda$ or a reduction in $b^{g}$ or $\eta_{y}$ ), which pushes the SA line down such that $r^{s}<0$ and the economy finds itself in a liquidity trap. Output drops below its natural level, and the economy features a higher bond premium. We call this equilibrium a Fundamental Liquidity Trap (FLT). In this equilibrium, an increase in the supply of safe

\footnotetext{
${ }^{7} \mathrm{We}$ assume that $i$ is independent of $y$ and $i^{s}$ in the stationary equilibrium of the economy. This is a typical result in standard models, where $i=\rho$ and $\rho$ is the households' subjective discount rate.
} 
assets by the government $\left(b^{g} \uparrow\right)$ shifts the SA line upward, generating an increase in output.

In Panel (b), we plot the equation (SA) when $\eta_{y}-\psi_{y}>0$, which implies a positive relation between the return on safe assets and the output gap. We assume that the natural interest rate of the economy is positive. This implies that, given monetary policy, a zero output gap is an equilibrium of the economy. However, there exists a second equilibrium in which the economy is at the ZLB, with a relative scarcity of safe assets and a higher bond premium. Starting from a full-employment steady state, agents' pessimism about the availability of safe assets or the level of output can push the economy into this liquidity trap equilibrium. This possibility is reminiscent of the mechanism in Benhabib et al. (2001b). We call this equilibrium a Self-Fulfilling Liquidity Trap (SFLT). In this equilibrium, a small increase in the provision of safe assets by the government can further reduce output and drive up the bond premium. ${ }^{8}$

It is useful to restate the previous results in terms of the cyclicality of the bond premium. Rearranging equation (SA), we get the following expression for the bond premium:

$$
i-i^{s}=\beta_{s} i^{s}+\beta_{g} b^{g}+\beta_{y}(y-\bar{y})+\beta_{\lambda} \lambda
$$

where $\beta_{s}>0$ denotes the sensitivity of the convenience yield to the central bank rate (see Nagel, 2016), $\beta_{g}<0$ captures the sensitivity to the quantity of safe government debt, $\beta_{\lambda}>0$ captures the sensitivity of the bond premium to the demand shifter $\lambda$, and $\beta_{y}$ denotes the cyclicality of the bond premium. It is immediately apparent that the bond premium is procyclical (i.e., $\beta_{y}>0$ ) if and only if $\eta_{y}-\psi_{y}<0$. Thus, this analysis allows us to connect the properties of the economy and the possibility of liquidity traps to the cyclicality of the bond premium. In particular, the previous results imply that FLTs can occur only if the bond premium is pro-cyclical, while SFLTs are associated with a counter-cyclical bond premium.

In Section 3, we present a microfounded model that clarifies the structural forces behind the cyclicality of the bond premium and the nature of liquidity traps. But first, we present some empirical evidence on two ingredients of our setup in order to assess the plausibility of SFLTs: the cyclicality of the bond premium and the cyclicality of the supply of safe assets.

\footnotetext{
${ }^{8}$ Since the equilibrium of the economy is not unique, changes in policy can also generate a change in expectations that lifts the economy from the liquidity trap. Here, we just want to point out that government bonds can be contractionary when $\eta_{y}-\psi_{y}>0$.
} 


\subsection{Empirical evidence}

\subsubsection{Data and measurement}

The estimating equation of interest is $(\mathrm{BP})$ evaluated at each period $t$

$$
i_{t}-i_{t}^{s}=\beta_{s} i_{t}^{s}+\beta_{g} b_{t}^{g}+\beta_{y}\left(y_{t}-\bar{y}_{t}\right)+\beta_{\lambda} \lambda_{t}+\varepsilon_{t}
$$

where $\varepsilon_{t}$ denotes the error term. Our main coefficient of interest is $\beta_{y}$, which measures the cyclicality of the bond premium conditional on the short-term policy rate and the public provision of safe assets.

In our baseline specification, we use monthly data from January 1948 until December 2011. Following the seminal contribution of Krishnamurthy and Vissing-Jorgensen (2012) (henceforth KVJ), we consider the Baa-Aaa corporate bond spread as our measure of the bond premium. This spread is measured as the percentage difference between Moody's Baarated long-maturity corporate bond yield and Moody's Aaa-rated long-maturity corporate bond yield. The Moody's Aaa and Baa indices are constructed from a sample of longmaturity ( $\geq 20$ years) industrial and utility bonds. Our results are robust to using other measures of the bond premium, such as long-term Aaa-Treasury, three-month banker's acceptance rates and Treasury spread (Ba-Tbill), three-month high-grade commercial paper and Treasury spread (AACP-Tbill), three-month certificate of deposit (CD) rates and Treasury spread (CD-Tbill), and spread between lower-grade commercial paper and Treasury (CPP2-Tbill). We borrow the Ba-Tbill and CD-Tbill series from Nagel (2016) and follow KVJ's data construction in extending Baa, Aaa, long-term and short-term Treasury, AACP and CPP2 yields to monthly frequency. We describe the data sources in Appendix B.

To proxy for the output gap, we use a variety of methods to estimate potential output. In our main specifications, we measure output gap using the year-on-year change in the log of industrial production index (Stock and Watson, 2003, 2019). A major advantage of using year-on-year growth as a filter to proxy for output gap is that it is one-sided and does not suffer from end-point problems nor does it induce revisions, as argued by Stock and Watson (2019). At the same time, there are disadvantages of using this one-sided filter: it passes more noise and has a phase shift relative to two-sided filters such as the band-pass filter. We conduct robustness to the following alternative measures of the output gap: the Hamilton (2018) filter, the band-pass filter of Baxter and King (1999), the polynomial sixth-degree time trend from Ramey and Zubairy (2018), the month-on-month growth rate of industrial production, the civilian unemployment rate, and the Chicago Fed National Activity Index (Brave, 2009). In Appendices C and D, we show robustness exercises that consider various 
combinations of output gap measures and financial spreads.

To be consistent across all specifications, we follow Nagel (2016) and use the overnight federal funds rate as our measure of the short-term safe rate, $i_{t}^{s}$, on the right-hand-side of equation (BP-est). We use the log of the ratio of the outstanding stock of T-bills and GDP as our measure of the public safe asset supply. ${ }^{9}$ We measure shifts in the demand for safety using the VIX index.

Following KVJ, we also control for the slope of the Treasury yield curve in our regressions. This slope is measured as the spread between the 10-year Treasury yield and the 3-month Treasury yield. ${ }^{10}$ We expect the coefficient on the slope to be positive. Even though the slope variable is likely to attenuate the effect of output gap, we include it in our main specifications in order to capture unmodeled confounding factors that may bias our estimation. In addition, we include a linear time-trend to proxy for linear secular movements in the bond premium. Our results are robust to excluding the slope and the linear time trend from the empirical specifications. We report Newey-West standard errors with twelve lags.

\subsubsection{Results}

Table 1 reports the coefficients from estimating equation (BP-est) using the long-term BaaAaa corporate bond spread as our measure of the bond premium and the year-on-year change in (log) industrial production index as our measure of the output gap. Across all columns, we find that the bond premium is counter-cyclical, i.e., $\beta_{y}<0$. The coefficients on the output gap in columns (4)-(5) imply reductions of 2.95 and 2.85 basis points (bps) in the bond premium, respectively, with a one percent increase in output growth above trend. Furthermore, the coefficients on the federal funds rate in row 2 are consistent with Nagel (2016), who finds that the convenience yield on liquid assets is positively related to the federal funds rate.

Table 2 reports the results for the baseline specification using different measures of the output gap. Columns (1-4) use common methods of extracting trends from monthly industrial production. The first row coefficient is interpreted as units of bps increase in the Baa-Aaa corporate bond spread associated with a one percent increase in output above

\footnotetext{
${ }^{9}$ The quarterly GDP series is interpolated to a monthly series for constructing the Tbill/GDP ratio. We find similar results using the (year-on-year) growth rate of Tbill supply instead of the Tbill/GDP ratio. The results are also robust to using debt-to-GDP ratio as in KVJ. However, debt-to-GDP ratio is only available at annual frequency.

${ }^{10} \mathrm{KVJ}$ write, "The slope of the yield curve is a measure of the state of the business cycle. It is known to predict the excess returns on stocks and may also pick up time-varying risk premia on corporate bonds. [...] We also note that to the extent that corporate default risk is likely to vary with the business cycle, the slope variable can furthermore help control for the expected default in the yield spread."
} 
TABLE 1: BAA-AAA SPREAD ON OUTPUT GAP (Y-O-Y $\Delta \log$ IP)

\begin{tabular}{|c|c|c|c|c|c|}
\hline & (1) & $(2)$ & (3) & (4) & $(5)$ \\
\hline Output gap & $\begin{array}{c}-3.69^{* * *} \\
(0.90)\end{array}$ & & $\begin{array}{c}-3.67^{* * *} \\
(0.90)\end{array}$ & $\begin{array}{c}-2.95^{* * *} \\
(0.64)\end{array}$ & $\begin{array}{c}-2.85^{* * *} \\
(0.55)\end{array}$ \\
\hline Fed funds rate & & $\begin{array}{c}4.61^{* * *} \\
(1.59)\end{array}$ & $\begin{array}{c}4.56^{* * *} \\
(1.24)\end{array}$ & $\begin{array}{c}5.46^{* * *} \\
(1.22)\end{array}$ & $\begin{array}{c}6.89^{* * *} \\
(1.09)\end{array}$ \\
\hline $\log (\mathrm{T}-\mathrm{Bill} / \mathrm{GDP})$ & & & & $\begin{array}{c}29.60^{*} \\
(17.50)\end{array}$ & $\begin{array}{c}9.77 \\
(14.50)\end{array}$ \\
\hline VIX & & & & $\begin{array}{c}2.11^{* * *} \\
(0.69)\end{array}$ & $\begin{array}{c}2.10^{* * *} \\
(0.77)\end{array}$ \\
\hline Slope & & & & & $\begin{array}{c}14.81^{* * *} \\
(2.86)\end{array}$ \\
\hline Intercept & $\begin{array}{c}68.74^{* * *} \\
(12.05)\end{array}$ & $\begin{array}{c}26.33^{* *} \\
(10.76)\end{array}$ & $\begin{array}{c}51.17^{* * *} \\
(9.30)\end{array}$ & $\begin{array}{c}88.28^{* *} \\
(37.13)\end{array}$ & $\begin{array}{c}34.35 \\
(30.00)\end{array}$ \\
\hline \# Obs. & 768 & $\begin{array}{l}768 \\
024\end{array}$ & $\begin{array}{l}768 \\
046\end{array}$ & 768 & $\begin{array}{l}768 \\
065\end{array}$ \\
\hline \multicolumn{6}{|c|}{$\begin{array}{l}\text { Note: Newey-West standard errors (12 lags) in parentheses. } * * * p<0.01, * * p< \\
0.05, * p<0.1 \text {. Includes a linear time-trend. Baa-Aaa spread measures the percent } \\
\text { age difference between Moody's Baa-rated long-maturity corporate bond yield an } \\
\text { Moody's Aaa-rated long-maturity corporate bond yield. output gap is computed witl } \\
\text { year on year change in log of (monthly) industrial production index. Sample: } 1948 \\
2011 \text { (monthly). }\end{array}$} \\
\hline
\end{tabular}

trend. The first row in column (5) is interpreted as units of bps increase in the Baa-Aaa corporate bond spread associated with a one percentage point increase in the unemployment rate. Using a Okun's law coefficient of two, row (1) in column (5) implies a 6.26 bps reduction in the Baa-Aaa spread when output falls one percent below potential. These estimates of the coefficient $\beta_{y}$ imply a reduction in the bond premium in the range of 2 to 7 bps when output is one percent above potential.

Table 3 reports the results for the full baseline specification using various measures for the bond premium. The output gap is measured using year-on-year change in the (log) industrial production index. We find a relatively stable estimate for the coefficient $\beta_{y}$. It is important to note that we find significant results even after controlling for several endogenous variables that are likely to mitigate the independent effects of output. We interpret this as robust evidence in favor of a counter-cyclical bond premium. In Appendices $\mathrm{C}$ and $\mathrm{D}$, we show robustness exercises that consider various combinations of output gap measures and financial spreads. 
TABLE 2: BAA-AAA SPREAD ON VARIOUS MEASURES OF OUTPUT GAP

\begin{tabular}{|c|c|c|c|c|c|}
\hline & Hamilton Filter & Band-Pass Filter & $\Delta_{m} \log \left(\mathrm{IP}_{t}\right)$ & Polynomial Filter & Unemployment Rate \\
\hline & $\begin{array}{c}(1) \\
1948-2011\end{array}$ & $\begin{array}{c}(2) \\
1948-2011\end{array}$ & $\begin{array}{c}(3) \\
1948-2011\end{array}$ & $\begin{array}{c}(4) \\
1948-2011\end{array}$ & $\begin{array}{c}(5) \\
1948-2011\end{array}$ \\
\hline Output gap & $\begin{array}{c}-2.94 * * * \\
(0.39)\end{array}$ & $\begin{array}{c}-6.19 * * * \\
(1.72)\end{array}$ & $\begin{array}{c}-6.96^{* * *} \\
(2.30)\end{array}$ & $\begin{array}{c}-2.37 * * * \\
(0.61)\end{array}$ & $\begin{array}{c}12.52^{* * *} \\
(2.46)\end{array}$ \\
\hline Fed funds rate & $\begin{array}{c}6.63^{* * *} \\
(0.88)\end{array}$ & $\begin{array}{c}7.61^{* * *} \\
(1.20)\end{array}$ & $\begin{array}{c}7.67^{* * *} \\
(1.24)\end{array}$ & $\begin{array}{c}6.90^{* * *} \\
(1.07)\end{array}$ & $\begin{array}{c}4.60^{* * *} \\
(1.08)\end{array}$ \\
\hline $\log (\mathrm{T}-\mathrm{Bill} / \mathrm{GDP})$ & $\begin{array}{c}1.03 \\
(12.88)\end{array}$ & $\begin{array}{c}18.73 \\
(15.78)\end{array}$ & $\begin{array}{l}36.31^{* *} \\
(15.58)\end{array}$ & $\begin{array}{c}-5.99 \\
(15.89)\end{array}$ & $\begin{array}{c}1.90 \\
(15.19)\end{array}$ \\
\hline VIX & $\begin{array}{l}1.97^{* *} \\
(0.81)\end{array}$ & $\begin{array}{c}2.55^{* * *} \\
(0.91)\end{array}$ & $\begin{array}{c}2.37^{* * *} \\
(0.89)\end{array}$ & $\begin{array}{c}2.61^{* * *} \\
(0.93)\end{array}$ & $\begin{array}{c}2.42^{* * *} \\
(0.90)\end{array}$ \\
\hline Slope & $\begin{array}{c}9.93^{* * *} \\
(2.57)\end{array}$ & $\begin{array}{c}13.96^{* * *} \\
(3.14)\end{array}$ & $\begin{array}{c}15.72^{* * * *} \\
(3.50)\end{array}$ & $\begin{array}{c}10.43^{* * * *} \\
(3.34)\end{array}$ & $\begin{array}{c}4.88 \\
(3.16)\end{array}$ \\
\hline Intercept & $\begin{array}{c}9.20 \\
(24.83)\end{array}$ & $\begin{array}{l}28.53 \\
(32.14)\end{array}$ & $\begin{array}{l}74.48^{* *} \\
(29.85)\end{array}$ & $\begin{array}{l}-32.51 \\
(34.75)\end{array}$ & $\begin{array}{l}-44.18 \\
(33.45)\end{array}$ \\
\hline $\begin{array}{l}\text { \# Obs. } \\
\text { Adj } R^{2}\end{array}$ & $\begin{array}{c}768 \\
0.69\end{array}$ & $\begin{array}{c}768 \\
0.59\end{array}$ & $\begin{array}{c}768 \\
0.56\end{array}$ & $\begin{array}{c}768 \\
0.59\end{array}$ & $\begin{array}{c}768 \\
0.63\end{array}$ \\
\hline
\end{tabular}

Note: Newey-West standard errors (12 lags) in parentheses. $* * * p<0.01, * * p<0.05, * p<0.1$. Includes a linear time-trend. output gap is computed with various filters common in the literature. Column 1 uses the Hamilton filter on the (monthly) industrial production index. The index is seasonally adjusted. Column 2 uses the Band-Pass filter at business cycle frequencies (18 and 96 months) on the (monthly) industrial production index. Column 3 uses month-over-month change in the log of (monthly) industrial production index. Column 4 estimates a counterfactual potential (monthly) industrial production index using a (sixth-degree) polynomial regression on time. Column 5 uses the civilian unemployment rate. Baa-Aaa spread measures the percentage difference between Moody's Baa-rated long-maturity corporate bond yield and Moody's Aaa-rated long-maturity corporate bond yield.

\subsection{Empirical evidence of the cyclicality of private safe asset sup- ply}

\subsubsection{Data and measurement}

Gorton et al. (2012) use the U.S. Financial Accounts to obtain a quarterly time-series of the total supply of safe assets. We follow their definitions to reproduce the time-series of privately issued safe assets. The safe assets include bank deposits, money market mutual fund shares, commercial paper, federal funds and repurchase agreements, short-term interbank loans, securitized debt, and high-grade financial sector corporate debt. Their rationale for defining these asset classes as safe is that they were information-insensitive assets before the Great Recession (see also Gorton and Metrick, 2012). Total private safe assets are disaggregated into five sub-categories: deposits, money-like debt, mortgage- and asset-backed securities (MBS/ABS), corporate bonds and loans, and other safe assets (miscellaneous liabilities of the financial sector). Money-like debt refers to commercial paper, net repurchase agreements, money market mutual fund assets, federal funds, interbank transactions, brokerdealer payables, and broker-dealer security credits. We briefly describe the data construction 
TABLE 3: FinANCIAL SPREAds ON OUTPUT GaP (Y-O-Y $\Delta$ log IP)

\begin{tabular}{|c|c|c|c|c|c|c|}
\hline & Baa-Aaа & Aaa-Tbill & BA-Tbill & AACP-Tbill & CD-Tbill & CPP2-Tbill \\
\hline & $\begin{array}{l}(1) \\
\end{array}$ & $(2)$ & $(3)$ & $(4)$ & $(5)$ & (6) \\
\hline & $1948-2011$ & $1948-2011$ & $1948-2011$ & $1948-2011$ & $1976-2011$ & $1998-2011$ \\
\hline Output gap & $\begin{array}{c}-2.85 * * * \\
(0.55)\end{array}$ & $\begin{array}{c}-2.25^{* * *} \\
(0.68)\end{array}$ & $\begin{array}{c}-1.45^{* * *} \\
(0.40)\end{array}$ & $\begin{array}{c}-1.08^{* *} \\
(0.43)\end{array}$ & $\begin{array}{c}-1.90^{* *} \\
(0.89)\end{array}$ & $\begin{array}{l}-1.83 \\
(1.94)\end{array}$ \\
\hline Fed funds rate & $\begin{array}{c}6.89^{* * *} \\
(1.09)\end{array}$ & $\begin{array}{c}4.15^{* * *} \\
(0.95)\end{array}$ & $\begin{array}{c}10.90^{* * *} \\
(1.13)\end{array}$ & $\begin{array}{c}6.96^{* * *} \\
(1.07)\end{array}$ & $\begin{array}{c}14.38^{* * * *} \\
(2.54)\end{array}$ & $\begin{array}{c}34.21^{* *} \\
(15.12)\end{array}$ \\
\hline $\log (\mathrm{T}-\mathrm{Bill} / \mathrm{GDP})$ & $\begin{array}{c}9.77 \\
(14.50)\end{array}$ & $\begin{array}{c}-59.08^{* * *} \\
(18.40)\end{array}$ & $\begin{array}{c}-25.68^{* *} \\
(11.60)\end{array}$ & $\begin{array}{l}-13.57 \\
(11.72)\end{array}$ & $\begin{array}{l}-28.38 \\
(37.71)\end{array}$ & $\begin{array}{l}-41.32 \\
(71.13)\end{array}$ \\
\hline VIX & $\begin{array}{c}2.10^{* * *} \\
(0.77)\end{array}$ & $\begin{array}{c}1.85^{* * *} \\
(0.47)\end{array}$ & $\begin{array}{c}1.75^{* * *} \\
(0.48)\end{array}$ & $\begin{array}{c}1.78^{* * *} \\
(0.44)\end{array}$ & $\begin{array}{c}3.42^{* * *} \\
(1.00)\end{array}$ & $\begin{array}{c}6.88^{* * * *} \\
(2.64)\end{array}$ \\
\hline Slope & $\begin{array}{c}14.81^{* * *} \\
(2.86)\end{array}$ & $\begin{array}{l}8.84^{* *} \\
(3.97)\end{array}$ & $\begin{array}{l}-1.05 \\
(2.77)\end{array}$ & $\begin{array}{l}-4.30 \\
(2.68)\end{array}$ & $\begin{array}{c}10.30^{*} \\
(6.08)\end{array}$ & $\begin{array}{c}27.61 \\
(17.64)\end{array}$ \\
\hline Intercept & $\begin{array}{c}34.35 \\
(30.00)\end{array}$ & $\begin{array}{c}-136.26^{* * *} \\
(35.32)\end{array}$ & $\begin{array}{c}-67.73^{* *} \\
(26.64)\end{array}$ & $\begin{array}{c}22.50 \\
(29.01)\end{array}$ & $\begin{array}{c}-300.65^{* *} \\
(133.19)\end{array}$ & $\begin{array}{c}-1223.77^{* *} \\
(520.80)\end{array}$ \\
\hline \# Obs. & 768 & 768 & 768 & 768 & 432 & 168 \\
\hline Adj $R^{2}$ & 0.65 & 0.47 & 0.62 & 0.49 & 0.38 & 0.52 \\
\hline
\end{tabular}

Note: Newey-West standard errors (12 lags) in parentheses. $* * * p<0.01, * * p<0.05, * p<0.1$. Includes a linear time-trend. Output gap is computed with year-on-year change in the log of (monthly) industrial production index. Column 1 uses the percentage spread between Moody's Baa-rated longmaturity corporate bond yield and Moody's Aaa-rated long-maturity corporate bond yield. Column 2 uses the percentage spread between Moody's Aaa-rated long-maturity corporate bond yield and the yield on long-maturity Treasury bonds. Column 3 use the three-month banker's acceptance rate and T-bills. The data series for the banker's acceptance rate ends in the 1990s. To create a series until 2011, we use the GC repo/T-bill spread from 1991 onward constructed by Nagel (2016). Column 4 uses the percentage yield spread between 3-month high-grade commercial paper and Treasury bills. Column 5 uses the spread between three-month certificate of deposit (CD) rates and T-bills as an alternative measure of the illiquid rate. Column 6 uses the percentage yield spread between lowergrade commercial paper and Treasury bills. It is calculated as the sum of the CP-bills yield spread described above (i.e., high-grade commercial paper minus Treasury bills) and the yield spread between 30-day A2/P2 nonfinancial commercial paper and 30-day AA nonfinancial commercial paper, with data obtained from the Federal Reserve Bank of New York.

and disaggregation of total private safe assets in Appendix B, but refer the reader to Gorton et al. (2012) for a detailed methodology.

\subsubsection{Results}

Figure 2 plots the detrended time series of safe assets along with real GDP. In Panel (a), we plot both series in terms of year-on-year growth rates, consistent with our empirical specifications in Section 2.3.2. In Panel (b), we plot both series using the Hamilton (2018) filter for robustness. A strong positive correlation between the two series suggests the procyclicality of private safe asset supply in the US. Figure 3 presents the cross-correlations between various components of the safe asset supply at $t+h$ and real GDP at time $t$. The top-left panel plots the cross-correlations for the total private safe assets. Remaining panels show the cross-correlations for the five sub-categories of total private safe assets. All series 
Figure 2: Cyclicality of privately supplied safe debt

(a) Growth rates

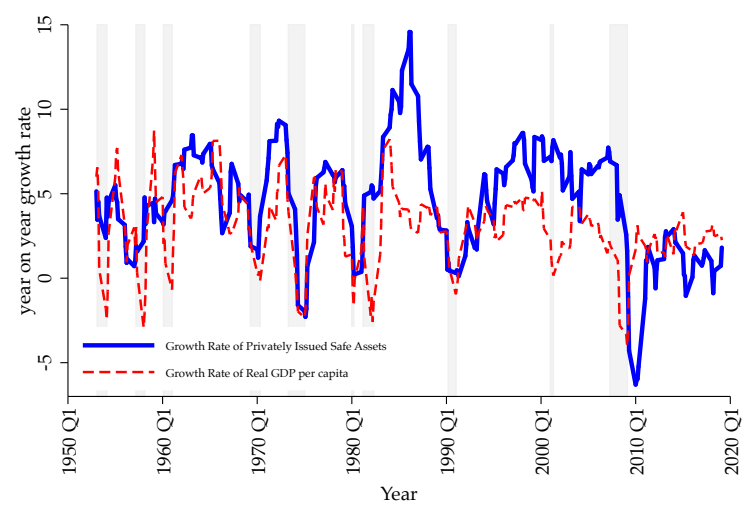

(b) Hamilton (2018) filter-based cycle

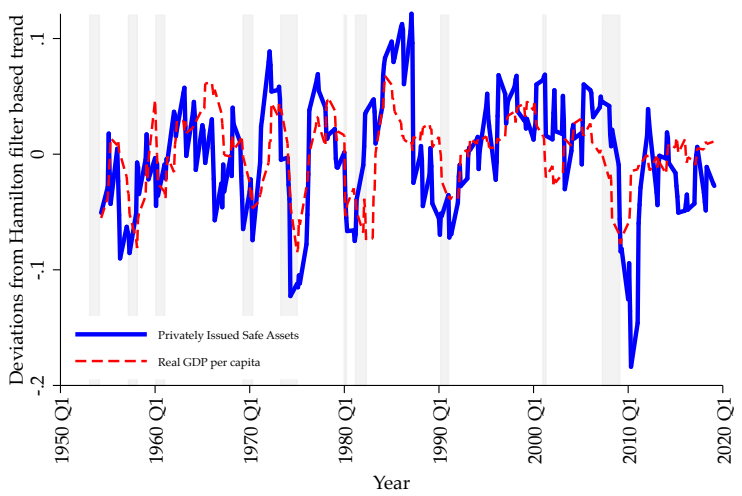

Source: Our calculations. We extended Gorton et al. (2012)'s definition to measure safe assets using US Financial Accounts data retrieved from FRED, St. Louis Fed. Shaded bars denote NBER Recession dates. See text.

are transformations of the underlying asset series into year-on-year growth rates. These cross-correlations between various components of private safe assets and output align with the pro-cyclicality of safe asset supply suggested by Figure 2. It is worth noting that our sample includes the Great Recession, but all the results are robust to excluding the 20082011 period. Moreover, the results are robust to using alternative measures of output gap. We present these additional robustness results in Appendix F.

\subsection{Summary of the Empirical Analysis}

Let us briefly summarize the key takeaways from our empirical analysis and the way it connects to the log-linearized model. We find strong suggestive evidence that: $a$ ) the bond premium is counter-cyclical, and $b$ ) safe assets supplied by the U.S. private sector are procyclical. As the simple model shows, the counter-cyclicality of the bond premium gives rise to the possibility of a self-fulfilling scarcity of safe assets that pushes the economy into a liquidity trap. Furthermore, we identified a force driving this result: the supply of private safe assets is pro-cyclical in the data. Importantly, we do not argue against the possibility of FLTs but instead interpret these results as providing empirical support to the plausibility of SFLTs. In the next section, we use these findings to build a microfounded model that clarifies the channels of transmission and provides a laboratory suitable for the analysis of policies that are robust to FLTs and SFLTs. 
Figure 3: Correlations of $x_{t+h}$ with time-t real GDP (y-o-y growth)
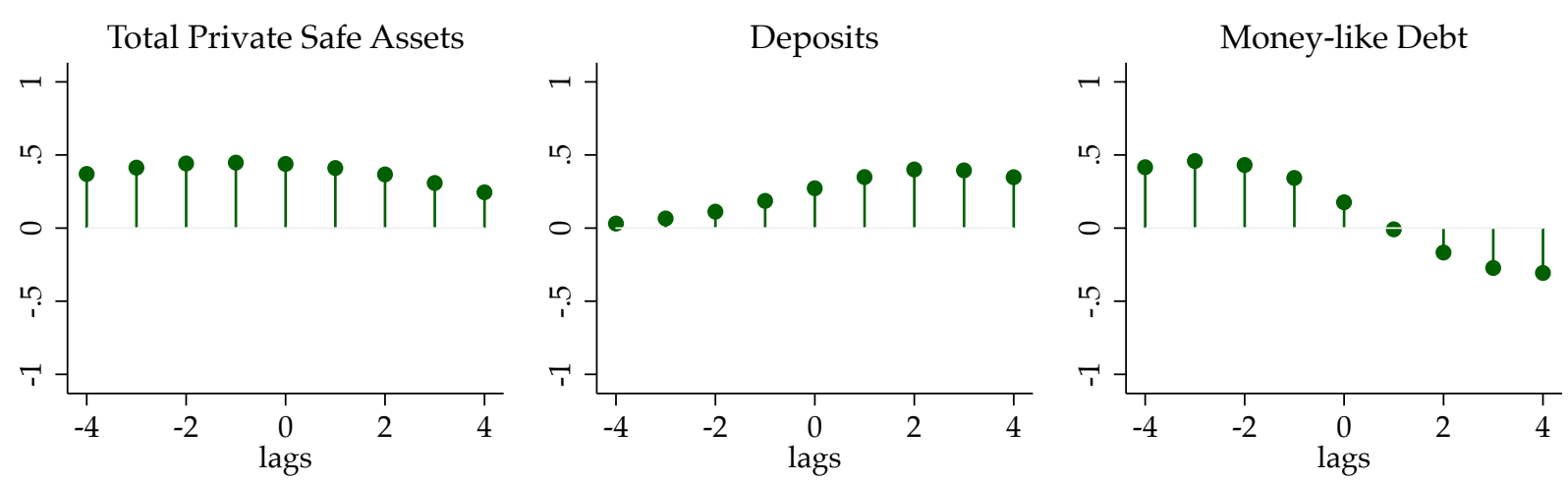

MBS/ABS

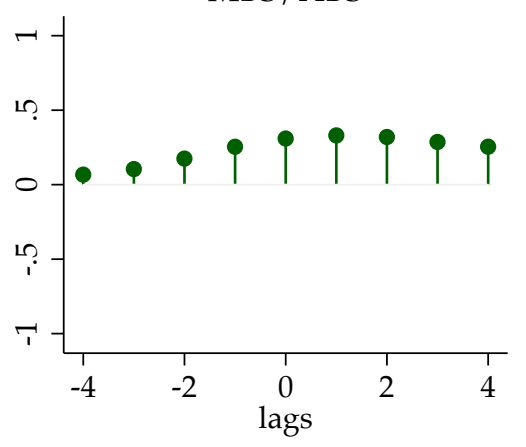

Corporate Bonds

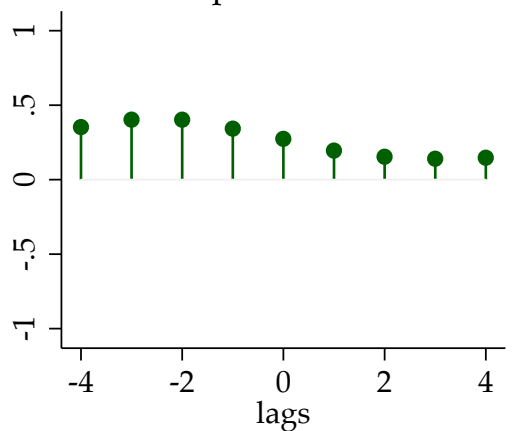

Other Safe Assets

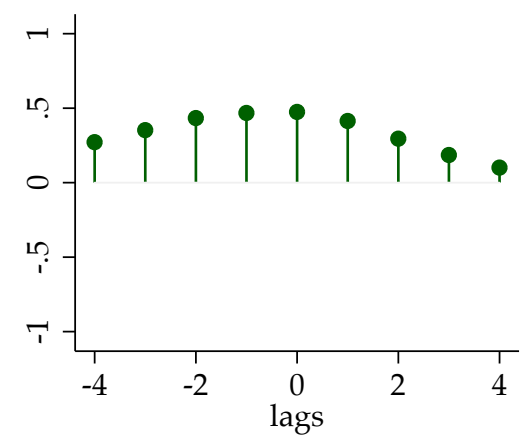

Source: Our calculations, using US Financial Accounts data retrieved from FRED, St. Louis Fed. The definitions follow Gorton et al. (2012). Real GDP and all of the safe asset component series are plotted in year-on-year growth rates. See text.

\section{A Microfounded Model}

In this section, we present a microfounded model featuring an endogenous supply of assets and a preference for safe and liquid bonds that arises endogenously from a retirement motive. We study an infinite-horizon closed economy in discrete time, which is indexed by $t \in$ $\{0,1,2, \ldots\}$. The economy is inhabited by households, firms and a government. We assume that the economy does not face any aggregate risk. ${ }^{11}$

\subsection{The Environment}

Households The economy is populated by a measure one of households. Households are comprised of a measure one of workers and a measure $\chi$ of retirees (with $\chi \in(0,1)$ ). In each period, workers are endowed with one unit of time, which they can sell in the labor market.

\footnotetext{
${ }^{11}$ This is a common assumption in the literature, which usually studies the response of the economy to an unexpected shock or a first-order approximation of the dynamics around a non-stochastic steady-state equilibrium, which effectively imposes a certainty-equivalence property on the model.
} 
In contrast, retirees cannot work, and they live for only one period. Every period a random fraction $\chi$ of workers retire and a measure $\chi$ of new agents is born. Thus, the composition of each household is constant over time. ${ }^{12}$

Workers supply their time inelastically to the labor market. In the presence of nominal wage rigidities, workers might be able to sell only a fraction $h_{t} \leq 1$ of their time. When $h_{t}<1$, the economy is operating below potential and there is involuntary unemployment. Households are the owners of the firms, which distribute nominal dividends $D_{t}$, they trade nominal risk-free assets $\tilde{B}_{t}$ at a nominal price $\frac{1}{1+i_{t}}$, where $i_{t}$ is the nominal interest rate, and receive nominal lump-sum transfers $T_{t}$.

Being a worker or a retiree determines the resources available for consumption. We assume that at the beginning of each period, and before agents know whether they are workers or retirees, the household distributes its portfolio of assets equally among its members. Once they leave the household, agents find out their type. Since retirees live for only one period, they cannot borrow in the financial markets, and their wealth is limited to the assets in their portfolio. ${ }^{13}$ In contrast, workers can also consume out of their labor income. At the end of the period, and after consumption takes place, the surviving members of each household pool their resources and make the saving decisions for the following period. Thus, workers have two motives to save. First, they face the traditional intertemporal substitution channel: savings allow them to substitute consumption tomorrow for consumption today. Second, workers have a retirement motive: with probability $\chi$ they will retire and lose their labor income. This second motive will generate the reduced form bond premium presented in Section 2.

Households maximize a utilitarian welfare function of their members' utility

$$
\sum_{t=0}^{\infty} \beta^{t}\left[u\left(C_{t}^{w}\right)+\chi v\left((1+\chi) C_{t}^{r}\right)\right]
$$

where $C_{t}^{w}$ and $C_{t}^{r}$ denote the consumption of a worker and a retiree in period $t$, respectively, and $\beta$ is the discount factor. For analytical tractability, we assume that $u\left(C_{t}^{w}\right)=\log \left(C_{t}^{w}\right)$ and $v\left((1+\chi) C_{t}^{r}\right)=\log \left((1+\chi) C_{t}^{r}\right)$, where the factor $1+\chi$ is a normalization that will prove useful below. Within a period, each member of the household makes their consumption

\footnotetext{
${ }^{12}$ This modeling assumption is similar to the tractable stochastic OLG model of Gertler (1999), recently used by Rachel and Summers (2019) to study the decline in the natural interest rate. The "big family" assumption has a long tradition in macroeconomics. Lucas Jr (1990) uses this framework to study the effect of open-market operations on the economy's interest rate. More recently, it has been used by Del Negro et al. (2017b), Bilbiie (2019) and Heathcote and Perri (2018). This formulation allows us to study a model with incomplete insurance at the individual level but without the need to keep track of the cross-sectional distribution of wealth as a relevant state variable.

${ }^{13}$ We also assume that retirees cannot leave debts to their families.
} 
decisions based on their portfolio and income. The intra-period budget constraints faced by individual agents are given by

$$
\begin{aligned}
P_{t} C_{t}^{w} & \leq W_{t} h_{t}+\frac{\tilde{B}_{t}}{1+\chi}+D_{t}+T_{t} \\
P_{t} C_{t}^{r} & \leq \frac{\tilde{B}_{t}}{1+\chi}
\end{aligned}
$$

where $P_{t}$ is the price level, $\tilde{B}_{t}$ is the holdings of nominal one-period bonds, and $W_{t}$ is the nominal wage. That is, agents can use the proceeds from maturing bonds and wage income to finance their consumption but not the proceeds from other instruments, like stocks, due to the illiquidity of other financial assets. ${ }^{14}$ We have also assumed that retirees do not receive any of the lump-sum transfers or firms' dividends. This assumption is not necessary for our results but simplifies the exposition. As long as the retirees' income is not high enough to allow full insurance, all our results would go through. ${ }^{15}$ At the end of the period, the household as a whole faces the following budget constraint:

$$
P_{t} C_{t}^{w}+\chi P_{t} C_{t}^{r}+\frac{\tilde{B}_{t+1}}{1+i_{t}} \leq W_{t} h_{t}+D_{t}+\tilde{B}_{t}+T_{t}
$$

The problem of the household consists of choosing processes $\left\{C_{t}^{w}, C_{t}^{r}, \tilde{B}_{t+1}\right\}_{t=0}^{\infty}$ in order to maximize (1) subject to the budget constraints (2), (3) and (4) for every $t \geq 0$, and a no-Ponzi condition. Since all households solve the same problem, we can treat the economy as populated by a single representative household.

In what follows, we limit attention to equilibria in which the budget constraint of retirees (3) is binding, so that $C_{t}^{r}=\frac{1}{1+\chi} \frac{\tilde{B}_{t}}{P_{t}}$. Replacing this into the household's utility function, we get

$$
\sum_{t=0}^{\infty} \beta^{t}\left[u\left(C_{t}^{w}\right)+\chi v\left(\frac{\tilde{B}_{t}}{P_{t}}\right)\right] .
$$

Thus, the household's problem looks as-if it was generated by an agent who values bonds directly (as in the bonds in the utility function tradition), even though it is the result of the workers' retirement concerns. Two differences that will become apparent below are that the retirement motive introduces a satiation point for bonds that is absent in non-microfounded environments, and that a fraction $\chi$ of the bonds enter in the resource constraint through

\footnotetext{
${ }^{14}$ Households' direct ownership of liquid equities is very low. Heathcote and Perri (2018) document that in 2010 , only $15.1 \%$ of households held stocks directly.

${ }^{15}$ In particular, all our results would hold even if equity provided partial safety services as in Del Negro et al. $(2017 b)$.
} 
the consumption of the retirees.

Firms The final consumption good is produced by a measure one of perfectly competitive firms using labor as the only factor of production according to the following technology:

$$
Y_{t}=A_{t} h_{t}^{1-\alpha}
$$

where $A_{t}$ is the TFP level, $h_{t}$ is the amount of labor hired and $\alpha \in(0,1)$. Firms hire workers at a nominal wage $W_{t}$ and must pay a per-period fixed cost $F$ (in units of the final good), which is rebated lump-sum to the households. ${ }^{16}$ Thus, a firm's per-period operating profit is given by

$$
\Pi_{t}=P_{t}\left(A_{t} h_{t}^{1-\alpha}-F\right)-W_{t} h_{t}
$$

The following assumption guarantees that the fixed cost is not too high so as to preclude the existence of equilibrium.

Assumption 1 The parameter values are such that

$$
\alpha A_{t} \geq F>0 \forall t
$$

Assumption 1 makes sure that it is always profitable for the firm to be active if the economy operates at full employment.

Since safe bonds carry a premium, the conditions for the Modigliani-Miller theorem do not hold in this economy. In particular, firms have an incentive to issue safe bonds to profit from the premium. In order for the bonds to be safe, we require that firms be able to pay their debt in full with internal funds alone. This way, firms' debt is not subject to roll-over risk. Formally, firms need to satisfy the following constraint:

$$
\tilde{B}_{t+1}^{p} \leq \Pi_{t+1}
$$

where $\tilde{B}_{t+1}^{p}$ denotes the face value of the nominal bonds issued by the firm in period $t$ and payable in $t+1$.

A firm's objective is to maximize the present discounted value of the stream of dividends

\footnotetext{
${ }^{16}$ This assumption about the fixed cost is reminiscent of the treatment of the Rotemberg price adjustment cost made in the literature (see, for example, Benhabib, Schmitt-Grohé and Uribe, 2001a, Ascari and Rossi, 2012 and Eggertsson and Singh, 2019). One can reinterpret the fixed cost as a technological requirement of a fixed amount of managerial services provided by households. The qualitative results would not change.
} 
paid out to their shareholders,

$$
V_{t} \equiv \max _{\left\{D_{t}, h_{t}, \widetilde{B}_{t+1}^{p}\right\}_{t=0}^{\infty}} \sum_{s=0}^{\infty} \Lambda_{t+s} D_{t+s}
$$

subject to

$$
\begin{gathered}
D_{t}=P_{t}\left(A_{t} h_{t}^{1-\alpha}-F\right)-W_{t} h_{t}-\tilde{B}_{t}^{p}+\frac{\tilde{B}_{t+1}^{p}}{1+i_{t}} \\
\tilde{B}_{t+1}^{p} \leq P_{t+1}\left(A_{t+1} h_{t+1}^{1-\alpha}-F\right)-W_{t+1} h_{t+1},
\end{gathered}
$$

where $\Lambda_{t}$ is the household's stochastic discount factor. The firm is active in period $t$ if and only if $P_{t}\left(Y_{t}-F\right)-W_{t} h_{t} \geq 0$.

The presence of a fixed cost of production has two important implications in our analysis. First, the fixed cost precludes the existence of steady-state equilibria with output levels that are implausibly low relative to potential. Second, the fixed cost implies that firms can issue bonds only if their production in the next period is above a certain threshold. This property will allow self-fulfilling liquidity traps to arise as an equilibrium outcome.

Nominal Rigidities To keep the analysis simple, in this section we assume that wages are perfectly rigid, that is,

$$
W_{t}=W_{t-1} \quad \forall t
$$

This assumption implies that labor markets will not always clear, so that $h_{t}<1$ can be part of an equilibrium. The rigidity assumption of this section has the added benefit of isolating our channel for an SFLT from the one in Benhabib et al. (2001b), which works through deflation. In the quantitative model of Section 5, we allow for a more flexible specification, in the spirit of Schmitt-Grohé and Uribe (2017).

Government To close the model, we need to introduce a rule for monetary policy and a budget constraint for the government. We assume that the central bank sets the nominal interest rate according to

$$
1+i_{t}=\max \left\{1, R_{t}^{*}+\phi_{Y}\left(\frac{Y_{t}}{Y_{t}^{*}}-1\right)\right\}
$$


where $R_{t}^{*}$ is the gross real interest rate consistent with the full employment equilibrium, and $Y_{t}^{*}$ denotes the full employment output level

$$
Y_{t}^{*}=A_{t}
$$

Finally, the government's budget constraint is given by

$$
\tilde{B}_{t}^{g}=\frac{\tilde{B}_{t+1}^{g}}{1+i_{t}}+T_{t}^{g}
$$

where $T_{t}^{g}$ denotes lump-sum taxes levied on the household. The lump-sum transfers received by the household are, then, comprised of the government taxes and the rebates of the fixed costs borne out by firms:

$$
T_{t}=F-T_{t}^{g}
$$

\subsection{Equilibrium}

Let $w_{t} \equiv \frac{W_{t}}{P_{t}}$ denote the real wage. A competitive equilibrium of this economy is an allocation $\left\{C_{t}^{w}, C_{t}^{r}, \tilde{B}_{t+1}, h_{t}, \tilde{B}_{t+1}^{p}\right\}_{t=0}^{\infty}$ and prices $\left\{w_{t}, \pi_{t}, i_{t}\right\}_{t=0}^{\infty}$ such that, given fiscal policy $\left\{\tilde{B}_{t}^{g}, T_{t}^{g}\right\}_{t=0}^{\infty}$,

1. $\left\{C_{t}^{w}, C_{t}^{r}, \tilde{B}_{t+1}, h_{t}\right\}_{t=0}^{\infty}$ solves the household's problem given $\left\{w_{t}, \pi_{t}, i_{t}\right\}_{t=0}^{\infty}$ and $\left\{T_{t}^{g}\right\}_{t=0}^{\infty}$

2. $\left\{h_{t}, \tilde{B}_{t+1}^{p}\right\}_{t=0}^{\infty}$ solves the firms' problem given $\left\{w_{t}, \pi_{t}, i_{t}\right\}_{t=0}^{\infty}$

3. $\left\{i_{t}\right\}_{t=0}^{\infty}$ follows $(6)$

4. Markets clear

$$
C_{t}^{w}+\chi C_{t}^{r}=A_{t} h_{t}^{1-\alpha}, \quad \tilde{B}_{t}=\tilde{B}_{t}^{p}+\tilde{B}_{t}^{g} .
$$

We focus our analysis on equilibria in which the budget constraint of retirees (3) is satisfied with equality; we specify the conditions under which this is true below. In this case, the optimality conditions associated with the household's problem are the budget constraint (4), and

$$
\begin{gathered}
\beta^{t} u^{\prime}\left(C_{t}^{w}\right)=P_{t} \Lambda_{t} \\
\frac{\Lambda_{t}}{1+i_{t}}=(1-\chi) \Lambda_{t+1}+\beta^{t+1} \chi v^{\prime}\left(B_{t+1}\right) \frac{1}{P_{t+1}}
\end{gathered}
$$

where $\Lambda_{t}>0$ is the Lagrange multiplier associated with the budget constraint (4), and $B_{t+1} \equiv \frac{\tilde{B}_{t+1}}{P_{t+1}}$. Combining equations (8) and (9), we get the following Generalized Euler 
Equation (GEE)

$$
1=\beta \frac{1+i_{t}}{1+\pi_{t+1}}[\underbrace{\frac{u^{\prime}\left(C_{t+1}^{w}\right)}{u^{\prime}\left(C_{t}^{w}\right)}}_{\begin{array}{c}
\text { intertemporal } \\
\text { substitution motive }
\end{array}}+\underbrace{\chi \frac{v^{\prime}\left(B_{t+1}\right)-u^{\prime}\left(C_{t+1}^{w}\right)}{u^{\prime}\left(C_{t}^{w}\right)}}_{\text {retirement motive }}] .
$$

Equation (10) determines the demand for safe assets, which is one of the main building blocks of the economy's equilibrium. It presents the two reasons households demand bonds. First, there is the intertemporal substitution motive. This is the typical motive in standard neoclassical models: households demand bonds in order to smooth the workers' consumption path. Second, there is a retirement motive. Since workers face the risk of retiring and losing their labor income, households demand bonds above and beyond the intertemporal substitution motive in order to smooth the consumption of those who cannot work.

We define the bond premium as

$$
b p \equiv \chi \frac{v^{\prime}\left(B_{t+1}\right)-u^{\prime}\left(C_{t+1}^{w}\right)}{u^{\prime}\left(C_{t}^{w}\right)} .
$$

Ceteris paribus, a higher bond premium implies a lower real interest rate. Note that equation (10) implies a retirement motive that is pro-cyclical, in the sense that it is increasing in $C_{t}^{w}$ and $C_{t+1}^{w}$ : the higher the workers' consumption, the higher the demand for the retirees' consumption. This feature will represent a force towards a pro-cyclical bond premium. ${ }^{17}$

Next, consider the firm's problem. Note that the choice of labor is essentially a static problem. Thus, optimality yields the following demand for labor:

$$
h_{t}=\left[\frac{(1-\alpha) A_{t}}{w_{t}}\right]^{\frac{1}{\alpha}}
$$

Let $\mu_{t}$ be the Lagrange multiplier associated with the constraint (5). The first-order condition with respect to bonds is

$$
\frac{\Lambda_{t}}{1+i_{t}}=\Lambda_{t+1}+\mu_{t}
$$

\footnotetext{
${ }^{17}$ In Appendix $\mathrm{H}$ we explore a variant of this model that generates a counter-cyclical demand for bonds. A pro-cyclical demand, in contrast, allows for a better comparison with the literature that studies fundamental safety traps. Introducing a counter-cyclical bond demand makes the economy even more vulnerable to the existence of a self-fulfilling liquidity trap.
} 
Comparing (10) and (12), it is immediate that

$$
P_{t+1} \mu_{t}=\beta^{t+1} \chi\left[v^{\prime}\left(B_{t+1}\right)-u^{\prime}\left(C_{t+1}^{w}\right)\right]
$$

that is, the Lagrange multiplier with respect to the borrowing constraint is proportional to the retirement motive. If the retirement motive is equal to zero (i.e., the retirement demand is satiated), then the firm is unconstrained. If the retirement motive is strictly positive, then the firm is constrained. Focusing on equilibria in which (3) is binding, the supply of bonds is an affine function of aggregate output

$$
B_{t}=\alpha Y_{t}-F+B_{t}^{g}
$$

where $B_{t}^{g} \equiv \frac{\tilde{B}_{t}^{g}}{P_{t}}$. Finally, equilibrium requires that $Y_{t}-F-w_{t} H_{t}=\alpha Y_{t}-F \geq 0$ for all $t$.

\section{3 $\quad$ Steady States}

A steady state is an equilibrium in which all endogenous and exogenous variables are constant over time. Given our wage rigidity assumption, if $w_{t}$ and $W_{t}$ are constant over time then the inflation rate is zero in any steady state. In what follows, variables without a time subscript denote the value of the variables in a non-stochastic steady state.

The households' GEE (10) becomes

$$
1=\beta(1+i)\left[1+\chi\left(\frac{v^{\prime}(B)}{u^{\prime}\left(C^{w}\right)}-1\right)\right] .
$$

If firms are active, the bond supply is given by equation (13) evaluated at steady state

$$
B(Y)=\alpha Y-F+B^{g} .
$$

Noting that the firm's profits in steady state are given by $\Pi=\alpha Y-F$, equilibrium requires that

$$
Y \geq Y^{\min } \equiv \frac{F}{\alpha},
$$

that is, there is a lower bound on admissible output levels. From the resource constraint, we get

$$
C^{w}=C^{w}(Y)=Y-\chi B(Y) .
$$

From equation (11) evaluated at steady state, we can write the bond premium as a function 
of output

$$
b p(Y) \equiv \chi\left(\frac{v^{\prime}(B(Y))}{u^{\prime}\left(C^{w}(Y)\right)}-1\right)
$$

Finally, equation (17) allows us to rewrite the GEE (14) as

$$
1=\beta(1+i)[1+b p(Y)]
$$

which defines an implicit function between output $Y$ and the nominal interest rate $i$. This is the analogue of the (SA) relation in Section 2. The following assumption guarantees that a steady-state equilibrium of the economy always exists, and that the bond premium is strictly positive in a full-employment steady state (i.e., retirees are always constrained).

Assumption 2 The parameters of the model and fiscal policy are such that, for all $Y \in$ $\left[Y^{\min }, Y^{*}\right]$,

$$
b p(Y)>0
$$

Moreover, there exists $Y \in\left[Y^{\mathrm{min}}, Y^{*}\right]$ such that

$$
b p(Y) \leq \frac{1-\beta}{\beta}
$$

Equation (19) states that the bond premium is positive for all admissible levels of output, so that the retirees' budget constraint (3) is binding in any steady state of the economy. Using our assumed functional forms with unit elasticities, equation (19) implies that

$$
Y>(1+\chi)\left(\alpha Y-F+B^{g}\right)
$$

for all $Y \in\left[Y^{\min }, Y^{*}\right]$. Since in our calibrations we find that $1-\alpha(1+\chi)>0$, we can further simplify the condition as

$$
B^{g}<\frac{F}{\alpha(1+\chi)}
$$

If $B^{g}$ and $\alpha$ are low, the supply of safe bonds is not too large, so perfect consumption smoothing is not possible. If $\chi$ is low, then the number of retirees relative to the workers is not too high, so that, given the total supply of bonds, the consumption of workers is high and the demand to smooth the consumption of retirees is also high.

Equation (20) implies that there exists a level of output greater than $Y^{\text {min }}$ such that the Euler equation (14) admits a solution with a weakly positive nominal rate. This condition is crucial to guarantee the existence of a steady-state equilibrium.

An equilibrium of the economy can be found from the intersection of equation (18) and 
the Taylor rule evaluated at steady state

$$
1+i=\max \left\{1, R^{*}+\phi_{Y}\left(\frac{Y}{A}-1\right)\right\}
$$

where $R^{*}=\frac{1}{\beta} \frac{1}{1+b p\left(Y^{*}\right)}$. The next proposition shows that Assumptions 1 and 2 are enough to guarantee the existence of a steady-state equilibrium in this economy (though it does not need to be a full-employment equilibrium).

Proposition 1 (Existence of a Steady-State Equilibrium) Suppose Assumptions 1 and 2 are satisfied. Then, a steady-state equilibrium of the economy exists.

The existence of a steady-state equilibrium requires that: $i)$ the set $\left[Y^{\min }, Y^{*}\right]$ is not empty; and $i i$ ) the bond premium is not too high for all levels of output. The rest of this section shows that the economy admits three types of steady-state equilibria: one characterized by full employment and two by involuntary unemployment.

First, we show the conditions for the existence of a full-employment steady-state equilibrium.

Proposition 2 (Existence of a Full-Employment Steady State) Suppose Assumptions 1 and 2 are satisfied. Moreover, assume that

$$
b p\left(Y^{*}\right) \leq \frac{1-\beta}{\beta}
$$

Then, there exists a unique full-employment steady state. The full-employment steady state is locally determinate and is the unique steady state with a positive interest rate if and only if $\phi_{y}>-\frac{b p^{\prime}\left(Y^{*}\right) Y^{*}}{1+b p\left(Y^{*}\right)} R^{*}$.

A full-employment steady state exists as long as the bond premium is not so large as to push the natural rate of interest below zero. This is the equilibrium that the monetary authority seeks to implement. However, Proposition 2 does not preclude the existence of other steady-state equilibria that feature involuntary unemployment. In order to characterize the properties of these liquidity trap steady states, it is useful to first study the cyclical properties of the bond premium.

We say that the bond premium is pro-cyclical if $b p^{\prime}(Y)>0$, which happens if and only if

$$
\underbrace{-\frac{u^{\prime \prime}\left(C^{w}(Y)\right)}{u^{\prime}\left(C^{w}(Y)\right)} C^{w}(Y)}_{\begin{array}{c}
\text { elasticity of intertemporal } \\
\text { substitution }
\end{array}} \underbrace{\frac{C^{w^{\prime}}(Y)}{C^{w}(Y)} Y}_{\begin{array}{c}
\text { elasticity of consumption } \\
\text { to output }
\end{array}}>\underbrace{-\frac{v^{\prime \prime}(B(Y))}{v^{\prime}(B(Y))} B(Y)}_{\begin{array}{c}
\text { elasticity of bond } \\
\text { demand }
\end{array}} \underbrace{\frac{B^{\prime}(Y)}{B(Y)} Y}_{\begin{array}{c}
\text { elasticity of bond } \\
\text { supply to output }
\end{array}} .
$$


In contrast, if $b p^{\prime}(Y)<0$, we say that the bond premium is counter-cyclical. ${ }^{18}$ Equation (23) characterizes two economic forces that determine the cyclical properties of the bond premium. Consider the effects of an increase in output. First, a higher output generates an increase in workers' consumption. Since households also value the consumption of the retirees, this will trigger an increase in the demand for bonds. The increased demand for bonds then translates into a higher bond premium. However, there is a second, and offsetting, effect. The increase in output relaxes the firms' issuance constraint and hence increases the supply of private bonds. As the supply of private bonds increases, the demand for bonds gets (partially) satiated, reducing the bond premium. The cyclicality of the bond premium depends on which of these two forces dominates. ${ }^{19}$ Note that by rearranging terms in equation (23), we get that the bond premium is pro-cyclical (counter-cyclical) if the elasticity with respect to output of the bond demand is larger (smaller) than the elasticity of the bond supply. ${ }^{20}$ That is, the cyclicality of the bond premium is a property that depends on the relative elasticity of the demand and the supply of bonds. In the model of this section, the bond premium is pro-cyclical if and only if $B^{g}>F$.

We are ready to characterize the liquidity trap steady states of the economy. The next proposition shows that if condition (22) does not hold and the bond premium is pro-cyclical, then the unique steady state of the economy features involuntary unemployment. Because this steady state does not co-exist with the full-employment steady state, we call it a Fundamental Liquidity Trap (FLT).

Proposition 3 (Existence of a Fundamental Liquidity Trap (FLT)) Suppose Assumptions 1 and 2 are satisfied and the bond premium is pro-cyclical. Moreover, assume that

$$
b p\left(Y^{*}\right)>\frac{1-\beta}{\beta} .
$$

\footnotetext{
${ }^{18}$ Strictly speaking, the cyclicality of the bond premium is defined locally at each level of $Y$. To simplify the analysis, we work under assumptions that define the cyclicality globally.

${ }^{19}$ In Appendix H, we consider other economic forces that affect the exact characterization of the bond premium, such as counter-cyclical self-insurance motives. Still, the intuition behind the results follows a logic analogous to the one behind equation (23).

${ }^{20}$ Conditional on $i$, totally differentiating (14), we get
}

$$
\beta(1+i) \chi \frac{v^{\prime \prime}(B) u^{\prime}\left(C^{w}(Y)\right) d B-v^{\prime}(B) u^{\prime \prime}\left(C^{w}(Y)\right) C^{w^{\prime}}(Y) d Y}{\left(u^{\prime}\left(C^{w}(Y)\right)\right)^{2}}=0
$$

and rearranging

$$
\frac{d B}{d Y} \frac{Y}{B}=\frac{\frac{u^{\prime \prime}\left(C^{w}(Y)\right)}{u^{\prime}\left(C^{w}(Y)\right)} C^{w}(Y) \frac{C^{w^{\prime}}(Y)}{C^{w}(Y)} Y}{\frac{v^{\prime \prime}(B)}{v^{\prime}(B)} B},
$$

which is the elasticity of the bond demand to output. The cyclicality of the bond premium depends on the comparison of the elasticity of the bond demand with the elasticity of the supply, given by $\frac{B^{\prime}(Y)}{B(Y)} Y$. 
Figure 4: Fundamental Liquidity Trap

(a) $(Y, i)$ space

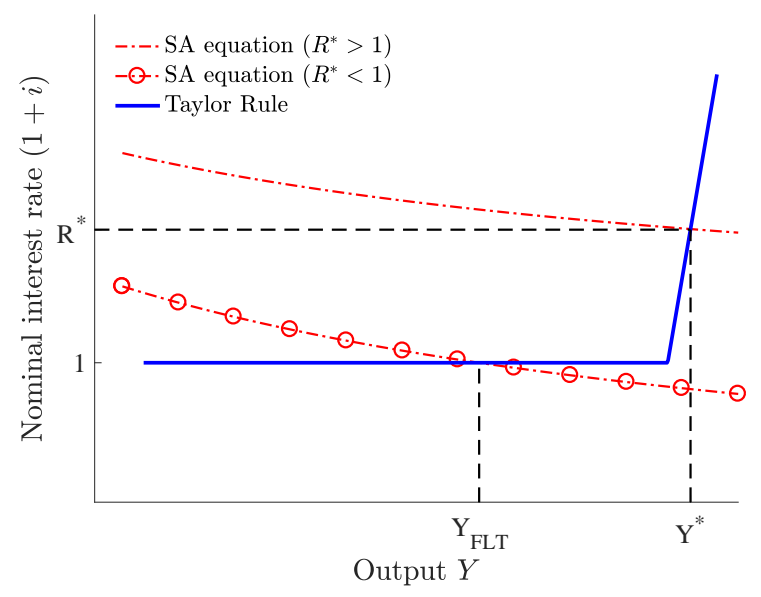

(b) $(Y, B)$ space

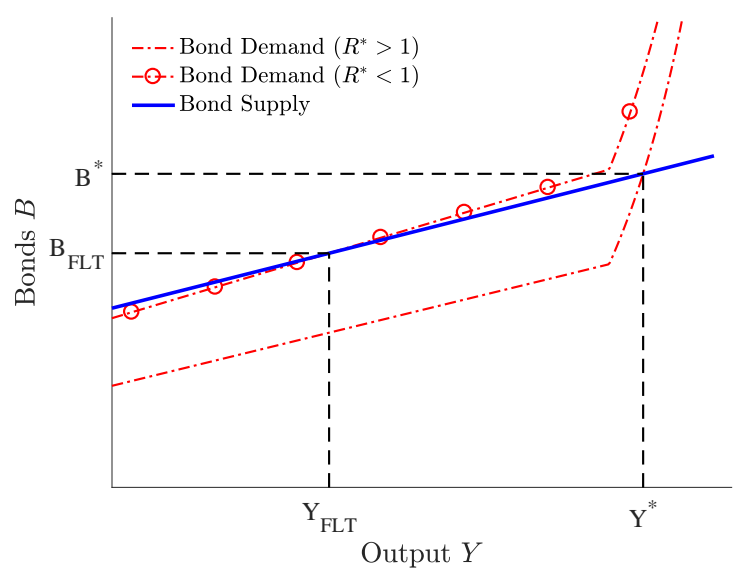

Then, the unique steady-state equilibrium of the economy features involuntary unemployment, a positive output gap and a zero nominal interest rate. The equilibrium is locally determinate.

An FLT is the type of liquidity trap that is most commonly studied in the literature. It is the result of structural characteristics of the economy that generate a negative natural rate of interest. Proposition 3's contribution is to show that the FLT is characterized by a pro-cyclical bond premium. Figure 4 shows an example of an economy featuring a procyclical bond premium that transitions from a full-employment steady state to an FLT after an unexpected increase in $\chi{ }^{21}$ Panel (a) represents the equilibrium of Proposition 3 in the $(Y, i)$ space, and it is the analogue of Figure 1. An increase in $\chi$ increases the bond premium for every level of output, generating a downward shift in the (SA) relation. If the increase in the bond premium is sufficiently large, the natural rate of interest at full employment becomes negative and the economy falls into a liquidity trap. Panel (b) presents the same economy but in the $(Y, B)$ space. Here, we plot the demand and the supply of safe assets. Since the demand for safe assets depends on the interest rate, it has a kink at the level of output below which the economy is in a liquidity trap. When $\chi$ increases, the demand for safe assets increases for each level of output, such that the demand and the supply of bonds now intersect at an inefficiently low level of output.

Next, we show that the full-employment steady-state equilibrium can co-exist with a liquidity trap steady state if the bond premium is counter-cyclical. Because this steady state co-exists with the full-employment steady state, and it can be the equilibrium of the economy if agents' beliefs coordinate on it, we label it as a Self-Fulfilling Liquidity Trap (SFLT).

\footnotetext{
${ }^{21}$ Calibration: $\beta=0.96, \alpha=1 / 3, A=1, F=0.05 A, B^{g}=0.1 A, \phi_{Y}=0.5$. Initially $\chi=0.011 ;$ after $\chi=0.029$.
} 
Figure 5: Self-Fulfilling Liquidity Trap

(a) $(Y, i)$ space

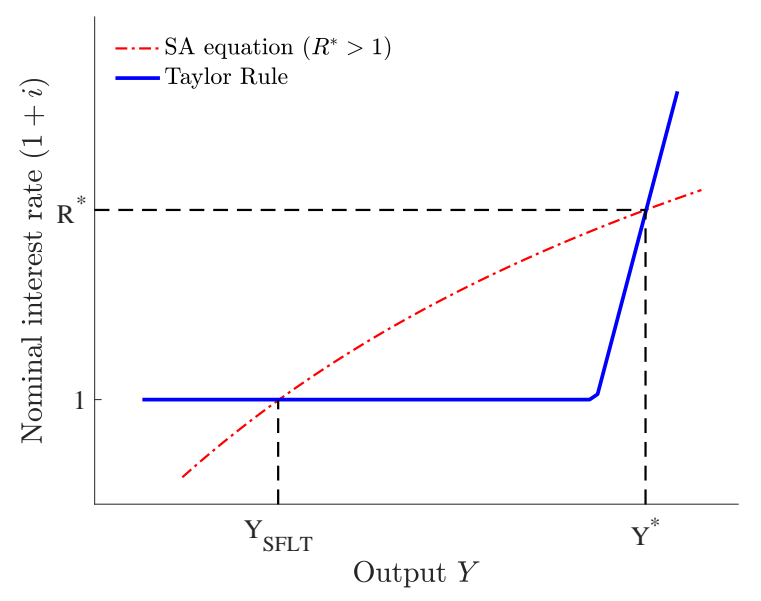

(b) $(Y, B)$ space

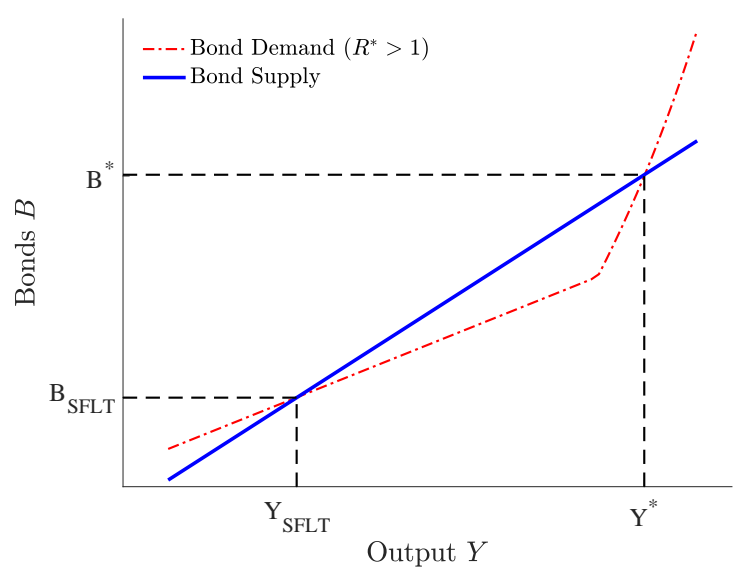

Proposition 4 (Existence of a Self-Fulfilling Liquidity Trap (SFLT)) Suppose Assumptions 1 and 2 are satisfied and the bond premium is counter-cyclical. Moreover, assume that

$$
b p\left(Y^{*}\right)<\frac{1-\beta}{\beta}, \quad \text { and } \quad b p\left(Y^{\min }\right) \geq \frac{1-\beta}{\beta},
$$

and $\phi_{Y}>-\frac{b p^{\prime}\left(Y^{*}\right) Y^{*}}{b p\left(Y^{*}\right)} R^{*}$. Then, the economy features two steady-state equilibria: one with full employment and another with involuntary unemployment, a positive output gap and a zero nominal interest rate. The full-employment steady state is locally determinate, while the unemployment steady state is locally indeterminate.

Figure 5 plots an economy featuring a counter-cyclical bond premium. ${ }^{22}$ There are two steady states: one with full employment and one with involuntary unemployment. It is crucial for the existence of the two equilibria that the (SA) relation in Panel (a) be upward sloping, i.e., that the bond premium decrease with the level of output. As Panel (b) shows, this can happen only if the supply of bonds is more elastic than the demand of bonds conditional on $i$. This result also shows the importance of modeling an endogenous (procyclical) supply of safe assets to capture complex interactions in the economy. ${ }^{23}$

The existence of an SFLT has been widely studied in the literature, starting with Benhabib et al. (2001b), who show how the non-linearity of the Taylor rule can give rise to

\footnotetext{
${ }^{22}$ Calibration: $\beta=0.96, \alpha=1 / 3, A=1, F=0.2 A, B^{g}=0.1 A, \phi_{Y}=0.5, \chi=0.011$.

${ }^{23}$ The analysis in this section is limited to steady-state equilibria. The main message of the paper would not change if we considered temporary liquidity traps. Since the dynamics around a steady state under a pro-cyclical bond premium are locally determinate, temporary SFLTs are ruled out in this case. In contrast, temporary (but not permanent) FLTs can arise when the bond premium is counter-cyclical. Still, a counter-cyclical bond premium opens the possibility of SFLTs, which might coexist (as a possible equilibrium outcome) with FLTs. This possibility is what makes the analysis of this paper relevant.
} 
an unintended steady-state equilibrium. Relative to the literature, our contribution in this paper is two-fold. First, we study the consequences of the SFLT in relation to the bond premium and its cyclical properties. This analysis is particularly relevant to the design of policies that can deal with sudden increases in the bond premium. Second, our analysis shows that the economy is not always exposed to an SFLT and characterizes the conditions that facilitate its appearance. In particular, if the bond premium is relatively low for all levels of output, then the full-employment steady-state equilibrium is unique even if the bond premium is counter-cyclical.

Corollary 1 (Full-Employment as the Unique Steady State) Suppose Assumptions 1 and 2 are satisfied, $\phi_{Y}>\frac{b p^{\prime}\left(Y^{*}\right) Y^{*}}{1+b p\left(Y^{*}\right)} R^{*}$ and

$$
b p\left(Y^{*}\right)<\frac{1-\beta}{\beta}
$$

Then, the unique steady-state equilibrium of the economy features full employment if and only if: $i$ ) the bond premium is pro-cyclical; or ii) the bond premium is counter-cyclical and

$$
b p\left(Y^{\min }\right)<\frac{1-\beta}{\beta}
$$

Moreover, the full-employment steady state is locally determinate.

\section{Policy in a Liquidity Trap}

A well-known result in the liquidity trap literature is that the policy recommendations for an economy facing a liquidity trap depend on the trap's nature. ${ }^{24}$ We contribute to the literature in two dimensions. First, we study the role of policy in a model in which the response of the bond premium to government policy is a key determinant of the policy's effect. Second, we ask whether there are robust policies that can be implemented and are beneficial independent of the nature of the trap. This exercise is particularly important if we believe that a policy maker might have difficulty identifying the exact nature of the shock that brought the economy to a liquidity trap just from observing aggregate dynamics. Our analysis highlights the importance of fiscal capacity for a successful implementation of these policies.

Next, we study the effects of two different policies. We first consider government bond issuances. This is the natural instrument in an economy that suffers from a scarcity of safe

${ }^{24}$ See, e.g., Bilbiie (2018); Cuba-Borda and Singh (2019); Nakata and Schmidt (2019). 
assets. We then analyze the effects of government spending. ${ }^{25}$

\subsection{Government Bonds}

In this economy, a liquidity trap is an equilibrium in which the bond premium is too high relative to a level that can sustain full employment. Thus, a natural intervention would be to increase the supply of (safe) government bonds and rebate the proceeds to the households. Since the bond premium is decreasing in the total supply of safe assets, an increase in the supply of government bonds should reduce the bond premium and increase aggregate demand. When the supply of private safe assets is exogenous (and the demand is pro-cyclical, as in Section 3), the previous intuition is correct, and government bonds are expansionary. This is the economy studied in Caballero and Farhi (2017) and Caballero et al. (2016). However, when the supply of private safe assets is endogenous (or the demand is countercyclical; see Appendix $\mathrm{H}$ for an example), the overall effect of an increase in the supply of government bonds depends on the general equilibrium response of the private sector. In this section we show that while small interventions have opposing effects depending on whether the economy is in an FLT or an SFLT (and hence, depending on whether the bond premium is pro-cyclical or counter-cyclical), a credible commitment to a sufficiently large intervention is always expansionary.

Consider an economy that is in a liquidity trap equilibrium and the government implements a "small" increase in the supply of government bonds. From equation (18) we know that, absent any change in the interest rate, a steady-state equilibrium requires no change of the bond premium relative to the initial steady state (i.e., before the change in the supply of government bonds). More formally, let $b p\left(Y ; B^{g}\right)$ denote the bond premium defined in (17), augmented to explicitly account for the dependence on the supply of government bonds. Totally differentiating $b p(\cdot ; \cdot)$, we get

$$
\frac{\partial b p\left(Y ; B^{g}\right)}{\partial Y} d Y+\frac{\partial b p\left(Y\left(B^{g}\right) ; B^{g}\right)}{\partial B^{g}} d B^{g} .
$$

Since a steady-state equilibrium requires that there be no change in the bond premium after the policy (recall that locally to a liquidity trap equilibrium the interest rate is constant at

\footnotetext{
${ }^{25}$ Del Negro et al. (2017b) study the role of unconventional monetary policy in the context of an economy suffering a shortage of safe assets. Policies like Quantitative Easing combine the issuance of government bonds with the purchase of private assets. The difference between this policy and just issuing government bonds is that private assets might provide (partial) backing to the debt and, hence, increase the government's fiscal capacity. As long as this backing is believed to be incomplete (which is likely to be true in times of high uncertainty) our results in this section would still apply (see also Barro, 1974).
} 
zero), we can equalize expression (24) to zero and rearrange to get

$$
\frac{d Y}{d B^{g}}=-\frac{\frac{\partial b p\left(Y\left(B^{g}\right) ; B^{g}\right)}{\partial B^{g}}}{\frac{\partial b p\left(Y ; B^{g}\right)}{\partial Y}}
$$

where $\frac{\partial b p\left(Y ; B^{g}\right)}{\partial Y} \neq 0$. Noting that $\frac{\partial b p\left(Y ; B^{g}\right)}{\partial B^{g}}<0$, equation (25) implies that the effect of government bonds on output depends entirely on the cyclicality of the bond premium, that is, on the sign of $\frac{\partial b p\left(Y ; B^{g}\right)}{\partial Y}$.

Consider first the case in which the bond premium is pro-cyclical, i.e., the economy is in an FLT. In this economy, an increase in the supply of government bonds is expansionary.

Proposition 5 (Government Bonds in an FLT) Suppose that Assumptions 1 and 2 are satisfied. Suppose the bond premium is pro-cyclical and the economy is in a liquidity trap steady state. Then,

$$
\frac{d Y}{d B^{g}}>0
$$

This result is consistent with the findings in Caballero and Farhi (2017). An increase in the supply of government bonds creates an excess supply in the bonds market. The definition of the bond premium (see equation (17)) implies that, ceteris paribus, the increase in bond supply induces a reduction in the bond premium. In order to restore the equilibrium of the economy, and since local to the initial liquidity trap equilibrium the interest rate is constant at zero, output needs to adjust to bring back the bond premium to its initial level. When the bond premium is pro-cyclical, an increase in output pushes the bond premium up, canceling out the direct effect of government policy. Moreover, since the increase in output relaxes the firms' borrowing constraint, government bonds crowd in private bonds. This effect reinforces the government's initial policy, further stimulating the economy. Thus, when the bond premium is pro-cyclical and the supply of private bonds is elastic, government bonds are expansionary and crowd in the private sector.

However, a quick inspection of equation (25) suggests that the opposite result of the one in Proposition 5 holds when the bond premium is counter-cyclical. Proposition 6 shows that, for a small change in the supply of government bonds, and as long as households' expectations remain pessimistic (i.e., agents coordinate on the liquidity trap steady state), the results are reversed in an SFLT.

Proposition 6 (Government Bonds in an SFLT) Suppose that Assumptions 1 and 2 are satisfied. Suppose the bond premium is counter-cyclical and the economy is in a liquidity 
trap steady state. Then, there exists a liquidity trap steady-state equilibrium such that

$$
\frac{d Y}{d B^{g}}<0
$$

Proposition 6 establishes that a small increase in the supply of government bonds reduces the steady-state level of output in an SFLT. When the bond premium is counter-cyclical, it is a reduction in output that pushes the bond premium up, which in turn offsets the direct effect of government policy. Moreover, this reduction in output crowds out private bond issuances. Thus, when the bond premium is counter-cyclical and the supply of private bonds is elastic, increases in the supply of government bonds is contractionary and crowds out private safe asset production.

Recall that the SFLT coexists with the full-employment steady state. We focus here on equilibria in which agents' expectations are anchored around the initial equilibrium. However, it is possible that the policy intervention changes agents' expectations in such a way that the economy transitions to the full-employment steady state. While theoretically interesting, our model does not provide a theory of expectations formation rich enough to allow us to study transitions to the other steady state. Moreover, we believe that small policy interventions are unlikely to coordinate agents' expectations on the good equilibrium. Such drastic changes usually require specific policies that generate a credible regime shift (see, e.g., Sargent, 1983).

Propositions 5 and 6 show that an increase in the supply of government bonds may be expansionary or contractionary, depending on the nature of the liquidity trap. This result is discouraging given that FLTs and SFLTs share similar features that make them hard to distinguish in real time. ${ }^{26}$ However, a suffiently large intervention can be desirable in both scenarios. While small increases can be contractionary under an SFLT, a sufficiently large increase in publicly supplied safe assets can impose a sufficiently low upper bound on the bond premium such that self-fulfilling pessimism becomes inconsistent with equilibrium. In particular, let $B^{g, *}$ be such that ${ }^{27}$

$$
b p\left(Y^{\min }, B^{g, *}\right)=\frac{1-\beta}{\beta} .
$$

The next proposition shows that if the government commits to issue bonds above $B^{g, *}$ when

\footnotetext{
${ }^{26}$ One could distinguish between the two equilibria by identifying the cyclicality of the bond premium or the response of the economy to changes in the supply of government bonds. However, both these tests require a sufficient number of observations, which is likely to be a constraint in reality. In Section 5 we study the dynamics of the economy as it transitions to a liquidity trap and show the similarity of the transition paths towards an FLT and an SFLT.

${ }^{27}$ If $B^{g, *}$ does not exist, set $B^{g, *}=0$.
} 
it faces a liquidity trap, SFLTs cannot arise in equilibrium.

Proposition 7 (Large Interventions) Suppose that Assumptions 1 and 2 are satisfied, the bond premium is counter-cyclical and $\phi_{Y}>\frac{b p^{\prime}\left(Y^{*}\right) Y^{*}}{1+b p\left(Y^{*}\right)} R^{*}$. Suppose that the government follows a bond rule $B^{g}(Y)$, with $B^{g^{\prime}}(\cdot)<0$, and

$$
B^{g}\left(Y^{\min }\right)>B^{g, *}
$$

where $B^{g, *}$ is defined in equation (26). Then, the unique steady-state equilibrium of the economy features full employment. ${ }^{28}$

Thus, we have identified a robust policy, i.e., a policy intervention that is expansionary independently of the type of liquidity trap affecting the economy. Note that this policy requires a discrete intervention, i.e., an intervention large enough that it precludes an SFLT from existing. This logic is reminiscent of Krugman (2014)'s timidity trap. In our model, a small increase in government debt can be contractionary, justifying the timidity of the government in carrying out such actions. However, if the government could commit to a sufficiently large intervention, the policy would be welfare-enhancing.

For the large intervention to achieve its objective, the policy announcement needs to be credible. For a policy to be credible, it needs to satisfy at least two conditions. First, if the government cannot distinguish between fundamental and self-fulfilling traps, it should be willing to intervene every time the economy transitions to a trap. If the government is successful in convincing households that it will always intervene, only FLTs can arise in equilibrium. Thus, for the policy to be credible, the government should implement a large intervention in FLTs. This should not be a problem since increasing the supply of government bonds stimulates the economy in fundamental traps.

The second dimension of credibility is related to fiscal capacity. Suppose that the government is subject to the same constraints as the private sector, in that only debt that can be backed by (potentially off-equilibrium) taxation power is deemed to be safe. That is, the government faces the following constraint

$$
B^{g} \leq \tau^{\max } Y
$$

\footnotetext{
${ }^{28}$ An analogous result appears in Benigno and Fornaro (2018) in the context of a model of endogenous growth. In their model, a sufficiently large innovation subsidy can prevent the liquidity trap from arising as an equilibrium outcome. Our results here differ in two dimensions. First, in our economy the liquidity trap is driven by spikes in the bond premium rather than by changes in the growth rate of the economy. Second, our setup allows us to have both FLT and SFLT as an equilibrium outcome. As a result, we can study what policies are desirable when policy makers do not know what type of trap they are facing.
} 
where $\tau^{\max }$ is the maximum tax rate the government can implement. We say that a policy $B^{g, *}$ is credible if and only if

$$
B^{g, *} \leq \tau^{\max } Y^{\min }
$$

that is, the government's taxation power is sufficient to back the outstanding government bonds even in the worst-case scenario, i.e., $Y=Y^{\min }{ }^{29}$ This is a relatively standard constraint on the government's ability to provide safe assets that are not subject to roll-over risk (see, e.g., Calvo (1988) and Cole and Kehoe (2000)). More recently, He et al. (2019) argue that safety of a country's debt is decreasing in roll-over risk.

Suppose that the minimum supply necessary to preclude the SFLT is $B^{g, *}>\tau^{\max } Y^{\min }$. In this case, the government cannot credibly commit to issue enough bonds to preclude an SFLT from materializing. If the economy is facing a liquidity trap under this scenario, an increase in the supply of government bonds could be contractionary. This example shows that sufficient fiscal capacity is crucial for the implementation of a robust policy intervention. The next proposition summarizes these results.

Proposition 8 (Fiscal capacity and safe asset provision) Suppose that Assumptions 1 and 2 are satisfied. Suppose that the government's fiscal capacity is given by $\bar{B}^{g}=\tau^{\max } Y^{\min }$. Let $B^{g, *}$ be the level of safe assets that precludes the existence of an SFLT, defined in (26). If $\bar{B}^{g}>B^{g, *}$, the economy does not admit an SFLT equilibrium. Furthermore, safe asset provision by the government is unambiguously expansionary in a liquidity trap if and only if $B^{g}>B^{g, *}$.

\subsection{Government Spending}

An alternative policy instrument available to the government is spending. Government spending can affect the bond premium indirectly through increases in aggregate demand. As we found with government bonds, the effect of government spending depends on the cyclicality of the bond premium. Despite the two policy instruments' similar effects on output, we show that government spending is dominated by government bond issuances in terms of households' welfare.

We extend the model of Section 3 to incorporate government spending as a policy tool. The budget constraint of the government is now given by

$$
B_{t}^{g}=\frac{B_{t+1}^{g}}{1+r_{t}}+T_{t}^{g}-G_{t}
$$

\footnotetext{
${ }^{29}$ One could relax the constraint to allow for some unbacked debt as long as the amount of safe debt that the government can issue is still related to its taxation capacity.
} 
where $1+r_{t} \equiv \frac{1+i_{t}}{1+\pi_{t+1}}$, and $G_{t}$ denotes real government spending. Moreover, the resource constraint of the economy is now given by

$$
C_{t}^{w}+\chi B_{t}+G_{t}=Y_{t}
$$

Consider an economy that is in a liquidity trap steady state and the government increases its spending. For a given level of $C^{w}$ and $B$, an increase in $G$ increases aggregate demand. The increase in aggregate demand relaxes the firms' bond issuance constraint, increasing, ceteris paribus, the supply of bonds, which is a force towards a lower bond premium. To restore equilibrium, output needs to adjust. Once again, the effect that this policy has on the equilibrium of the economy depends on the cyclicality of the bond premium.

Proposition 9 (Government Spending in a Liquidity Trap) Suppose that Assumptions 1 and 2 are satisfied. Consider an economy that is in a liquidity trap and the government increases government spending by $d G$. Then,

1. if the bond premium is pro-cyclical, $\frac{d Y}{d G}>0$,

2. if the bond premium is counter-cyclical, there exists a steady-state equilibrium such that $\frac{d Y}{d G}<0$.

Moreover, if the bond premium is counter-cyclical, there exists $G^{*}$ such that, if $G>G^{*}$, the unique steady state of the economy features full employment.

Proposition 9 states that government spending generates results in terms of output that are similar to the results obtained with government bonds. However, the costs for the economy can be substantially higher when government spending is used as a policy tool. The intuition is simple: while the proceeds of government bonds are rebated back to the households, government spending involves the use of actual resources. Thus, government bond issuances are a superior policy.

Proposition 10 (Superiority of $B^{g}$ over $G$ ) Suppose that Assumptions 1 and 2 are satisfied. Consider an economy that is in a liquidity trap. Consider two policies. In one case, the government increases the supply of bonds by $\Delta B^{g}>0$ and output is $Y^{B}$. In the second case, the government increases spending by $\Delta G>0$ and output is $Y^{G}$. Suppose that $\Delta B^{g}$ and $\Delta G$ are such that $Y^{B}=Y^{G}$. Then, households' welfare is higher under an increase in government bonds than under an increase in government spending.

Finally, note that we are assuming that government spending is financed by lump-sum taxes. In contrast, government bonds have no fiscal cost since they can be rolled over at zero 
TABLE 4: PARAMETERS

\begin{tabular}{lll}
\hline Fixed parameters & Value & Source/Target \\
\hline Discount Factor & $\beta=0.96$ & Standard \\
Price inflation at full emp. & $\pi^{*}=1.02$ & Standard \\
Capital share parameter & $\alpha=1 / 3$ & Standard \\
Depreciation rate & $\delta=0.10$ & (Del Negro et al., 2017b) \\
Elas. intertemporal substitution & $\frac{1}{\sigma}=0.1$ & (Best, Cloyne, Ilzetzki and Kleven, 2019) \\
TFP & $A=8$ & normalization \\
Wage rigidity parameter & $\kappa=0.92$ & normalization \\
\hline Jointly calibrated parameters & SFLT & FLT \\
\hline Span of Control & $\nu=0.5$ & $\nu=0.975$ \\
Retirement risk & $\chi=0.153$ & $\left(\chi^{f}, \chi^{L T}\right)=(0.116,0.480) / 100$ \\
Fixed Cost & $F=5.9$ & $F=2$ \\
Safety constraint & $(\eta, \phi)=(2,0.84)$ & $(\eta, \phi)=(0.15,3)$ \\
Government Bonds & $B^{g}=4.9$ & $B^{g}=14$ \\
Targeted moments & SFLT & FLT \\
\hline Full emp Profits to GDP & $5.45 \%$ & $5.68 \%$ \\
Full emp Govt Bonds to GDP & $40 \%$ & $43 \%$ \\
Full emp bond premium & $270 \mathrm{bps}$ & $268 \mathrm{bps}$ \\
$\uparrow$ in bond premia in LT & $295 \mathrm{bps}$ & $304 \mathrm{bps}$ \\
Unemployment in LT & $6.80 \%$ & $6.28 \%$ \\
Inflation (net) in LT & $1.45 \%$ & $1.50 \%$ \\
\hline \hline
\end{tabular}

Notes: The table shows the parameter values of the model for the baseline calibration. Time is measured at an annual frequency.

interest rate in a liquidity trap. ${ }^{30}$ If taxation were distortionary, the results of Proposition 10 would be even starker.

\section{Quantitative Model}

In this section, we develop a quantitative model that extends the microfounded model developed in Section 3. The model in this section presents two innovations. First, we incorporate physical capital as a factor of production. Second, we relax the assumption about wage rigidity and allow deflation in equilibrium, as in Schmitt-Grohé and Uribe (2017). We first illustrate the transitional dynamics of an economy from a full-employment steady state to a liquidity trap equilibrium (both FLT and SFLT). Then, we use the model to calculate the size of the intervention necessary to preclude the existence of SFLTs.

Here, we briefly summarize the extensions; we present the detailed model in Appendix $\mathrm{G}$. The final consumption good is produced combining labor and capital in a Cobb-Douglas production function: $Y_{t}=A\left(K_{t}^{\alpha} h_{t}^{1-\alpha}\right)^{\nu}$, with $\alpha, \nu \in(0,1)$. The parameter $\nu$ denotes span

\footnotetext{
${ }^{30}$ This would not be true if the trap were transitory.
} 
of control, which measures the degree of decreasing returns in variable factors of production. As in Section 3, the firms face a per-period fixed cost $F$, so that their per-period profits are given by $\Pi_{t}=P_{t}\left(A\left(K_{t}^{\alpha} h_{t}^{1-\alpha}\right)^{\nu}-F\right)-W_{t} h_{t}$. The firms' borrowing constraint is generalized to

$$
\frac{\tilde{B}_{t+1}^{p}}{P_{t+1}} \leq \phi\left(\frac{\Pi_{t+1}}{P_{t+1}}\right)^{\eta}
$$

where $\phi>0$ and $\eta>0$ are parameters governing the degree of financial frictions and the elasticity of the borrowing constraint with respect to profits. Recall that the elasticity of the supply of bonds is a key determinant of the cyclicality of the bond premium.

Following Schmitt-Grohé and Uribe (2017), we assume the following downward-wage rigidity process to allow for deflation in steady state:

$$
\frac{W_{t}}{W_{t-1}} \geq \gamma\left(u_{t}\right)
$$

where $u_{t}=1-h_{t}$ is the economy's unemployment rate and $\gamma\left(u_{t}\right)$ is a given function of the unemployment rate. We assume a simple functional form for this process: $\gamma\left(u_{t}\right)=[\kappa+(1-$ $\left.\kappa)\left(1-u_{t}\right)\right] \pi^{*}$, where $\kappa>0$ and $\pi^{*}$ is the exogenous wage inflation rate in the full-employment steady state. The central bank follows a monetary rule targeting full employment, subject to a ZLB constraint.

We solve the model numerically. Table 4 summarizes the values of the parameters in the extended model with annual time periods. We set the discount factor to $\beta=0.96$, inflation at full employment to $2 \%$, and capital depreciation rate to $\delta=0.10$. These are standard values in the business cycle literature. The inverse of the elasticity of inter-temporal substitution is set to $\sigma=10$ consistent with estimates by Best et al. (2019). We set the span of control $\nu$ so that the profits to GDP ratio is around $5.6 \%$, consistent with average estimates of the corporate profits to GDP ratio in the data. ${ }^{31}$ The value of government bonds $B^{g}$ is calibrated so that public bonds to GDP ratio is about $40 \%$ in the full-employment steady state (Del Negro et al., 2017b; Krishnamurthy and Vissing-Jorgensen, 2012).

To generate SFLT and FLT steady states, we jointly set the four (non-standard) parameters $\chi, F, \eta$ and $\phi$ to target the following moments: a full-employment bond premium of 250 bps; an unemployment in the liquidity trap steady state of $6.50 \%$; (annualized) inflation rate in the liquidity trap steady state of $1.50 \mathrm{pp}$, and an increase in the bond premium in the liquidity trap of $300 \mathrm{bps}$. The average of Moody's BAA Corporate Bond yield relative

\footnotetext{
${ }^{31}$ We use data from 1953Q1 to 2007Q4 obtained from FRED series CP_GDP. Estimates of span of control are usually in the range of 0.85 and 0.92 in the literature. See also Basu and Fernald (1997), and Atkeson and Kehoe (2005). Given that the fixed cost is rebated back to the households in our model, the capital and labor shares lie close to the standard estimates of 34 percent and 66 percent respectively, assuming equal returns to managerial labor and intangible/organizational capital.
} 
Figure 6: Transitional dynamics of unemployment, nominal interest rate, change in bond premium, and inflation to liquidity trap steady state
(1) SFLT
(2) FLT
(1) SFLT
(2) FLT

(a) Unemployment

(b) Federal Funds Rate
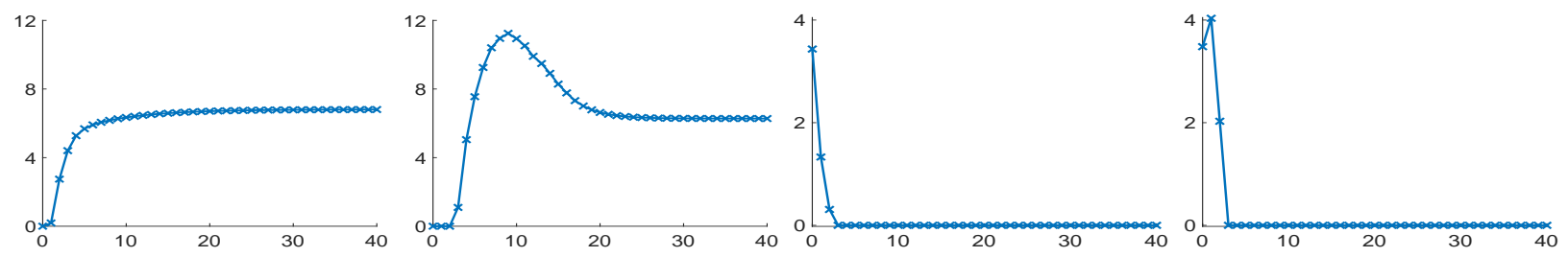

(c) $\Delta$ Bond Premium

(d)Inflation
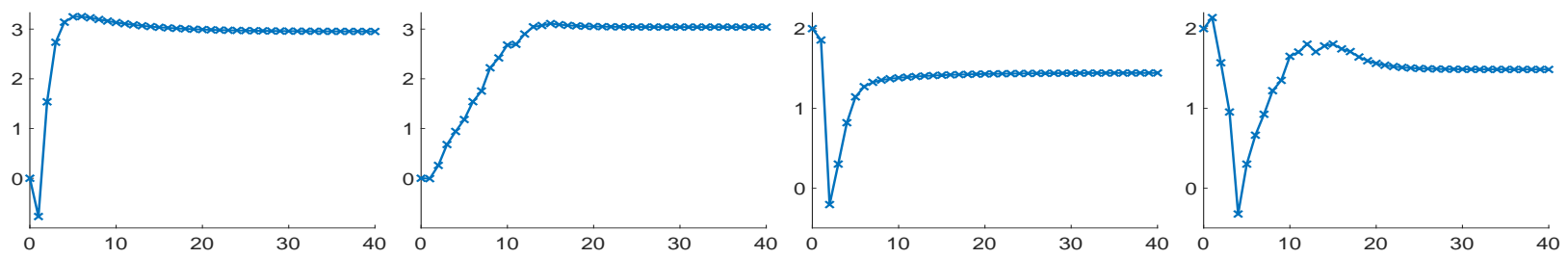

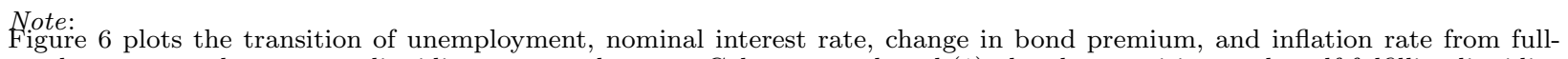
employment steady state to a liquidity trap steady state. Columns numbered (1) plot the transition to the self-fulfilling liquidity trap (SFLT) steady state, and columns numbered (2) plot the transition to the fundamental liquidity trap (FLT) steady state. Time is in quarters. Unemployment is in percentage points. The nominal interest rate in the model is the annualized level of the nominal interest rate in percentage points. $\Delta$ bond premium represents the annual percentage point change in the bond premium relative to the full-employment steady state bond premium (250 bps). Inflation is measured in annualized percentage points. The inflation target of the central bank is $2 \%$.

to 10 year treasury constant maturity was 260 bps from 2000 to 2019, and 550 bps during 2008Q4-2009Q1 at the trough of the Great Recession. In this period, the US civilian unemployment rate rose to $10 \%$ relative to a natural rate of unemployment in the range of 3.50-4\%. ${ }^{32}$ Given this inflation drop and the calibrated increase in convenience yield, the (annualized) real interest rate on government bonds falls by $280-290$ bps in both liquidity trap steady states.

Figure 6 plots the transitional dynamics from a full-employment steady state to the corresponding liquidity trap steady state. In the FLT case, we construct a grid that gradually increases $\chi$ from $\chi^{f}$ to $\chi^{L T}$ to generate a negative natural rate of interest. Increased demand for safe assets by households increases the premium on liquid bonds. The nominal interest rate on government bonds declines until it hits the ZLB. An interest rate gap from the natural rate manifests in the form of increased unemployment and inflation below the central bank's target. In the SFLT case, the transition to the liquidity trap is triggered by a decline of households' confidence in the economy. The interaction between this pessimism and the counter-cyclical bond premium pushes the bond premium up. The central bank reacts to this recessionary pressure by lowering the policy rate until it hits the ZLB. In the liquidity trap

\footnotetext{
${ }^{32}$ We obtain data from FRED series BAA10Y and UNRATE.
} 
steady state, bond premium and unemployment remain elevated, while (annual) inflation runs persistently below the central bank's target.

Figure 6 shows the remarkable similarities of the paths towards the liquidity trap equilibrium in both economies. These similarities make it difficult for policy makers to determine what type of trap they are facing. We further use the model of this section to quantify the amount of public debt that can eliminate the SFLT. This is the quantitative counterpart of the results in Proposition 7. Del Negro et al. (2017b) evaluate the effects of a $\$ 1.4$ trillion (10\% of GDP) increase in the Fed's balance sheet through issuances of government debt during the Great Recession. Our quantitative model suggests that an increase in government bonds-to-GDP ratio of $16 \%$ would have been sufficient to preclude a SFLT during the Great Recession. From Proposition 8, if the maximum tax rate that government can implement is at least $56 \%$ (i.e., $\tau^{\max }>0.56$ ), the government can credibly issue new safe assets by up to $16 \%$ of GDP. ${ }^{33}$ Hence, the robust policy commitment to supply safe assets at this scale in a liquidity trap would be credible and eliminates SFLT. Moreover, it would also be expansionary in an FLT, restoring the natural rate to 400 basis points.

\section{Conclusion}

In this paper, we develop a theory of endogenous supply of safe assets and derive its implications for the macroeconomy. Safe asset shortages can expose the economy to a liquidity trap. In particular, there are two kinds of liquidity traps -self-fulfilling and fundamentalsdriven- with conflicting policy implications. Both feature a constrained monetary authority, below-potential output, and a heightened bond premium. A counter-cyclical bond premium opens the possibility of self-fulfilling liquidity traps (SFLT). In an SFLT, small issuances of government debt crowd out private debt and exacerbate the pessimism-driven recession. In contrast, government debt is always expansionary in fundamental liquidity traps. In the data, we found evidence of a counter-cyclical bond premium and a pro-cyclical supply of safe assets. We proposed robust policies that prevent the existence of self-fulfilling traps and are expansionary in fundamental traps. In our framework, we have further underscored the importance of fiscal capacity in a government's ability to manage liquidity traps. We build a quantitative model calibrated to match the evolution of employment and asset prices during the Great Recession and show that the observable dynamics of the aggregate variables look similar across SFLT and FLT. Moreover, we use the model to calculate the size of the fiscal response necessary to preclude the existence of SFLTs and find that a promise to increase

\footnotetext{
${ }^{33}$ While this estimate of taxation power may be high, note that these results hold in a model with a tight roll-over risk constraint.
} 
the government debt-to-GDP ratio by 16 percentage points would be sufficient. Future research should focus on developing models that can better quantify the fiscal space needed to implement such policies.

\section{References}

Acharya, Sushant, and Keshav Dogra. 2018. "The side effects of safe asset creation." FRB of New York Staff Report 842.

Ascari, Guido, and Lorenza Rossi. 2012. "Trend inflation and firms price-setting: Rotemberg versus Calvo." The Economic Journal, 122(563): 1115-1141.

Atkeson, Andrew, and Patrick J Kehoe. 2005. "Modeling and measuring organization capital." Journal of political Economy, 113(5): 1026-1053.

Barro, Robert J. 1974. "Are government bonds net wealth?" Journal of political economy, 82(6): 1095-1117.

Barro, Robert J, and Andrew Mollerus. 2014. "Safe Assets."

Basu, Susanto, and John G Fernald. 1997. "Returns to scale in US production: Estimates and implications." Journal of political economy, 105(2): 249-283.

Baxter, Marianne, and Robert G King. 1999. "Measuring business cycles: approximate band-pass filters for economic time series." Review of Economics and Statistics, 81(4): 575593.

Benhabib, Jess, Stephanie Schmitt-Grohé, and Martin Uribe. 2001a. "Monetary policy and multiple equilibria." American Economic Review, 91(1): 167-186.

Benhabib, Jess, Stephanie Schmitt-Grohé, and Martín Uribe. 2001b. "The Perils of Taylor Rules." Journal of Economic Theory, 96(1): 40-69.

Benhabib, Jess, Stephanie Schmitt-Grohé, and Martín Uribe. 2002. "Avoiding liquidity traps." Journal of Political Economy, 110(3): 535-563.

Benigno, Gianluca, and Luca Fornaro. 2018. "Stagnation Traps." The Review of Economic Studies, 85(3): 1425-1470.

Bernanke, B. 2005. "The Global Saving Glut and the US Current Account Deficit." Sandrige Lecture, Virginia Association of Economics, Richmond, Virginia, Federal Reserve Board, March 2005.

Best, Michael Carlos, James S Cloyne, Ethan Ilzetzki, and Henrik J Kleven. 2019. "Estimating the Elasticity of Intertemporal Substitution Using Mortgage Notches." The Review of Economic Studies. 
Bilbiie, Florin Ovidiu. 2018. "Neo-Fisherian Policies and Liquidity Traps." C.E.P.R. Discussion Papers 13334.

Bilbiie, Florin Ovidiu. 2019. "Monetary Policy and Heterogeneity: An Analytical Framework."

Brave, Scott. 2009. "The Chicago fed national activity index and business cycles." Chicago Fed Letter 268.

Caballero, Ricardo J. 2006. "On the Macroeconomics of Asset Shortages." In The Role of Money: Money and Monetary Policy in the Twenty-First Century. Vol. 4, , ed. Andreas Beyer and Lucrezia Reichlin, 272-283.

Caballero, Ricardo J, and Emmanuel Farhi. 2017. "The safety trap." The Review of Economic Studies, 85(1): 223-274.

Caballero, Ricardo J, Emmanuel Farhi, and Pierre-Olivier Gourinchas. 2015. "Global Imbalances and Currency Wars at the ZLB." National Bureau of Economic Research.

Caballero, Ricardo J., Emmanuel Farhi, and Pierre-Olivier Gourinchas. 2016. "Safe Asset Scarcity and Aggregate Demand." American Economic Review, 106(5): 51318.

Calvo, Guillermo A. 1988. "Servicing the public debt: The role of expectations." The American Economic Review.

Cole, Harold L, and Timothy J Kehoe. 2000. "Self-fulfilling debt crises." The Review of Economic Studies, 67(1): 91-116.

Cuba-Borda, Pablo, and Sanjay R Singh. 2019. "Understanding Persistent Stagnation." FRB International Finance Discussion Paper 1243.

Curdia, Vasco, and Michael Woodford. 2011. "The central-bank balance sheet as an instrument of monetarypolicy." Journal of Monetary Economics, 58(1): 54-79.

Del Negro, Marco, Domenico Giannone, Marc P Giannoni, and Andrea Tambalotti. 2017a. "Safety, liquidity, and the natural rate of interest." Brookings Papers on Economic Activity, 2017(1): 235-316.

Del Negro, Marco, Gauti Eggertsson, Andrea Ferrero, and Nobuhiro Kiyotaki. 2017b. "The great escape? A quantitative evaluation of the Fed's liquidity facilities." American Economic Review, 107(3): 824-57.

Eggertsson, Gauti B, and Michael Woodford. 2003. "Zero bound on interest rates and optimal monetary policy." Brookings Papers on Economic Activity, 2003(1): 139-233.

Eggertsson, Gauti B, and Paul Krugman. 2012. "Debt, Deleveraging, and the Liquidity Trap: A Fisher-Minsky-Koo Approach." Quarterly Journal of Economics, 127(3): 14691513. 
Eggertsson, Gauti B, and Sanjay R Singh. 2019. "Log-linear Approximation versus an Exact Solution at the ZLB in the New Keynesian Model." Journal of Economic Dynamics and Control, 105: 21-43.

Geromichalos, Athanasios, Lucas Herrenbrueck, and Sukjoon Lee. 2018. "Asset safety versus asset liquidity."

Gertler, Mark. 1999. "Government debt and social security in a life-cycle economy." Carnegie-Rochester Conference Series on Public Policy, 50: 61-110.

Gorton, Gary, and Andrew Metrick. 2012. "Securitized banking and the run on repo." Journal of Financial Economics, 104(3): 425-451.

Gorton, Gary, Stefan Lewellen, and Andrew Metrick. 2012. "The safe-asset share." The American Economic Review, 102(3): 101-06.

Gourinchas, Pierre-Olivier, and Olivier Jeanne. 2013. "Global Safe Assets."

Greenwood, Robin, Samuel G Hanson, and Jeremy C Stein. 2015. "A comparativeadvantage approach to government debt maturity." The Journal of Finance, 70(4): 16831722 .

Guerrieri, Veronica, and Guido Lorenzoni. 2017. "Credit crises, precautionary savings, and the liquidity trap." The Quarterly Journal of Economics, 132(3): 1427-1467.

Hamilton, James D. 2018. "Why you should never use the Hodrick-Prescott filter." Review of Economics and Statistics, 100(5): 831-843.

Heathcote, Jonathan, and Fabrizio Perri. 2018. "Wealth and Volatility." The Review of Economic Studies.

He, Zhiguo, Arvind Krishnamurthy, and Konstantin Milbradt. 2019. "A model of safe asset determination." American Economic Review, 109(4): 1230-62.

Jiang, Zhengyang, Arvind Krishnamurthy, and Hanno N Lustig. 2019. "Dollar safety and the global financial cycle." Available at SSRN 3328808.

Jordà, Òscar, Moritz Schularick, and Alan M Taylor. 2016. "Sovereigns versus banks: credit, crises, and consequences." Journal of the European Economic Association, 14(1): 45-79.

Kiyotaki, Nobuhiro, and John Moore. 2019. "Liquidity, business cycles, and monetary policy." Journal of Political Economy, 127(6).

Krishnamurthy, Arvind, and Annette Vissing-Jorgensen. 2012. "The aggregate demand for treasury debt." Journal of Political Economy, 120(2): 233-267.

Krishnamurthy, Arvind, and Annette Vissing-Jorgensen. 2015. "The impact of treasury supply on financial sector lending and stability." Journal of Financial Economics, 118(3): 571-600. 
Krugman, Paul. 2014. "The timidity trap." The New York Times, 20.

Lucas Jr, Robert E. 1990. "Liquidity and interest rates." Journal of Economic Theory, 50(2): 237-264.

Mian, Atif, Ludwig Straub, and Amir Sufi. 2019. "Indebted Demand."

Nagel, Stefan. 2016. "The liquidity premium of near-money assets." The Quarterly Journal of Economics, 131(4): 1927-1971.

Nakata, Taisuke, and Sebastian Schmidt. 2019. "Expectations-Driven Liquidity Traps: Implications for Monetary and Fiscal Policy."

Obstfeld, Maurice. 2013. "On Keeping Your Powder Dry: Fiscal Foundations of Financial and Price Stability." Monetary and Economic Studies, 31: 25-38.

Rachel, Łukasz, and Lawrence H Summers. 2019. "On Secular Stagnation in the Industrialized World." National Bureau of Economic Research.

Ramey, Valerie A, and Sarah Zubairy. 2018. "Government spending multipliers in good times and in bad: evidence from US historical data." Journal of Political Economy, 126(2): 850-901.

Romer, Christina D, and David H Romer. 2018. "Why Some Times Are Different: Macroeconomic Policy and the Aftermath of Financial Crises." Economica, 85(337): 1-40.

Sargent, Thomas J. 1983. "The ends of four big inflations." In Inflation: Causes and effects. 41-98. University of Chicago Press.

Schmitt-Grohé, Stephanie, and Martín Uribe. 2017. "Liquidity traps and jobless recoveries." American Economic Journal: Macroeconomics, 9(1): 165-204.

Stock, James H, and Mark W Watson. 2003. "Has the business cycle changed? Evidence and explanations." Monetary policy and uncertainty: adapting to a changing economy, 956 .

Stock, James H, and Mark W Watson. 2019. "Slack and cyclically sensitive inflation." National Bureau of Economic Research.

Sunderam, Adi. 2015. "Money creation and the shadow banking system." The Review of Financial Studies, 28(4): 939-977. 


\section{A Proofs}

Proof of Proposition 1. Assumption 1 guarantees that $Y^{\min }<Y^{*}$. If $b p\left(Y^{*}\right) \leq \frac{1-\beta}{\beta}, R^{*}=$ $\frac{1}{\beta} \frac{1}{1+b p\left(Y^{*}\right)}$ implies that $R^{*} \geq 1$. Thus, a full-employment steady state exists. If $b p\left(Y^{*}\right)>\frac{1-\beta}{\beta}$, then $R^{*}=\frac{1}{\beta} \frac{1}{1+b p\left(Y^{*}\right)}$ implies that $R^{*}<1$ and, hence, from the Taylor rule $(21), 1+i=1$. Moreover, Assumption 2 guarantees that there exists $\tilde{Y} \in\left[Y^{\mathrm{min}}, Y^{*}\right)$ such that $b p(\tilde{Y}) \leq \frac{1-\beta}{\beta}$. By continuity of $b p(Y)$, there exists $\hat{Y} \in\left[\tilde{Y}, Y^{*}\right)$ such that $b p(\hat{Y})=\frac{1-\beta}{\beta}$, and hence $\hat{Y}$ is a steady state of the economy.

Proof of Proposition 2. Proposition 1 guarantees that a steady-state equilibrium exists. Note that $R^{*}=\frac{1}{\beta} \frac{1}{1+b p\left(Y^{*}\right)} \geq 1$, so, if $Y=Y^{*}$, then the Taylor rule implies $1+i=R^{*}$. Moreover, the bond demand (18) holds by construction of $R^{*}$. Hence, a full-employment steady state exists. Since $R^{*}$ is unique, there is a unique full-employment steady state.

For the local determinacy of the full-employment steady state, we need to study the dynamic properties of the model in a neighborhood of the steady state. The system of equations characterizing the equilibrium is given by

$$
\begin{gathered}
\beta \frac{1+i_{t}}{1+\pi_{t+1}}\left[(1-\chi) \frac{C_{t}^{w}}{C_{t+1}^{w}}+\chi \frac{C_{t}^{w}}{B_{t+1}}\right]=1 \\
C_{t}^{w}=Y_{t}-\chi B_{t}=(1-\chi \alpha) Y_{t}+\chi F-\chi B^{g} \\
B_{t}=\alpha Y_{t}-F+B^{g} \\
\pi_{t+1}=\left(\frac{Y_{t+1}}{Y_{t}}\right)^{\frac{\alpha}{1-\alpha}} \\
1+i_{t}=R^{*}+\phi_{Y}\left(\frac{Y_{t}}{Y^{*}}-1\right)
\end{gathered}
$$

Log-linearizing the system around the full-employment steady state, we get

$$
\begin{gathered}
i_{t}-\pi_{t+1}-r^{*}+\beta R^{*}(1-\chi)\left(c_{t}^{w}-c_{t+1}^{w}\right)+\beta R^{*} \chi \frac{C^{w *}}{B^{*}}\left(c_{t}^{w}-b_{t+1}\right)=0 \\
c_{t}^{w}=\frac{(1-\chi \alpha) Y^{*}}{C^{w *}} y_{t} \\
b_{t}=\frac{\alpha Y^{*}}{B^{*}} y_{t} \\
\pi_{t+1}=\frac{\alpha}{1-\alpha}\left(y_{t+1}-y_{t}\right) \\
i_{t}-r^{*}=\frac{\phi_{Y}}{R^{*}} y_{t},
\end{gathered}
$$


where $r^{*} \equiv \log \left(R^{*}\right)$. We can combine these equations to obtain a difference equation in $y_{t}$

$$
\begin{aligned}
{\left[\frac{\alpha}{1-\alpha}+\beta R^{*}(1-\chi) \frac{(1-\chi \alpha) Y^{*}}{C^{w *}}+\beta R^{*} \chi \frac{C^{w *}}{B^{*}} \frac{(1-\chi \alpha) Y^{*}}{C^{w *}}+\frac{\phi_{Y}}{R^{*}}\right] y_{t}=} & \\
& {\left[\frac{\alpha}{1-\alpha}+\beta R^{*}(1-\chi) \frac{(1-\chi \alpha) Y^{*}}{C^{w *}}+\beta R^{*} \chi \frac{C^{w *}}{B^{*}} \frac{\alpha Y^{*}}{B^{*}}\right] y_{t+1} }
\end{aligned}
$$

The system is locally determinate if and only if

$$
\beta R^{*} \chi \frac{(1-\chi \alpha) Y^{*}}{B^{*}}+\frac{\phi_{Y}}{R^{*}}>\beta R^{*} \chi \frac{C^{w *}}{B^{*}} \frac{\alpha Y^{*}}{B^{*}}
$$

or, after some algebra,

$$
\frac{\phi_{Y}}{R^{*}}>\beta R^{*} \chi \frac{Y^{*}}{B^{*}} \frac{F-B^{g}}{B^{*}} .
$$

Note that

$$
b p(Y)=\chi\left(\frac{C^{w}(Y)}{B(Y)}-1\right)=\chi\left(\frac{Y-\chi\left(\alpha Y-F+B^{g}\right)}{\alpha Y-F+B^{g}}-1\right)
$$

hence

$$
b p^{\prime}(Y)=-\chi \frac{F-B^{g}}{B(Y)^{2}}
$$

and

$$
\beta^{*} R^{*}=\frac{1}{1+b p(Y)}
$$

hence, the system is locally determinate if and only if

$$
\phi_{Y}>-\frac{b p^{\prime}\left(Y^{*}\right) Y^{*}}{1+b p\left(Y^{*}\right)} R^{*}
$$

Since either $b p^{\prime}(Y)>0$ or $b p^{\prime \prime}(Y)>0$, if $\phi_{Y}>-\frac{b p^{\prime}\left(Y^{*}\right) Y^{*}}{1+b p\left(Y^{*}\right)} R^{*}$, there is no other steady state with a positive interest rate.

Proof of Proposition 3. The existence of a FLT is immediate from the proof of Proposition 1. Moreover, note that $b p^{\prime}(Y)>0$, so $\phi_{Y}=0$ guarantees determinacy.

Proof of Proposition 4. Since $b p\left(Y^{*}\right)<\frac{1-\beta}{\beta}, R^{*}>1$ and a full-employment equilibrium exists. Moreover, since $b p\left(Y^{\mathrm{min}}\right) \geq \frac{1-\beta}{\beta}$, by continuity of $b p(Y)$, there exists $\tilde{Y} \in\left[Y^{\mathrm{min}}, Y^{*}\right)$ such that equations (18) and (21) intersect. Finally, since $b p^{\prime}(Y)<0, \phi_{Y}=0$ is not sufficient for determinacy, so the SFLT is locally indeterminate.

Proof of Corollary 1. Since $b p\left(Y^{*}\right)<\frac{1-\beta}{\beta}$, Proposition 2 guarantees the existence of a fullemployment steady state. Since $\phi_{Y}>\frac{b p^{\prime}\left(Y^{*}\right) Y^{*}}{1+b p\left(Y^{*}\right)} R^{*}$, there is no other steady state with a positive interest rate. If the bond premium is pro-cyclical, Proposition 3 implies that there cannot exist a 
(fundamental) liquidity trap steady state (and SFLTs require a counter-cyclical bond premium). If the bond premium is counter-cyclical, $b p\left(Y^{\mathrm{min}}\right)<\frac{1-\beta}{\beta}$ implies that $i=0$ cannot be an equilibrium, and hence the economy does not admit SFLTs (and FLTs require a pro-cyclical bond premium).

Proof of Proposition 5. Immediate from equation (25).

Proof of Proposition 6. Immediate from equation (25).

Proof of Proposition 7. Under the rule $B^{g}(Y)$ and with $\phi_{Y}>\frac{b p^{\prime}\left(Y^{*}\right) Y^{*}}{1+b p\left(Y^{*}\right)} R^{*}$, the economy is under the conditions of Corollary 1.

Proof of Proposition 8. Immediate from Propositions 5, 6 and 7.

Proof of Proposition 9. In a liquidity trap, the bond premium must remained unchanged after the change in $G$. The bond premium is given by

$$
b p(Y ; G)=\chi\left(\frac{C^{w}(Y ; G)}{B(Y)}-1\right)
$$

where

$$
\begin{gathered}
C^{w}(Y ; G)=Y-\chi B(Y)-G=(1-\alpha \chi) Y+\chi\left(F-B^{g}\right)-G, \\
B(Y)=\alpha Y-F+B^{g} .
\end{gathered}
$$

Fully differentiating $b p(Y ; G)$ and equalizing to zero, we get

$$
\frac{\partial b p(Y ; G)}{\partial Y} d Y+\frac{\partial b p(Y ; G)}{\partial G} d G=0
$$

or

$$
\frac{d Y}{d G}=-\frac{\frac{\partial b p(Y ; G)}{\partial G}}{\frac{\partial b p(Y ; G)}{\partial Y}},
$$

where we have used that $\frac{\partial b p(Y ; G)}{\partial Y} \neq 0$. Note that

$$
\frac{\partial b p(Y ; G)}{\partial G}=\chi \frac{\partial C^{w}(Y ; G)}{\partial G} \frac{1}{B(Y)}
$$

Given $Y, C^{w}(Y ; \cdot)$ is decreasing in $G$, so $\frac{\partial b p(Y ; G)}{\partial G}<0$. Thus, $\frac{d Y}{d G}>0$ if the bond premium is pro-cyclical and $\frac{d Y}{d G}<0$ if the bond premium is counter-cyclical.

Suppose the bond premium is counter-cyclical and let $G^{*}$ be such that $b p\left(Y^{\mathrm{min}} ; G^{*}\right)=\frac{1-\beta}{\beta}$ (set $G^{*}=0$ if there is no $G>0$ satisfying this condition). Then, if $G>G^{*}, b p\left(Y^{\min } ; G^{*}\right)<\frac{1-\beta}{\beta}<\frac{1-\beta}{\beta}$ and by Corollary 1 the unique steady state of the economy features full employment. 
Proof of Proposition 10. The steady state level of utility is given by

$$
U=\frac{1}{1-\beta}\left[\log \left(C^{w}\right)+\chi \log \left(C^{r}\right)\right]=\frac{1}{1-\beta}\left[\log \left(Y-\chi\left(\alpha Y-F+B^{g}\right)-G\right)+\chi \log \left(\alpha Y-F+B^{g}\right)\right]
$$

The change in steady state utility after increasing government bonds is

$$
\Delta U_{B}=\frac{1}{1-\beta}\left[\frac{1-\alpha \chi}{C^{w}} d Y^{B}-\frac{\chi}{C^{w}} d B^{g}+\frac{\alpha \chi}{C^{r}} d Y^{B}+\frac{\chi}{C^{r}} d B^{g}\right]
$$

and after an increase in government spending

$$
\Delta U_{G}=\frac{1}{1-\beta}\left[\frac{1-\alpha \chi}{C^{w}} d Y^{G}-\frac{1}{C^{w}} d G+\frac{\alpha \chi}{C^{r}} d Y^{G}\right]
$$

Since $Y^{B}=Y^{G}$ and $C^{w}>C^{r}$ (so that the bond premium is positive), we get that $\Delta U_{B}>\Delta U_{G}$. 


\section{B Data Sources}

\section{B.1 Section 2.3}

Time period: Monthly. For most series in this section, our sample extended from 01/1948 until $12 / 2011$. We note some exceptions below as we describe the data construction and sources.

1. Industrial Production Index: FRED series INDPRO.

2. Unemployment rate: FRED Series UNRATE.

3. Baa: Moody's Seasoned Baa Corporate Bond Yield Index from FRED (series BAA). The Moody's Baa index is constructed from a sample of long-maturity ( $\geq 20$ years) industrial and utility bonds (industrial only from 2002 onward).

4. Aaa: Moody's Seasoned Aaa Corporate Bond Yield Index from FRED (series AAA). The Moody's Aaa index is constructed from a sample of long-maturity ( $\geq 20$ years) industrial and utility bonds (industrial only from 2002 onward).

5. long-term Treasury yields: we follow the data construction of Krishnamurthy and VissingJorgensen (2012). Their data series is annual. We went back to their sources and constructed a monthly data series. This series is a combination of LTGOVTBD and GS20 in the FRED database. GS20 is available from 2000 onwards.

6. three-month high-grade commercial paper (AACP) yields: obtained from the FRED database. For 1971-96 it is the series CP3M (the average of offering rates on 3-month commercial paper placed by several leading dealers for firms whose bond rating is AA or the equivalent), and for 1997-2011 the series CPN3M (the 3-month AA non-financial commercial paper rate).

7. lower-grade commercial paper yields (CPP2): calculated as the sum of the CP-bills yield spread described above (i.e., high-grade commercial paper minus Treasury bills) and the yield spread between 30-day A2/P2 non-financial commercial paper and 30-day AA nonfinancial commercial paper, with data obtained from the Federal Reserve Bank of New York. Sample used: 01/1998-12/2011.

8. short-term Treasury yield: we follow the data construction of Krishnamurthy and VissingJorgensen (2012). Their data series is annual. We went back to their sources and constructed a monthly data series. The Treasury bill yield is for 3-month Treasury bills for 1971-2008 (from FRED, series TB3MS), 6-month Treasury bills for 1959-70 (from FRED, series TB6MS), and 3-6 month Treasury bills for 1948-58 from the NBER Macro History database (series $\mathrm{m} 13029 \mathrm{~b}$ for 1931-58).

9. slope of the Treasury yield curve: follows Krishnamurthy and Vissing-Jorgensen (2012). Their data series is annual. We went back to their sources and constructed a monthly data series. 
This series is measured as the spread between the 10-year Treasury yield and the 3-month Treasury yield. The interest rate on Treasuries with 10-year maturity is from FRED for 1953-2011 (series GS10). Prior to 1953 we use series m13033b (1948-52) from the NBER Macro History Database. It is referred to as the yield on long-term Treasuries. The interest rate on Treasuries with 3-month maturity is from FRED for 1948-2011 (series TB3MS).

10. three-month certificate of deposit (CD) rates and Treasury spread: Obtained from published supplementary material in Nagel (2016).

11. three-month banker's acceptance rates and Treasury spread (BA-Tbill): Obtained from published supplementary material in Nagel (2016).

12. VIX index: Obtained from published supplementary material in Nagel (2016).

13. outstanding stock of T-bills: Obtained as Tbill/GDP ratio from published supplementary material in Nagel (2016). Quarterly GDP is interpolated by Nagel (2016) to a monthly series for computing this ratio.

14. federal funds rate: FRED database.

15. Chicago Fed National Activity Index (CFNAI-MA3): The Chicago Fed National Activity Index (CFNAI) is a weighted average of 85 existing monthly indicators of national economic activity. The Chicago Fed normalizes the index to have an average value of zero and a standard deviation of one. A positive value of the index corresponds to above trend growth (and vice-versa). We obtain the 3 month moving average series from the Chicago Fed Website. Data is available only March 1967 onwards. Sample used: 03/1967-12/2011.

\section{B.2 Section 2.4}

The online appendix of Gorton et al. (2012) prints a table with the identifiers in the US Financial Accounts for safe assets. Following their methodology, we constructed our data series for private safe assets. We used a series that they refer to as the "High" estimate of private safe assets. The key difference between the high and the low categories is in three asset class categories: "Financial business; other loans and advances; liability', "Real estate investment trusts; total mortgages; liability," and "Financial business; total miscellaneous liabilities" are not considered safe in the low category and some of these are considered safe in the high estimate. Results with their "Low" estimate are similar and are available upon request.

Figure 7 plots the share of each of these components in total private safe assets over time. Time period: Quarterly. Sample: 1952Q1 - 2019Q2. Total private safe assets is the sum of the following categories. 
Figure 7: Components of privately produced safe debt

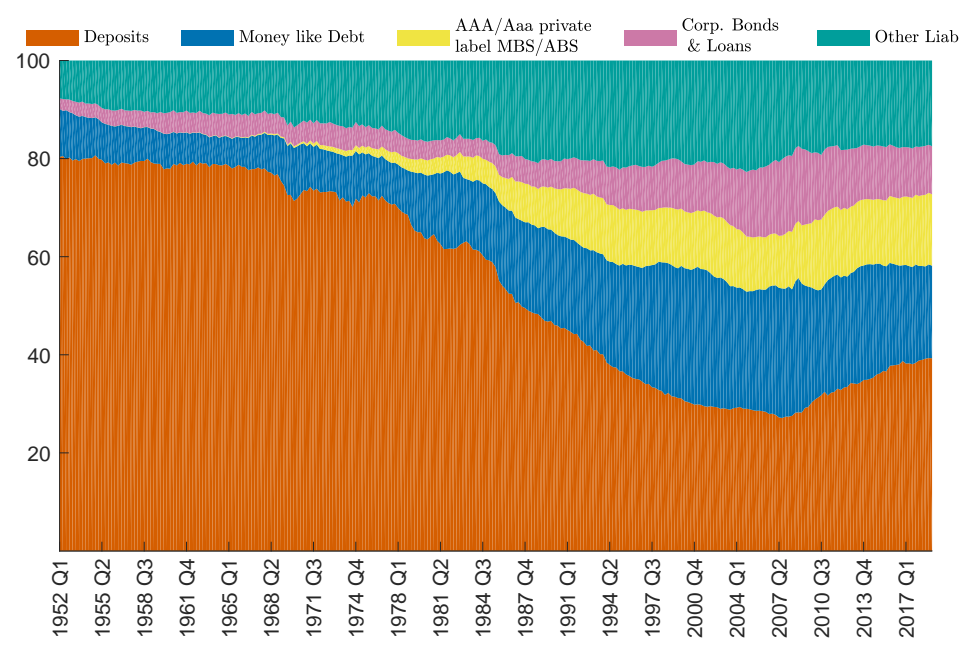

Source: Our calculations. Extended Gorton et al. (2012) using US Financial Accounts data retrieved from FRED, St. Louis Fed.

1. Deposits: "Financial business; checkable deposits and currency; liability," "Financial business; total time and savings deposits; liability"

2. Money-like Debt: This refers to commercial paper, net repurchase agreements, federal funds, money market mutual fund assets, interbank transactions, broker-dealer payables, and brokerdealer security credits.

3. MBS/ABS: MBS/ABS Debt includes all GSE and private-label MBS debt, as well as all ABS debt.

4. Corporate Bonds: "Corporate Bonds and Loans" includes "Financial business; corporate and foreign bonds; liability," "Private nonbank financial institutions; bank loans not elsewhere classified; liability," and "Financial business; other loans and advances; liability."

5. Other Safe Assets: "Financial business; total miscellaneous liabilities" 


\section{Robustness to Table 1}

TABLE 5: BAA-AAA SPREAD ON OUTPUT GAP (CFNAI)

\begin{tabular}{|c|c|c|c|c|c|}
\hline & (1) & (2) & (3) & (4) & (5) \\
\hline Output gap & $\begin{array}{c}-4.03^{* * *} \\
(1.18)\end{array}$ & & $\begin{array}{c}-3.77^{* * *} \\
(1.28)\end{array}$ & $\begin{array}{c}-2.74 * * * \\
(0.69)\end{array}$ & $\begin{array}{c}-2.87^{* * *} \\
(0.68)\end{array}$ \\
\hline Fed funds rate & & $\begin{array}{l}3.83^{*} \\
(2.05)\end{array}$ & $\begin{array}{c}2.75 \\
(1.93)\end{array}$ & $\begin{array}{c}4.78^{* * * *} \\
(1.64)\end{array}$ & $\begin{array}{c}6.75^{* * *} \\
(1.53)\end{array}$ \\
\hline $\log (\mathrm{T}-\mathrm{Bill} / \mathrm{GDP})$ & & & & $\begin{array}{c}96.98^{* * *} \\
(26.72)\end{array}$ & $\begin{array}{c}46.52 \\
(30.84)\end{array}$ \\
\hline VIX & & & & $\begin{array}{c}1.97^{* * *} \\
(0.67)\end{array}$ & $\begin{array}{l}1.95^{* *} \\
(0.77)\end{array}$ \\
\hline Slope & & & & & $\begin{array}{c}14.17^{* * *} \\
(3.80)\end{array}$ \\
\hline Intercept & $\begin{array}{c}145.50^{* * *} \\
(28.00)\end{array}$ & $\begin{array}{c}57.33 \\
(36.84)\end{array}$ & $\begin{array}{c}97.04^{* * * *} \\
(35.49)\end{array}$ & $\begin{array}{c}312.97^{* * *} \\
(73.05)\end{array}$ & $\begin{array}{l}142.03^{*} \\
(85.87)\end{array}$ \\
\hline \# Obs. & 538 & 538 & 538 & 538 & 538 \\
\hline Adj $R^{2}$ & 0.21 & 0.06 & 0.24 & 0.42 & 0.51 \\
\hline \multicolumn{6}{|c|}{$\begin{array}{l}\text { Note: Newey-West standard errors (12 lags) in parentheses. } * * * p<0.01, * * p \\
0.05, * p<0.1 \text {. Includes a linear time-trend. Baa-Aaa spread measures the percentag, } \\
\text { difference between Moody's Baa-rated long-maturity corporate bond yield and Moody' } \\
\text { Aaa-rated long-maturity corporate bond yield. Economic slack is computed with th } \\
\text { monthly Chicago Fed National Activity Index (MA3). We normalized } \beta_{y} \text { to correspon } \\
\text { to } 0.2 \text { units of increase in the CFNAI, which is associated with the onset of an expansion } \\
\text { A zero value for the CFNAI has been associated with the national economy expand } \\
\text { ing at its historical trend (average) rate of growth; negative values with below-averag } \\
\text { growth; and positive values with above-average growth. Sample: 1967-2011 (monthly). }\end{array}$} \\
\hline
\end{tabular}

TABLE 6: BAA-AAA SPREAD ON OUTPUT GAP (BAND PASS FILTER)

\begin{tabular}{|c|c|c|c|c|c|}
\hline & (1) & (2) & (3) & (4) & (5) \\
\hline Output gap & $\begin{array}{c}-7.01^{* * * *} \\
(2.42)\end{array}$ & & $\begin{array}{c}-8.83^{* * *} \\
(2.41)\end{array}$ & $\begin{array}{c}-7.40^{* * * *} \\
(2.07)\end{array}$ & $\begin{array}{c}-6.19^{* * *} \\
(1.72)\end{array}$ \\
\hline Fed funds rate & & $\begin{array}{c}4.61^{* * * *} \\
(1.59)\end{array}$ & $\begin{array}{c}5.36^{* * *} \\
(1.43)\end{array}$ & $\begin{array}{c}6.27^{* * *} \\
(1.25)\end{array}$ & $\begin{array}{c}7.61^{* * *} \\
(1.20)\end{array}$ \\
\hline $\log (\mathrm{T}-\mathrm{Bill} / \mathrm{GDP})$ & & & & $\begin{array}{l}34.33^{*} \\
(17.62)\end{array}$ & $\begin{array}{c}18.73 \\
(15.78)\end{array}$ \\
\hline VIX & & & & $\begin{array}{c}2.58^{* * *} \\
(0.83)\end{array}$ & $\begin{array}{c}2.55^{* * *} \\
(0.91)\end{array}$ \\
\hline Slope & & & & & $\begin{array}{c}13.96^{* * *} \\
(3.14)\end{array}$ \\
\hline Intercept & $\begin{array}{c}44.15^{* * *} \\
(11.80)\end{array}$ & $\begin{array}{c}26.33^{* *} \\
(10.76)\end{array}$ & $\begin{array}{c}23.74^{* *} \\
(11.17)\end{array}$ & $\begin{array}{l}71.28^{*} \\
(36.33)\end{array}$ & $\begin{array}{l}28.53 \\
(32.14)\end{array}$ \\
\hline \# Obs. & 768 & 768 & 768 & 768 & 768 \\
\hline Adj $R^{2}$ & 0.19 & 0.24 & 0.36 & 0.50 & 0.59 \\
\hline \multicolumn{6}{|c|}{$\begin{array}{l}\text { Note: Newey-West standard errors (12 lags) in parentheses. } * * * p<0.01, * * p< \\
0.05, * p<0.1 \text {. Includes a linear time-trend. Baa-Aaa spread measures the percent- } \\
\text { age difference between Moody's Baa-rated long-maturity corporate bond yield and } \\
\text { Moody's Aaa-rated long-maturity corporate bond yield. Economic slack is computed } \\
\text { with band-pass filtering of log of (monthly) industrial production index at business } \\
\text { cycle frequencies (18 and } 96 \text { months). Sample: 1948-2011 (monthly). }\end{array}$} \\
\hline
\end{tabular}


TABLE 7: BAA-AAA SPREAD ON OUTPUT GAP (HAMiLTON FILTER)

\begin{tabular}{lccccc}
\hline & $(1)$ & $(2)$ & $(3)$ & $(4)$ & $(5)$ \\
\hline Output gap & $-3.51^{* * *}$ & & $-3.78^{* * *}$ & $-3.38^{* * *}$ & $-2.94^{* * *}$ \\
& $(0.66)$ & & $(0.54)$ & $(0.44)$ & $(0.39)$ \\
Fed funds rate & & $4.61^{* * *}$ & $5.39^{* * *}$ & $5.58^{* * *}$ & $6.63^{* * *}$ \\
& & $(1.59)$ & $(0.93)$ & $(0.90)$ & $(0.88)$ \\
$\log$ (T-Bill/GDP) & & & & 8.37 & 1.03 \\
& & & & $(14.74)$ & $(12.88)$ \\
VIX & & & & $1.91^{* *}$ & $1.97^{* *}$ \\
& & & & $(0.75)$ & $(0.81)$ \\
Slope & & & & & $9.93^{* * *}$ \\
& & & & & $(2.57)$ \\
Intercept & $57.33^{* * *}$ & $26.33^{* *}$ & $37.79^{* * *}$ & 33.89 & 9.20 \\
& $(10.90)$ & $(10.76)$ & $(8.42)$ & $(29.53)$ & $(24.83)$ \\
\hline \# Obs. & 768 & 768 & 768 & 768 & 768 \\
Adj R & 0.42 & 0.24 & 0.59 & 0.65 & 0.69 \\
\hline
\end{tabular}

Note: Newey-West standard errors (12 lags) in parentheses. $* * * p<0.01, * * p<$ $0.05, * p<0.1$. Includes a linear time-trend. Baa-Aaa spread measures the percentage difference between Moody's Baa-rated long-maturity corporate bond yield and Moody's Aaa-rated long-maturity corporate bond yield. Economic slack is computed with filtering of $\log$ of (monthly) industrial production index using the Hamilton filter. Sample: 1948-2011 (monthly).

TABLE 8: BaA-AaA SPREAd on output gap (Polynomial Filter)

\begin{tabular}{lccccc}
\hline & $(1)$ & $(2)$ & $(3)$ & $(4)$ & $(5)$ \\
\hline Output gap & $-2.32^{* * *}$ & & $-3.08^{* * *}$ & $-3.29^{* * *}$ & $-2.37^{* * *}$ \\
& $(0.70)$ & & $(0.63)$ & $(0.70)$ & $(0.61)$ \\
Fed funds rate & & $4.61^{* * *}$ & $5.93^{* * *}$ & $5.74^{* * *}$ & $6.90^{* * *}$ \\
& & $(1.59)$ & $(1.20)$ & $(0.96)$ & $(1.07)$ \\
$\log$ (T-Bill/GDP) & & & & -10.84 & -5.99 \\
& & & & $(17.98)$ & $(15.89)$ \\
VIX & & & & $2.66^{* * *}$ & $2.61^{* * *}$ \\
& & & & $(0.86)$ & $(0.93)$ \\
Slope & & & & & $10.43^{* * *}$ \\
& & & & & $(3.34)$ \\
Intercept & $38.11^{* * *}$ & $26.33^{* *}$ & 13.59 & -40.82 & -32.51 \\
& $(11.94)$ & $(10.76)$ & $(11.05)$ & $(39.33)$ & $(34.75)$ \\
\hline \# Obs. & 768 & 768 & 768 & 768 & 768 \\
Adj R & 0.22 & 0.24 & 0.42 & 0.55 & 0.59 \\
\hline
\end{tabular}

Note: Newey-West standard errors (12 lags) in parentheses. $* * * p<0.01, * * p<$ $0.05, * p<0.1$. Includes a linear time-trend. Baa-Aaa spread measures the percentage difference between Moody's Baa-rated long-maturity corporate bond yield and Moody's Aaa-rated long-maturity corporate bond yield. Economic slack is computed as deviation from trend estimated using a (sixth-degree) polynomial regression on time. Sample: 1948-2011 (monthly). 
TABLE 9: BAA-AaA SPREAD ON OUTPUt GaP (UNEMPloyment RATE)

\begin{tabular}{lccccc}
\hline & $(1)$ & $(2)$ & $(3)$ & $(4)$ & $(5)$ \\
\hline Output gap & $16.38^{* * *}$ & & $15.26^{* * *}$ & $14.63^{* * *}$ & $12.52^{* * *}$ \\
& $(2.85)$ & & $(2.20)$ & $(2.28)$ & $(2.46)$ \\
Fed funds rate & & $4.61^{* * *}$ & $3.69^{* * *}$ & $3.76^{* * *}$ & $4.60^{* * *}$ \\
& & $(1.59)$ & $(1.16)$ & $(0.88)$ & $(1.08)$ \\
$\log$ (T-Bill/GDP) & & & & 0.20 & 1.90 \\
& & & & $(15.47)$ & $(15.19)$ \\
VIX & & & & $2.40^{* * *}$ & $2.42^{* * *}$ \\
& & & & $(0.88)$ & $(0.90)$ \\
Slope & & & & & 4.88 \\
& & & & & $(3.16)$ \\
Intercept & -18.33 & $26.33^{* *}$ & $-28.14^{* *}$ & -52.21 & -44.18 \\
& $(17.56)$ & $(10.76)$ & $(14.21)$ & $(34.71)$ & $(33.45)$ \\
\hline \# Obs. & 768 & 768 & 768 & 768 & 768 \\
Adj R & 0.44 & 0.24 & 0.52 & 0.62 & 0.63 \\
\hline
\end{tabular}

Note: Newey-West standard errors (12 lags) in parentheses. $* * * p<0.01, * * p<$ $0.05, * p<0.1$. Includes a linear time-trend. Baa-Aaa spread measures the percentage difference between Moody's Baa-rated long-maturity corporate bond yield and Moody's Aaa-rated long-maturity corporate bond yield. Economic slack variable is civilian unemployment rate. Sample: 1948-2011 (monthly).

TABLE 10: BAA-AAA SPREAD ON ECONOMIC SLACK (YOY FILTER)

\begin{tabular}{lccccc}
\hline & $(1)$ & $(2)$ & $(3)$ & $(4)$ & $(5)$ \\
\hline Output gap & $-4.23^{* * *}$ & & $-4.47^{* * *}$ & $-3.75^{* * *}$ & $-3.22^{* * *}$ \\
& $(0.99)$ & & $(0.85)$ & $(0.75)$ & $(0.60)$ \\
Fed funds rate & & $4.61^{* * *}$ & $5.01^{* * *}$ & $5.64^{* * *}$ & $6.96^{* * *}$ \\
& & $(1.59)$ & $(1.19)$ & $(1.15)$ & $(1.05)$ \\
$\log$ (T-Bill/GDP) & & & & 22.98 & 10.14 \\
& & & & $(18.25)$ & $(15.79)$ \\
VIX & & & & $2.24^{* * *}$ & $2.26^{* *}$ \\
& & & & $(0.83)$ & $(0.90)$ \\
Slope & & & & & $12.76^{* * *}$ \\
& & & & & $(2.83)$ \\
Intercept & $73.38^{* * *}$ & $26.33^{* *}$ & $55.95^{* * *}$ & $77.00^{* *}$ & 36.68 \\
& $(13.70)$ & $(10.76)$ & $(10.17)$ & $(35.08)$ & $(29.61)$ \\
\hline \# Obs. & 768 & 768 & 768 & 768 & 768 \\
Adj R & 0.31 & 0.24 & 0.46 & 0.56 & 0.63 \\
\hline
\end{tabular}

Note: Newey-West standard errors (12 lags) in parentheses. $* * * p<0.01, * * p<$ $0.05, * p<0.1$. Includes a linear time-trend. Baa-Aaa spread measures the percentage difference between Moody's Baa-rated long-maturity corporate bond yield and Moody's Aaa-rated long-maturity corporate bond yield. Economic slack is computed with year on year change in a twelve month average of the log of industrial production index following Stock and Watson (2019). A zero value for the CFNAI has been associated with the national economy expanding at its historical trend (average) rate of growth; negative values with below-average growth; and positive values with aboveaverage growth. Sample: 1967-2011 (monthly). 


\section{Robustness to Table 3}

TABLE 11: FinANCIAL SPREADS ON OUtPUt GAP (CFNAI)

\begin{tabular}{|c|c|c|c|c|c|c|}
\hline & (20Y)BAA/AAA & (20Y)AAA/T-Bill & (3M) BA-Tbill & (3M) AACP/T-Bill & CD/T-Bill & CPP2/T-Bill \\
\hline & (1) & $(2)$ & $(3)$ & (4) & (5) & (6) \\
\hline & $1967-2011$ & $1967-2011$ & $1967-2011$ & $1967-2011$ & $1976-2011$ & $1998-2011$ \\
\hline Economic Slack & $\begin{array}{c}-2.87^{* * *} \\
(0.68)\end{array}$ & $\begin{array}{c}-1.75^{* * *} \\
(0.60)\end{array}$ & $\begin{array}{c}-1.39 * * * \\
(0.53)\end{array}$ & $\begin{array}{c}-1.47^{* * *} \\
(0.42)\end{array}$ & $\begin{array}{c}-3.00^{* * *} \\
(0.79)\end{array}$ & $\begin{array}{c}-4.58^{* * *} \\
(1.59)\end{array}$ \\
\hline Fed funds rate & $\begin{array}{c}6.75^{* * *} \\
(1.53)\end{array}$ & $\begin{array}{l}-1.92 \\
(1.96)\end{array}$ & $\begin{array}{c}9.91^{* * *} \\
(1.05)\end{array}$ & $\begin{array}{c}6.16^{* * *} \\
(1.13)\end{array}$ & $\begin{array}{c}13.44^{* * *} \\
(2.33)\end{array}$ & $\begin{array}{c}32.95^{* *} \\
(13.74)\end{array}$ \\
\hline $\log (\mathrm{T}-\mathrm{Bill} / \mathrm{GDP})$ & $\begin{array}{c}46.52 \\
(30.84)\end{array}$ & $\begin{array}{l}-29.23 \\
(23.61)\end{array}$ & $\begin{array}{l}-27.03 \\
(23.42)\end{array}$ & $\begin{array}{l}-15.54 \\
(21.07)\end{array}$ & $\begin{array}{l}-25.26 \\
(35.14)\end{array}$ & $\begin{array}{l}-21.71 \\
(65.67)\end{array}$ \\
\hline VIX & $\begin{array}{l}1.95^{* * *} \\
(0.77)\end{array}$ & $\begin{array}{c}2.20 * * * \\
(0.52)\end{array}$ & $\begin{array}{c}2.03^{* * *} \\
(0.50)\end{array}$ & $\begin{array}{c}1.90 * * * \\
(0.46)\end{array}$ & $\begin{array}{c}3.11^{* * *} \\
(0.86)\end{array}$ & $\begin{array}{c}5.62^{* * *} \\
(2.12)\end{array}$ \\
\hline Slope & $\begin{array}{c}14.17^{* * * *} \\
(3.80)\end{array}$ & $\begin{array}{c}1.73 \\
(3.45)\end{array}$ & $\begin{array}{l}-1.90 \\
(3.28)\end{array}$ & $\begin{array}{l}-4.81 \\
(3.12)\end{array}$ & $\begin{array}{l}9.86^{*} \\
(5.79)\end{array}$ & $\begin{array}{l}26.99^{*} \\
(16.19)\end{array}$ \\
\hline Intercept & $\begin{array}{c}142.03^{*} \\
(85.87)\end{array}$ & $\begin{array}{l}113.46 \\
(79.49)\end{array}$ & $\begin{array}{l}-49.91 \\
(66.02)\end{array}$ & $\begin{array}{c}36.20 \\
(64.28)\end{array}$ & $\begin{array}{c}-256.17^{* *} \\
(119.75)\end{array}$ & $\begin{array}{c}-993.20^{* *} \\
(450.39)\end{array}$ \\
\hline \# Obs. & 538 & 538 & 538 & 538 & 432 & 168 \\
\hline Adj $R^{2}$ & 0.51 & 0.37 & 0.62 & 0.55 & 0.40 & 0.55 \\
\hline
\end{tabular}

Note: Newey-West standard errors (12 lags) in parentheses. $* * * p<0.01, * * p<0.05, * p<0.1$. Includes a linear time-trend. Economic slack is proxied with Chicago Fed National Activity Index (MA3). We normalized $\beta_{y}$ to correspond to 0.2 units of increase in the CFNAI, which is associated with the onset of an expansion. Column 1 uses the percentage spread between Moody's Baa-rated long-maturity corporate bond yield and Moody's Aaa-rated long-maturity corporate bond yield. Column 2 uses the percentage spread between Moody's Aaa-rated long-maturity corporate bond yield and the yield on long-maturity Treasury bonds. Column 3 use the three-month banker's acceptance rate and T-bills. The data series for the banker's acceptance rate ends in the 1990s. To create a series until 2011, we use the GC repo/T-bill spread from 1991 onward constructed by Nagel (2016). Column 4 uses the percentage yield spread between 3-month high-grade commercial paper and Treasury bills. Column 5 uses the spread between three-month certificate of deposit (CD) rates and T-bills as an alternative measure of the illiquid rate. Column 6 uses the percentage yield spread between lower-grade commercial paper and Treasury bills. It is calculated as the sum of the CP-bills yield spread described above (i.e., high-grade commercial paper minus Treasury bills) and the yield spread between 30-day A2/P2 nonfinancial commercial paper and 30-day AA nonfinancial commercial paper, with data obtained from the Federal Reserve Bank of New York. 
TABLE 12: FinANCIAL SPREAds On OUtPut GAP (BAND PASS Filter)

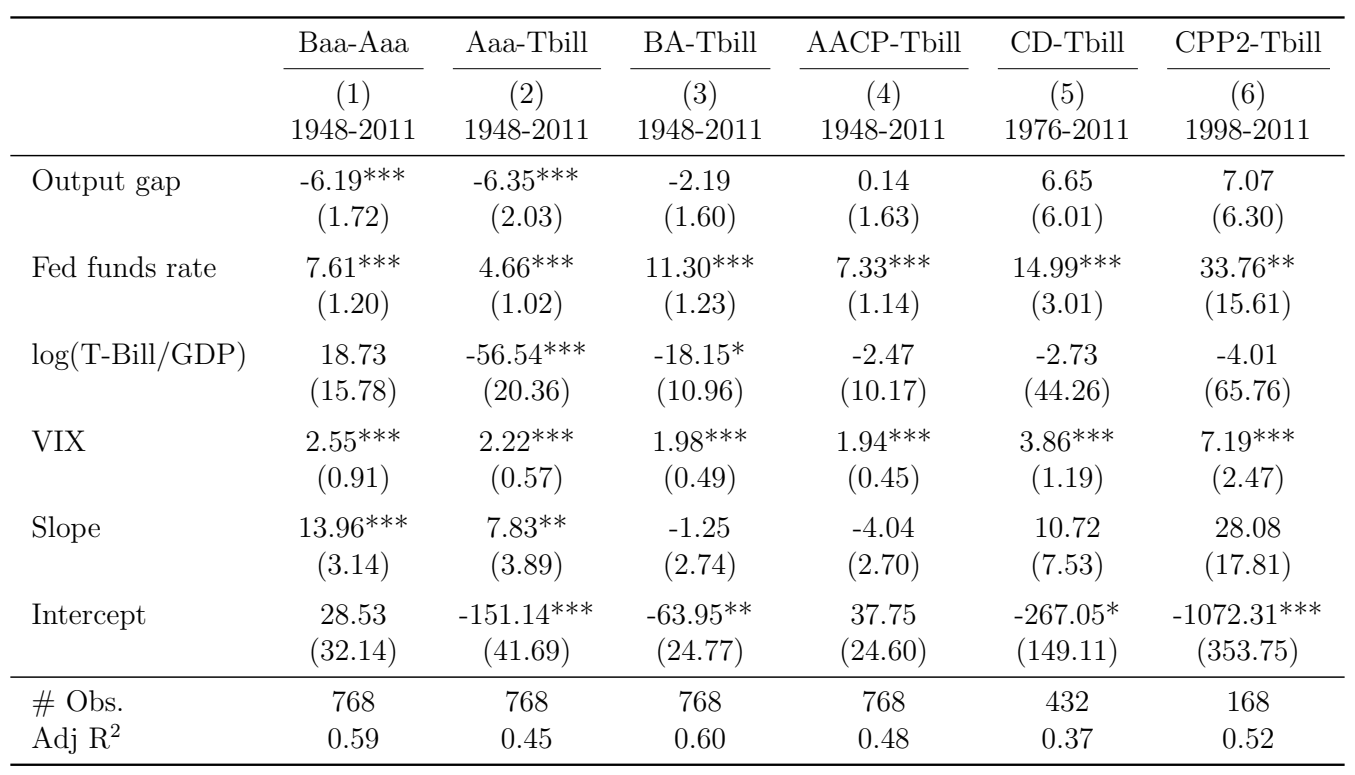

Note: Newey-West standard errors (12 lags) in parentheses. $* * * p<0.01, * * p<0.05, * p<0.1$. Includes a linear time-trend. Economic slack is computed with band-pass filtering of log of (monthly) industrial production index at business cycle frequencies (18 and 96 months). Column 1 uses the percentage spread between Moody's Baa-rated long-maturity corporate bond yield and Moody's Aaa-rated longmaturity corporate bond yield. Column 2 uses the percentage spread between Moody's Aaa-rated long-maturity corporate bond yield and the yield on long-maturity Treasury bonds. Column 3 use the three-month banker's acceptance rate and T-bills. The data series for the banker's acceptance rate ends in the 1990s. To create a series until 2011, we use the GC repo/T-bill spread from 1991 onward constructed by Nagel (2016). Column 4 uses the percentage yield spread between 3-month high-grade commercial paper and Treasury bills. Column 5 uses the spread between three-month certificate of deposit $(\mathrm{CD})$ rates and T-bills as an alternative measure of the illiquid rate. Column 6 uses the percentage yield spread between lower-grade commercial paper and Treasury bills. It is calculated as the sum of the CP-bills yield spread described above (i.e., high-grade commercial paper minus Treasury bills) and the yield spread between 30-day A2/P2 nonfinancial commercial paper and 30-day AA nonfinancial commercial paper, with data obtained from the Federal Reserve Bank of New York. 
TABLE 13: Financial spreads on output gap (HAMilton Filter)

\begin{tabular}{|c|c|c|c|c|c|c|}
\hline & $\begin{array}{c}\text { Baa-Aaa } \\
(1) \\
1948-2011\end{array}$ & $\begin{array}{c}\text { Aaa-Tbill } \\
(2) \\
1948-2011\end{array}$ & $\begin{array}{c}\text { BA-Tbill } \\
(3) \\
1948-2011\end{array}$ & $\begin{array}{c}\text { AACP-Tbill } \\
(4) \\
1948-2011\end{array}$ & $\begin{array}{c}\text { CD-Tbill } \\
(5) \\
1976-2011\end{array}$ & $\begin{array}{c}\text { CPP2-Tbill } \\
(6) \\
1998-2011\end{array}$ \\
\hline Output gap & $\begin{array}{c}-2.94^{* * *} \\
(0.39)\end{array}$ & $\begin{array}{c}-2.49^{* * * *} \\
(0.59)\end{array}$ & $\begin{array}{l}-0.23 \\
(0.37)\end{array}$ & $\begin{array}{c}0.20 \\
(0.39)\end{array}$ & $\begin{array}{l}-0.22 \\
(0.66)\end{array}$ & $\begin{array}{c}1.95 \\
(1.85)\end{array}$ \\
\hline Fed funds rate & $\begin{array}{c}6.63^{* * *} \\
(0.88)\end{array}$ & $\begin{array}{c}3.87^{* * *} \\
(0.98)\end{array}$ & $\begin{array}{c}11.28^{* * *} \\
(1.26)\end{array}$ & $\begin{array}{c}7.41^{* * *} \\
(1.16)\end{array}$ & $\begin{array}{c}15.16^{* * *} \\
(2.83)\end{array}$ & $\begin{array}{c}38.74^{* *} \\
(15.74)\end{array}$ \\
\hline $\log (\mathrm{T}-\mathrm{Bill} / \mathrm{GDP})$ & $\begin{array}{c}1.03 \\
(12.88)\end{array}$ & $\begin{array}{c}-68.13^{* * *} \\
(21.00)\end{array}$ & $\begin{array}{l}-14.28 \\
(10.91)\end{array}$ & $\begin{array}{c}-0.45 \\
(10.83)\end{array}$ & $\begin{array}{l}-23.66 \\
(38.27)\end{array}$ & $\begin{array}{c}-9.70 \\
(47.90)\end{array}$ \\
\hline VIX & $\begin{array}{c}1.97^{* *} \\
(0.81)\end{array}$ & $\begin{array}{c}1.72^{* * *} \\
(0.51)\end{array}$ & $\begin{array}{c}1.93^{* * *} \\
(0.51)\end{array}$ & $\begin{array}{c}1.98^{* * *} \\
(0.47)\end{array}$ & $\begin{array}{c}3.71^{* * *} \\
(1.15)\end{array}$ & $\begin{array}{c}7.49^{* * *} \\
(2.58)\end{array}$ \\
\hline Slope & $\begin{array}{c}9.93^{* * *} * \\
(2.57)\end{array}$ & $\begin{array}{c}4.67 \\
(3.45)\end{array}$ & $\begin{array}{l}-1.16 \\
(2.96)\end{array}$ & $\begin{array}{l}-3.70 \\
(2.88)\end{array}$ & $\begin{array}{l}10.81 \\
(6.91)\end{array}$ & $\begin{array}{c}37.62^{* *} \\
(18.30)\end{array}$ \\
\hline Intercept & $\begin{array}{c}9.20 \\
(24.83)\end{array}$ & $\begin{array}{c}-159.77^{* * *} \\
(41.41)\end{array}$ & $\begin{array}{c}-53.51^{* *} \\
(25.01)\end{array}$ & $\begin{array}{c}40.96 \\
(26.26)\end{array}$ & $\begin{array}{c}-326.42^{* *} \\
(136.33)\end{array}$ & $\begin{array}{c}-1328.28^{* * *} \\
(468.29)\end{array}$ \\
\hline $\begin{array}{l}\text { \# Obs. } \\
\text { Adj R }{ }^{2}\end{array}$ & $\begin{array}{l}768 \\
0.69\end{array}$ & $\begin{array}{l}768 \\
0.51\end{array}$ & $\begin{array}{c}768 \\
0.60\end{array}$ & $\begin{array}{c}768 \\
0.48\end{array}$ & $\begin{array}{l}432 \\
0.36\end{array}$ & $\begin{array}{l}168 \\
0.52\end{array}$ \\
\hline
\end{tabular}

Note: Newey-West standard errors (12 lags) in parentheses. $* * * p<0.01, * * p<0.05, * p<0.1$. Includes a linear time-trend. Economic slack is computed with filtering of log of (monthly) industrial production index using the Hamilton filter. Column 1 uses the percentage spread between Moody's Baa-rated long-maturity corporate bond yield and Moody's Aaa-rated long-maturity corporate bond yield. Column 2 uses the percentage spread between Moody's Aaa-rated long-maturity corporate bond yield and the yield on long-maturity Treasury bonds. Column 3 use the three-month banker's acceptance rate and T-bills. The data series for the banker's acceptance rate ends in the 1990s. To create a series until 2011, we use the GC repo/T-bill spread from 1991 onward constructed by Nagel (2016). Column 4 uses the percentage yield spread between 3-month high-grade commercial paper and Treasury bills. Column 5 uses the spread between three-month certificate of deposit (CD) rates and T-bills as an alternative measure of the illiquid rate. Column 6 uses the percentage yield spread between lower-grade commercial paper and Treasury bills. It is calculated as the sum of the CP-bills yield spread described above (i.e., high-grade commercial paper minus Treasury bills) and the yield spread between 30-day A2/P2 nonfinancial commercial paper and 30-day AA nonfinancial commercial paper, with data obtained from the Federal Reserve Bank of New York. 
TABlE 14: Financial spreads on output gap (Polynomial filter)

\begin{tabular}{|c|c|c|c|c|c|c|}
\hline & 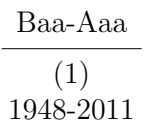 & 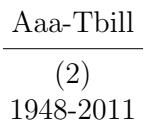 & 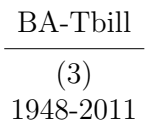 & $\begin{array}{c}\text { AACP-Tbill } \\
(4) \\
1948-2011\end{array}$ & $\frac{\text { CD-Tbill }}{(5)}$ & $\begin{array}{c}\text { CPP2-Tbill } \\
(6) \\
1998-2011\end{array}$ \\
\hline Output gap & $\begin{array}{c}-2.37^{* * *} \\
(0.61)\end{array}$ & $\begin{array}{c}0.17 \\
(0.71)\end{array}$ & $\begin{array}{l}-0.72 \\
(0.60)\end{array}$ & $\begin{array}{l}-0.03 \\
(0.54)\end{array}$ & $\begin{array}{l}-0.33 \\
(1.14)\end{array}$ & $\begin{array}{c}12.95^{* * * *} \\
(4.80)\end{array}$ \\
\hline Fed funds rate & $\begin{array}{c}6.90^{* * *} \\
(1.07)\end{array}$ & $\begin{array}{c}4.96^{* * *} \\
(1.17)\end{array}$ & $\begin{array}{c}11.10^{* * *} \\
(1.31)\end{array}$ & $\begin{array}{c}7.31^{* * *} \\
(1.18)\end{array}$ & $\begin{array}{c}15.05^{* * *} \\
(3.05)\end{array}$ & $\begin{array}{c}31.11^{* *} \\
(13.49)\end{array}$ \\
\hline $\log (\mathrm{T}-\mathrm{Bill} / \mathrm{GDP})$ & $\begin{array}{c}-5.99 \\
(15.89)\end{array}$ & $\begin{array}{l}-33.77 \\
(24.00)\end{array}$ & $\begin{array}{c}-24.66^{*} \\
(13.74)\end{array}$ & $\begin{array}{c}-3.39 \\
(12.11)\end{array}$ & $\begin{array}{l}-29.48 \\
(53.58)\end{array}$ & $\begin{array}{c}205.08^{* *} \\
(101.26)\end{array}$ \\
\hline VIX & $\begin{array}{c}2.61^{* * *} \\
(0.93)\end{array}$ & $\begin{array}{c}2.18^{* * *} \\
(0.61)\end{array}$ & $\begin{array}{c}2.00^{* * *} \\
(0.49)\end{array}$ & $\begin{array}{c}1.94^{* * *} \\
(0.45)\end{array}$ & $\begin{array}{c}3.76^{* * *} \\
(1.13)\end{array}$ & $\begin{array}{c}7.09^{* * *} \\
(1.95)\end{array}$ \\
\hline Slope & $\begin{array}{c}10.43^{* * *} \\
(3.34)\end{array}$ & $\begin{array}{l}9.69^{* *} \\
(4.63)\end{array}$ & $\begin{array}{l}-2.24 \\
(2.91)\end{array}$ & $\begin{array}{l}-4.13 \\
(2.84)\end{array}$ & $\begin{array}{l}10.60 \\
(6.82)\end{array}$ & $\begin{array}{c}32.52^{* *} \\
(16.03)\end{array}$ \\
\hline Intercept & $\begin{array}{l}-32.51 \\
(34.75)\end{array}$ & $\begin{array}{c}-99.08^{*} \\
(52.19)\end{array}$ & $\begin{array}{c}-80.21^{* * *} \\
(29.99)\end{array}$ & $\begin{array}{c}35.62 \\
(29.38)\end{array}$ & $\begin{array}{c}-342.31^{* *} \\
(156.68)\end{array}$ & $\begin{array}{c}-1344.17^{* * *} \\
(330.47)\end{array}$ \\
\hline \# Obs. & 768 & 768 & 768 & 768 & 432 & 168 \\
\hline $\operatorname{Adj~} R^{2}$ & 0.59 & 0.40 & 0.60 & 0.48 & 0.36 & 0.58 \\
\hline
\end{tabular}

Note: Newey-West standard errors (12 lags) in parentheses. $* * * p<0.01, * * p<0.05, * p<0.1$. Includes a linear time-trend. Economic slack is computed as deviation from trend estimated using a (sixth-degree) polynomial regression on time. Column 1 uses the percentage spread between Moody's Baa-rated long-maturity corporate bond yield and Moody's Aaa-rated long-maturity corporate bond yield. Column 2 uses the percentage spread between Moody's Aaa-rated long-maturity corporate bond yield and the yield on long-maturity Treasury bonds. Column 3 use the three-month banker's acceptance rate and T-bills. The data series for the banker's acceptance rate ends in the 1990s. To create a series until 2011, we use the GC repo/T-bill spread from 1991 onward constructed by Nagel (2016). Column 4 uses the percentage yield spread between 3-month high-grade commercial paper and Treasury bills. Column 5 uses the spread between three-month certificate of deposit (CD) rates and T-bills as an alternative measure of the illiquid rate. Column 6 uses the percentage yield spread between lower-grade commercial paper and Treasury bills. It is calculated as the sum of the CP-bills yield spread described above (i.e., high-grade commercial paper minus Treasury bills) and the yield spread between 30-day A2/P2 nonfinancial commercial paper and 30-day AA nonfinancial commercial paper, with data obtained from the Federal Reserve Bank of New York. 
TABLE 15: Financial spreads on output gap (UnEMPloyment Rate)

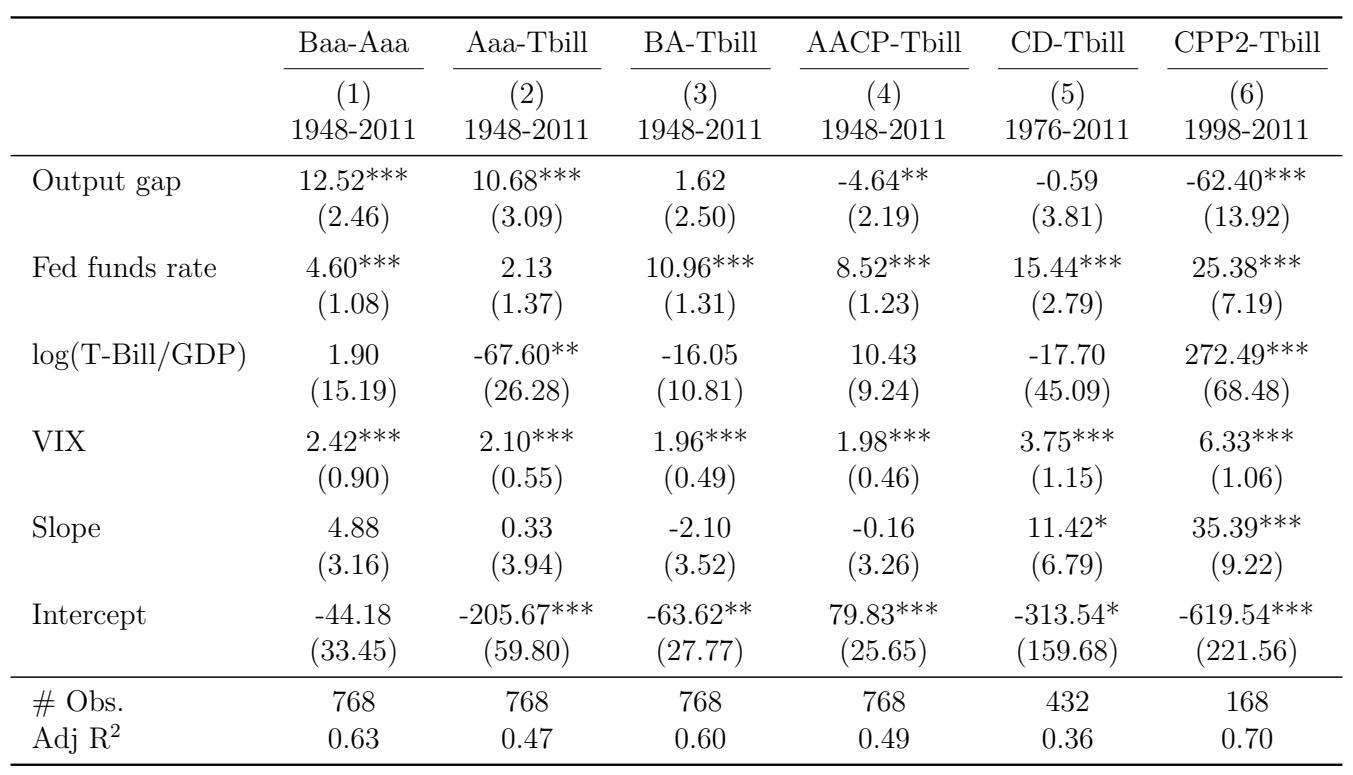

Note: Newey-West standard errors (12 lags) in parentheses. $* * * p<0.01, * * p<0.05, * p<0.1$. Includes a linear time-trend. Economic slack variable is civilian unemployment rate. Column 1 uses the percentage spread between Moody's Baa-rated long-maturity corporate bond yield and Moody's Aaarated long-maturity corporate bond yield. Column 2 uses the percentage spread between Moody's Aaa-rated long-maturity corporate bond yield and the yield on long-maturity Treasury bonds. Column 3 use the three-month banker's acceptance rate and T-bills. The data series for the banker's acceptance rate ends in the 1990s. To create a series until 2011, we use the GC repo/T-bill spread from 1991 onward constructed by Nagel (2016). Column 4 uses the percentage yield spread between 3-month high-grade commercial paper and Treasury bills. Column 5 uses the spread between threemonth certificate of deposit (CD) rates and T-bills as an alternative measure of the illiquid rate. Column 6 uses the percentage yield spread between lower-grade commercial paper and Treasury bills. It is calculated as the sum of the CP-bills yield spread described above (i.e., high-grade commercial paper minus Treasury bills) and the yield spread between 30-day A2/P2 nonfinancial commercial paper and 30-day AA nonfinancial commercial paper, with data obtained from the Federal Reserve Bank of New York. 
TABLE 16: FinANCIAL SPREADS ON OUTPUt GAP (Y-O-Y FILTER)

\begin{tabular}{|c|c|c|c|c|c|c|}
\hline & $\begin{array}{c}\text { Baa-Aaa } \\
(1) \\
1948-2011\end{array}$ & $\begin{array}{c}\text { Aaa-Tbill } \\
(2) \\
1948-2011\end{array}$ & $\begin{array}{c}\text { BA-Tbill } \\
(3) \\
1948-2011\end{array}$ & $\begin{array}{c}\text { AACP-Tbill } \\
(4) \\
1948-2011\end{array}$ & $\begin{array}{c}\text { CD-Tbill } \\
(5) \\
1976-2011\end{array}$ & $\begin{array}{c}\text { CPP2-Tbill } \\
(6) \\
1998-2011\end{array}$ \\
\hline Output gap & $\begin{array}{c}-3.22 * * * \\
(0.60)\end{array}$ & $\begin{array}{c}-2.99^{* * *} \\
(0.86)\end{array}$ & $\begin{array}{l}-0.51 \\
(0.52)\end{array}$ & $\begin{array}{c}0.36 \\
(0.54)\end{array}$ & $\begin{array}{l}-0.30 \\
(1.24)\end{array}$ & $\begin{array}{c}3.33 \\
(2.48)\end{array}$ \\
\hline Fed funds rate & $\begin{array}{c}6.96^{* * *} \\
(1.05)\end{array}$ & $\begin{array}{c}4.07^{* * *} \\
(0.96)\end{array}$ & $\begin{array}{c}11.24^{* * *} \\
(1.21)\end{array}$ & $\begin{array}{c}7.42^{* * *} \\
(1.14)\end{array}$ & $\begin{array}{c}15.21^{* * *} \\
(2.79)\end{array}$ & $\begin{array}{c}41.70^{* *} \\
(16.36)\end{array}$ \\
\hline $\log (\mathrm{T}-\mathrm{Bill} / \mathrm{GDP})$ & $\begin{array}{c}10.14 \\
(15.79)\end{array}$ & $\begin{array}{c}-62.69^{* * *} \\
(19.65)\end{array}$ & $\begin{array}{l}-15.78 \\
(11.15)\end{array}$ & $\begin{array}{c}0.24 \\
(11.14)\end{array}$ & $\begin{array}{l}-22.95 \\
(39.01)\end{array}$ & $\begin{array}{c}-5.47 \\
(50.82)\end{array}$ \\
\hline VIX & $\begin{array}{c}2.26^{* *} \\
(0.90)\end{array}$ & $\begin{array}{c}1.95^{* * *} \\
(0.55)\end{array}$ & $\begin{array}{c}1.93^{* * *} \\
(0.49)\end{array}$ & $\begin{array}{c}1.97^{* * *} \\
(0.45)\end{array}$ & $\begin{array}{c}3.72^{* * *} \\
(1.17)\end{array}$ & $\begin{array}{c}7.43^{* * *} \\
(2.49)\end{array}$ \\
\hline Slope & $\begin{array}{c}12.76^{* * * *} \\
(2.83)\end{array}$ & $\begin{array}{l}6.86^{*} \\
(3.61)\end{array}$ & $\begin{array}{l}-1.15 \\
(2.87)\end{array}$ & $\begin{array}{l}-3.77 \\
(2.84)\end{array}$ & $\begin{array}{l}10.98 \\
(6.77)\end{array}$ & $\begin{array}{c}41.15^{* *} \\
(19.97)\end{array}$ \\
\hline Intercept & $\begin{array}{c}36.68 \\
(29.61)\end{array}$ & $\begin{array}{c}-139.38^{* * *} \\
(36.36) \\
\end{array}$ & $\begin{array}{c}-54.19^{* *} \\
(25.76)\end{array}$ & $\begin{array}{c}40.78 \\
(26.48)\end{array}$ & $\begin{array}{c}-324.79^{* *} \\
(136.95) \\
\end{array}$ & $\begin{array}{c}-1336.73^{* * *} \\
(458.78)\end{array}$ \\
\hline \# Obs. & 768 & 768 & 768 & 768 & 432 & 168 \\
\hline $\operatorname{Adj~} R^{2}$ & 0.63 & 0.48 & 0.60 & 0.48 & 0.36 & 0.53 \\
\hline
\end{tabular}

Note: Newey-West standard errors (12 lags) in parentheses. $* * * p<0.01, * * p<0.05, * p<0.1$. Includes a linear time-trend. Economic slack is computed with year on year change in a twelve month average of the log of industrial production index following Stock and Watson (2019). Column 1 uses the percentage spread between Moody's Baa-rated long-maturity corporate bond yield and Moody's Aaa-rated long-maturity corporate bond yield. Column 2 uses the percentage spread between Moody's Aaa-rated long-maturity corporate bond yield and the yield on long-maturity Treasury bonds. Column 3 use the three-month banker's acceptance rate and T-bills. The data series for the banker's acceptance rate ends in the 1990s. To create a series until 2011, we use the GC repo/T-bill spread from 1991 onward constructed by Nagel (2016). Column 4 uses the percentage yield spread between 3-month high-grade commercial paper and Treasury bills. Column 5 uses the spread between three-month certificate of deposit (CD) rates and T-bills as an alternative measure of the illiquid rate. Column 6 uses the percentage yield spread between lower-grade commercial paper and Treasury bills. It is calculated as the sum of the CP-bills yield spread described above (i.e., high-grade commercial paper minus Treasury bills) and the yield spread between 30-day A2/P2 nonfinancial commercial paper and 30-day AA nonfinancial commercial paper, with data obtained from the Federal Reserve Bank of New York. 


\section{E Robustness to Figure 2}

Figure 8: Cyclicality of privately supplied safe debt

(a) Growth rates

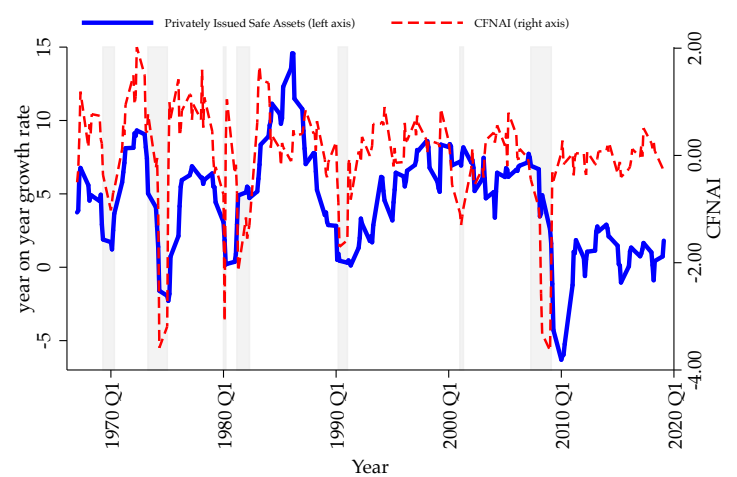

(b) Hamilton (2018) filter-based cycle

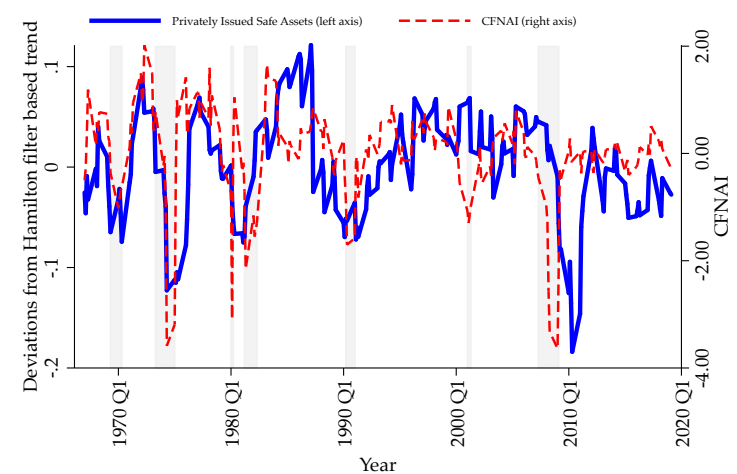

Source: Our calculations. We extended Gorton et al. (2012)'s definition to measure safe assets using US Financial Accounts data retrieved from FRED, St. Louis Fed. Shaded bars denote NBER Recession dates. See text. 


\section{F Robustness to Figure 3}

Figure 9: Correlations of $x_{t+h}$ with time-t real GDP (filtered with Hamilton filter)
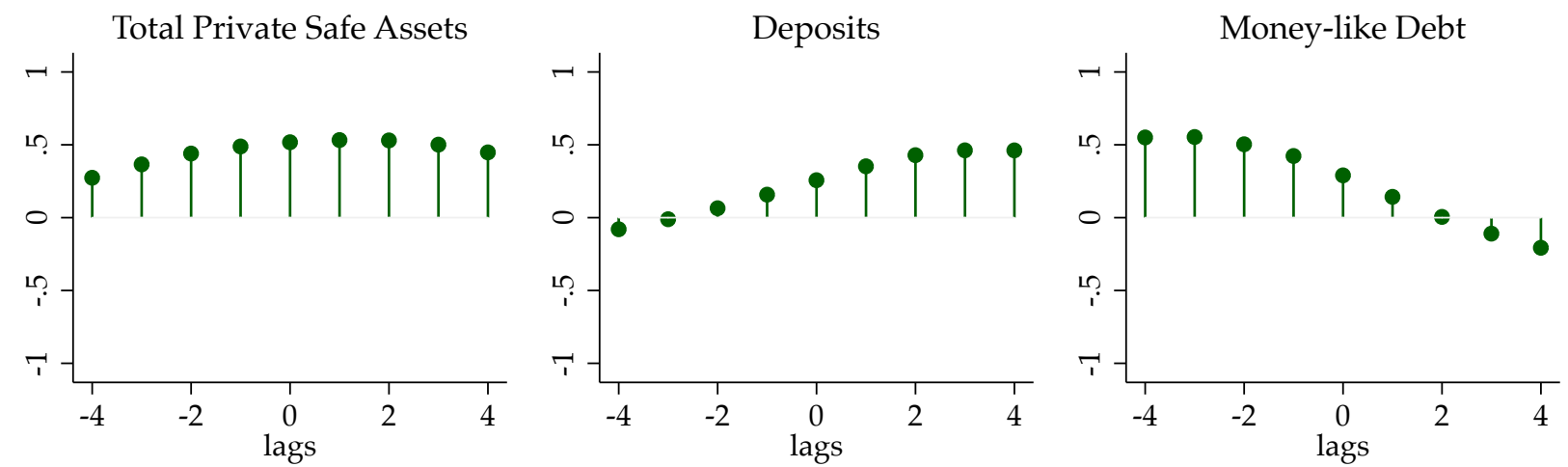

$\mathrm{MBS} / \mathrm{ABS}$

Corporate Bonds
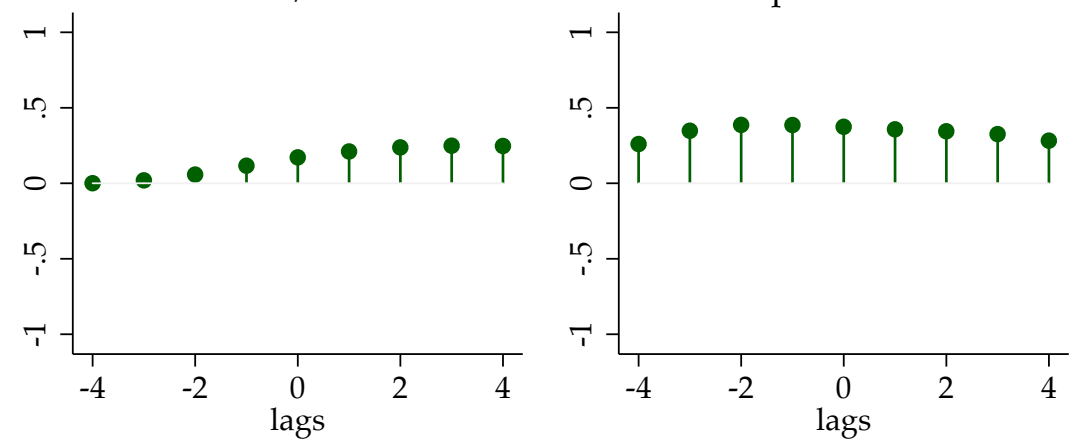

Other Safe Assets

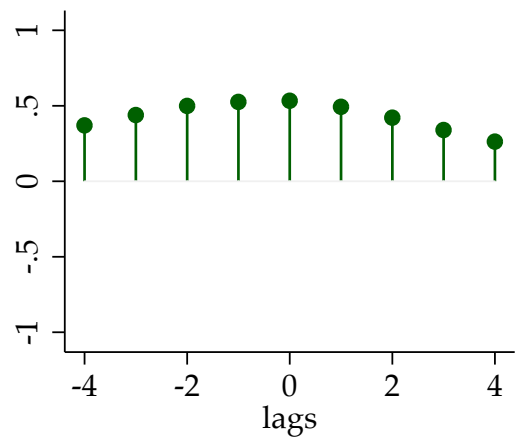

Source: Our calculations using US Financial Accounts data retrieved from FRED, St. Louis Fed. The definitions follow Gorton et al. (2012). Real GDP and all the safe asset component series are detrended with the Hamilton filter. See text. 
Figure 10: Correlations of $x_{t+h}$ with time-t real GDP (polynomial filter)
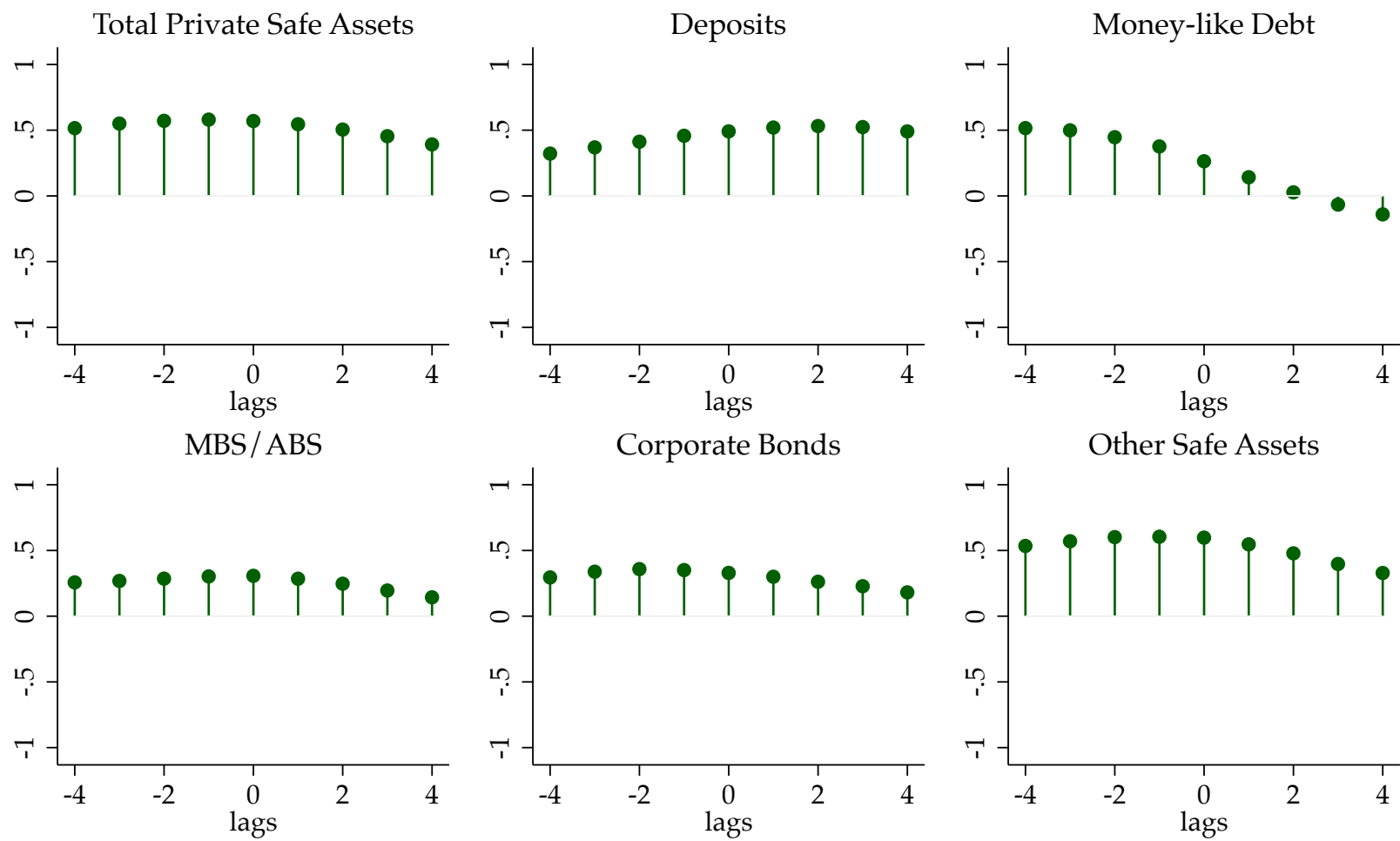

Other Safe Assets

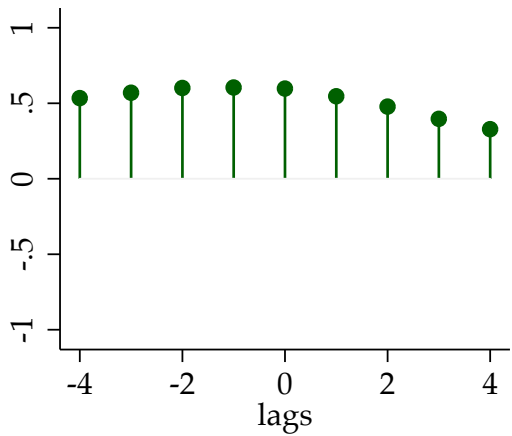

Source: Our calculations using US Financial Accounts data retrieved from FRED, St. Louis Fed. The definitions follow Gorton et al. (2012). Real GDP and all of the safe asset component series are detrended using a (sixth-degree) polynomial regression on time. See text. 
Figure 11: Correlations of $x_{t+h}$ with time-t real GDP (band pass filter)
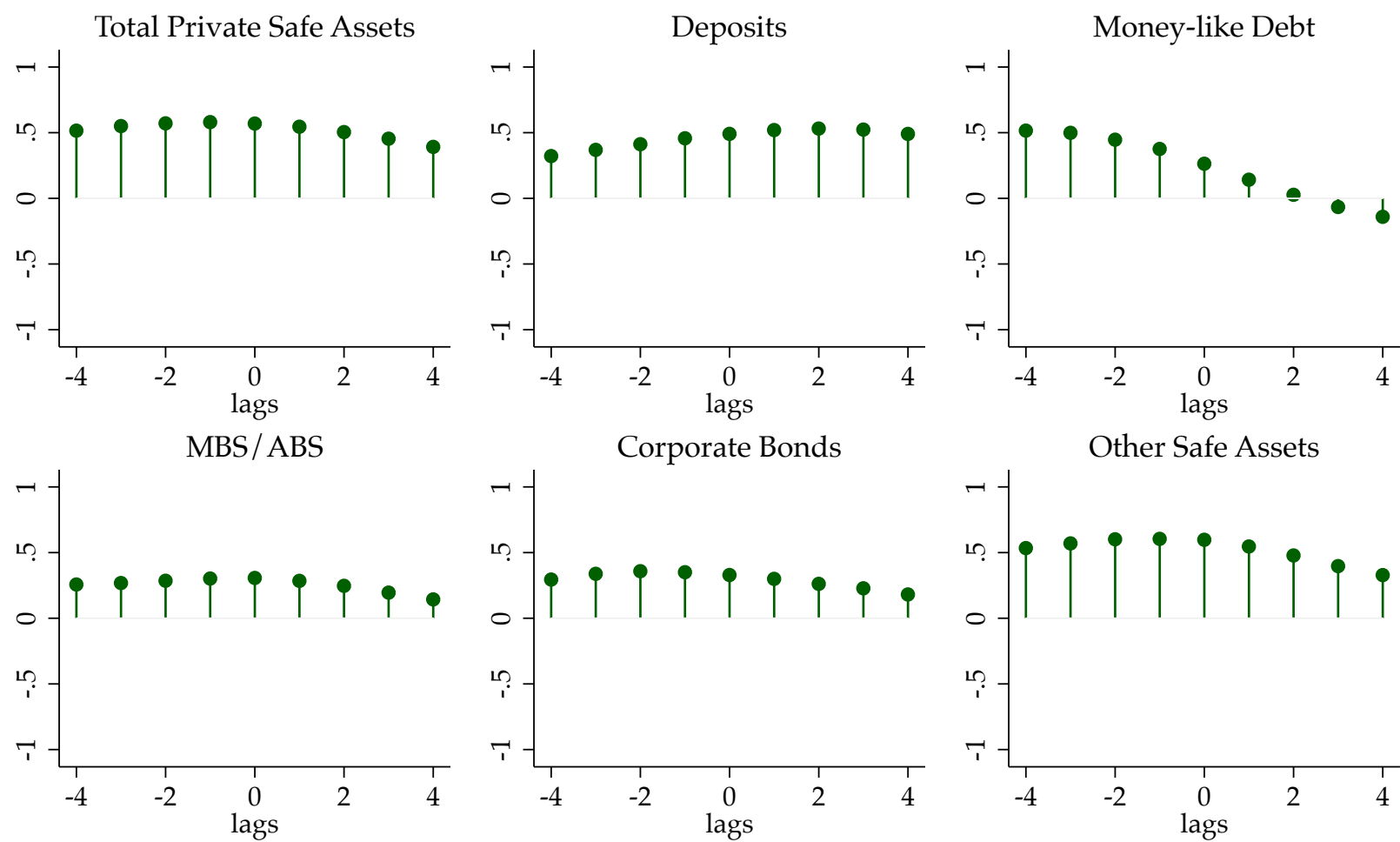

Other Safe Assets

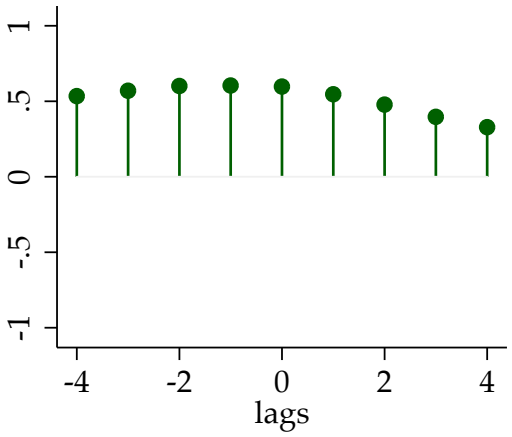

Source: Our calculations using US Financial Accounts data retrieved from FRED, St. Louis Fed. The definitions follow Gorton et al. (2012). Real GDP and all of the safe asset component series are detrended using a band-pass filter at business cycle frequencies (18 and 96 months). See text. 
Figure 12: Correlations of $x_{t+h}$ with time-t real GDP (linearly detrended)
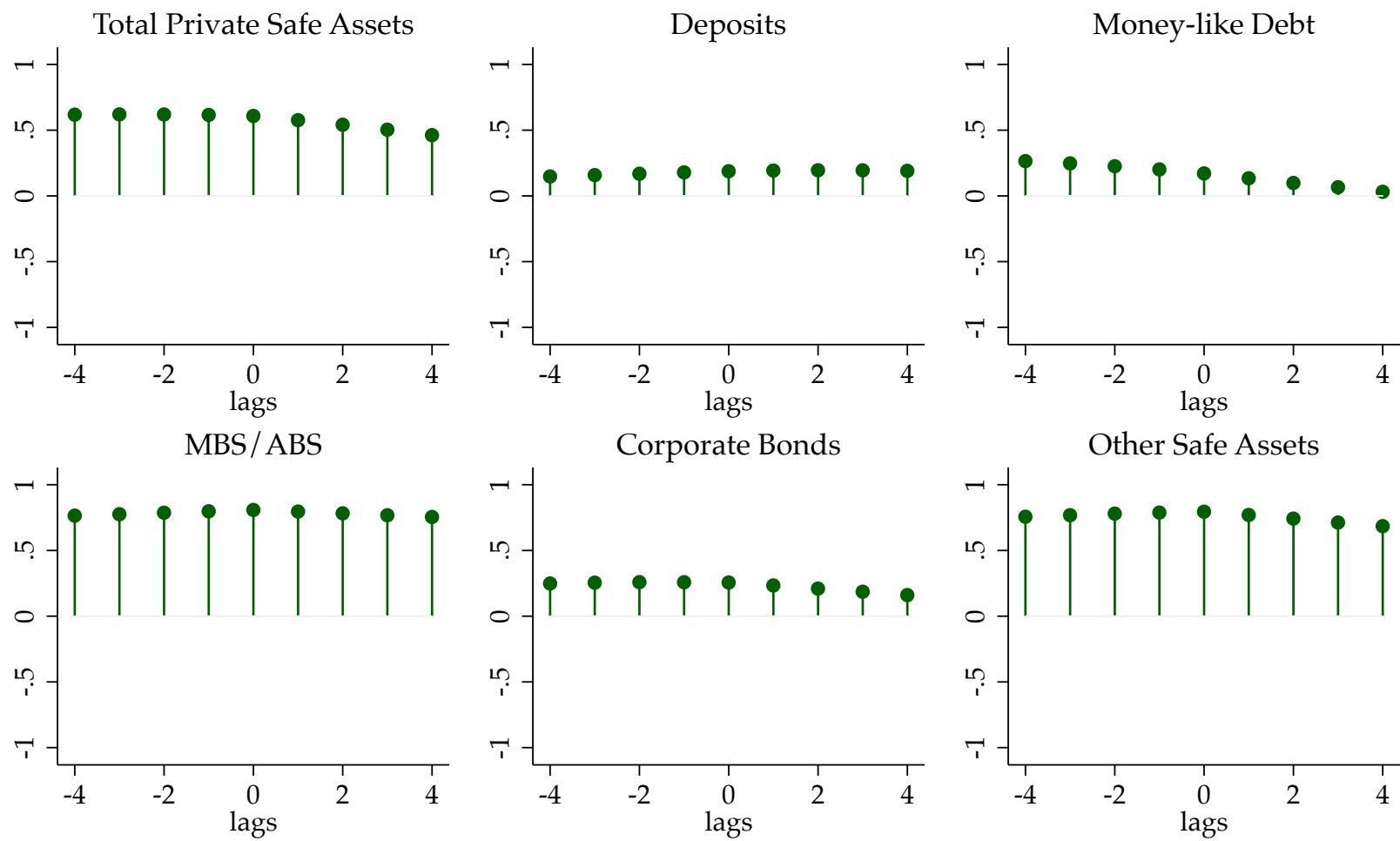

Other Safe Assets

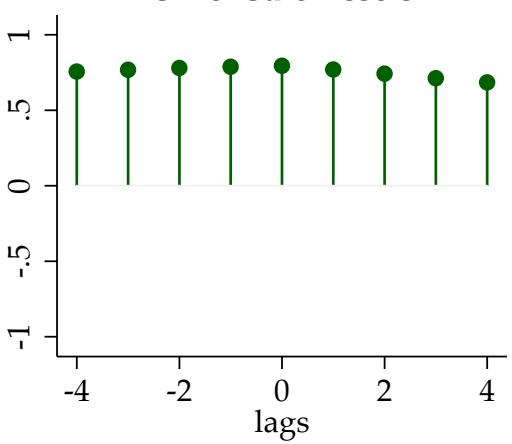

Source: Our calculations using US Financial Accounts data retrieved from FRED, St. Louis Fed. The definitions follow Gorton et al. (2012). Real GDP and all of the safe asset component series are linearly detrended. See text. 
Figure 13: Correlations of $x_{t+h}$ (Hamilton filtered) with time-t CFNAI
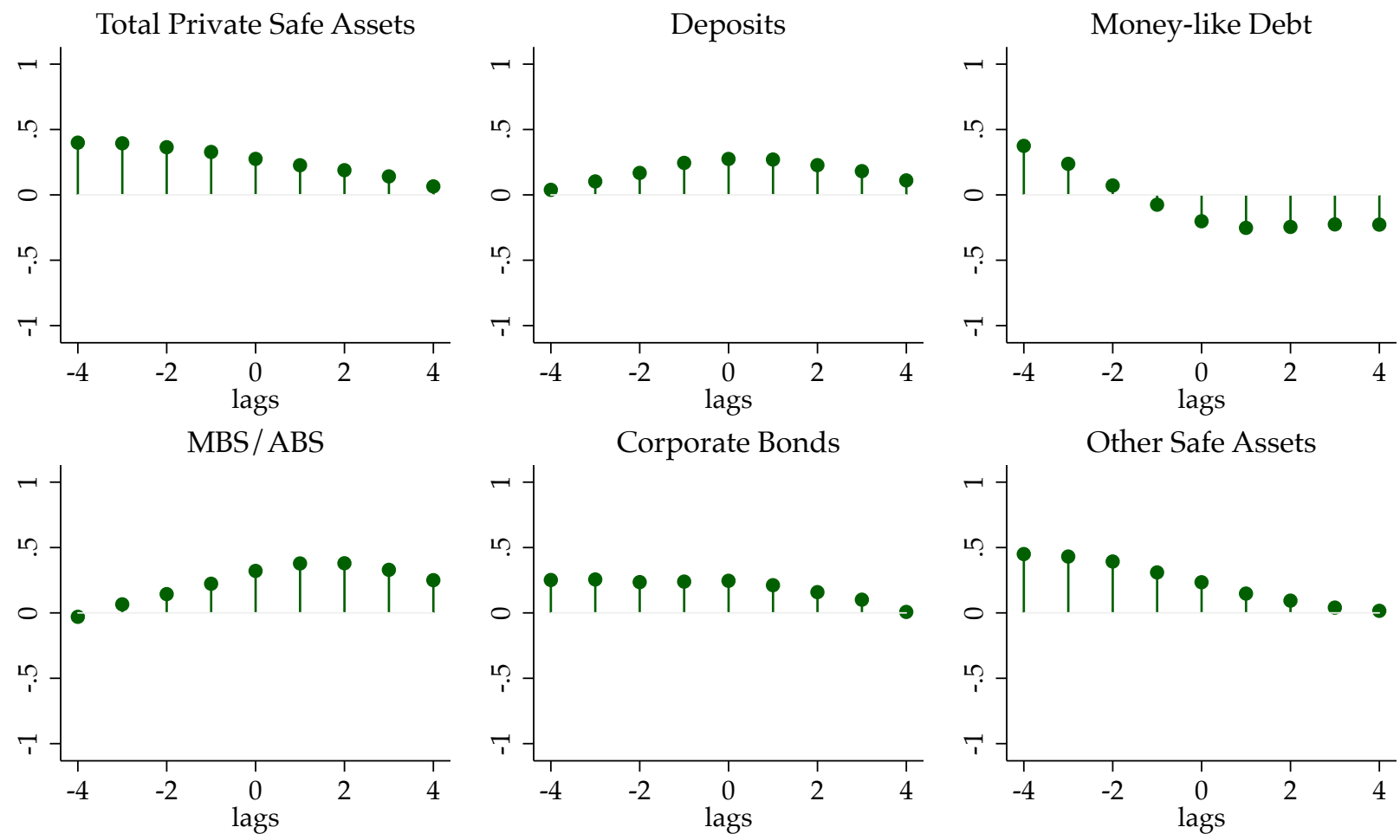

Other Safe Assets

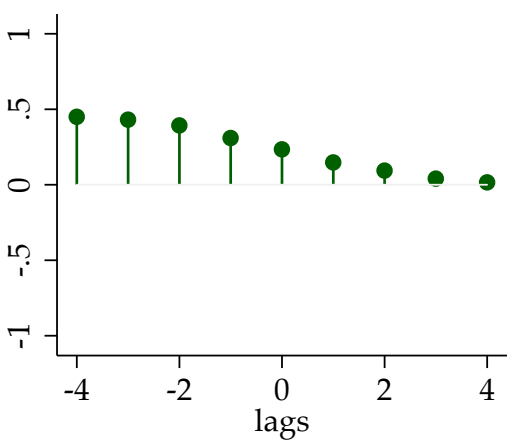

Source: Our calculations using US Financial Accounts data retrieved from FRED, St. Louis Fed. The definitions follow Gorton et al. (2012). All safe asset component series are detrended with Hamilton filter. See text. 
Figure 14: Correlations of $x_{t+h}$ (y-o-y growth) with time-t CFNAI
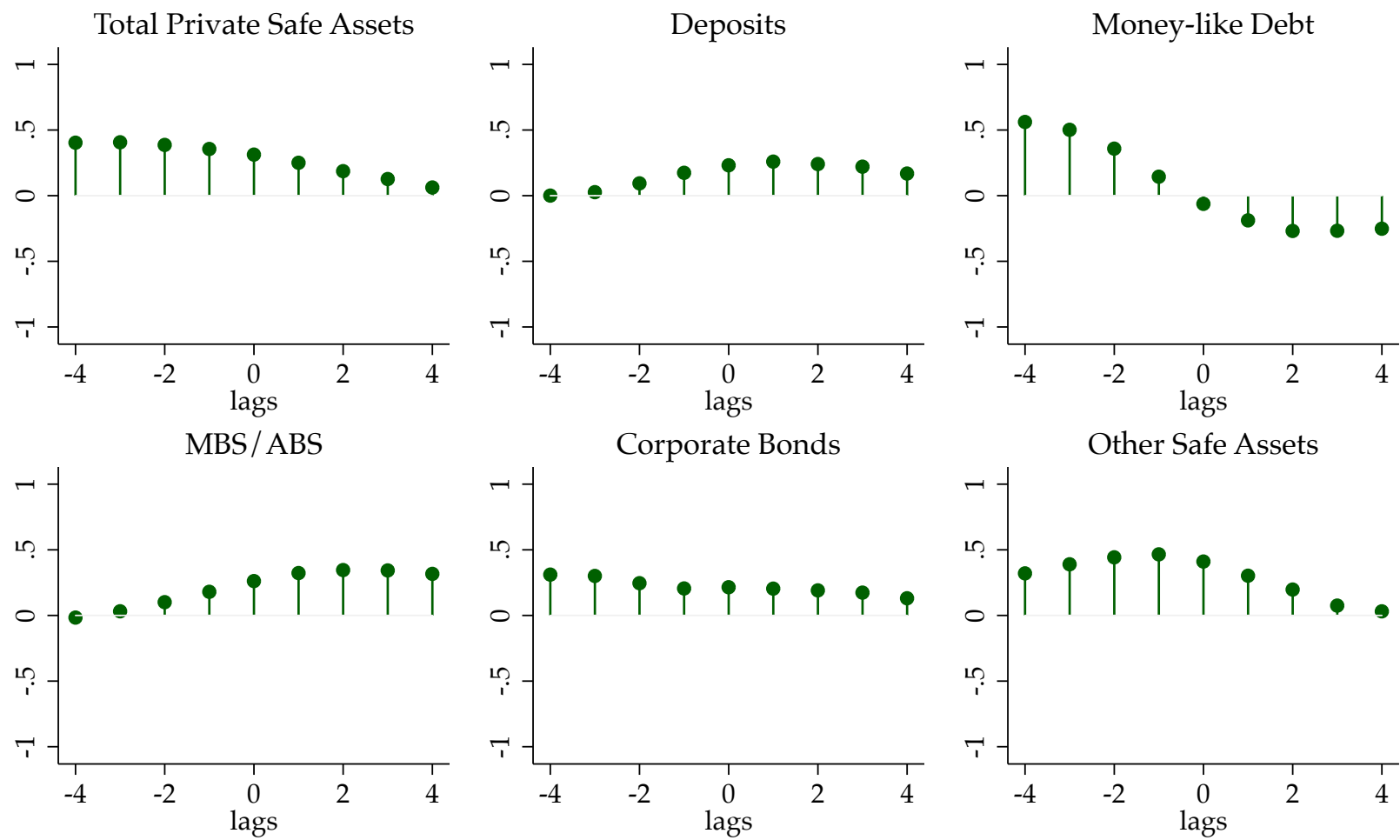

Other Safe Assets

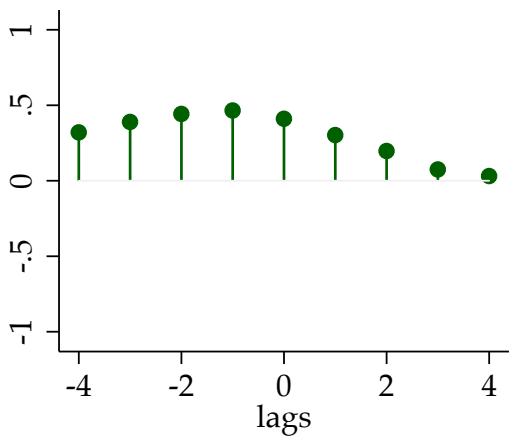

Source: Our calculations using US Financial Accounts data retrieved from FRED, St. Louis Fed. The definitions follow Gorton et al. (2012). All safe asset component series are plotted in year on year growth rates. See text. 


\section{G Quantitative Model}

The economy of Section 5 is an extension of the one described in Section 3. We study an infinite horizon economy in discrete time that is populated by households, firms and a government. The households of this economy are analogous to the ones in Section 3. The main difference with respect to the model presented in Section 3 is on the firms' side.

Firms are the owners of the capital of the economy, which they combine with labor to produce the final consumption good according to the following production function:

$$
Y_{t}=A\left(K_{t}^{\alpha} h_{t}^{1-\alpha}\right)^{\nu}
$$

where $\alpha, \nu \in(0,1)$. The parameter $\nu$ denotes span of control, which measures the degree of decreasing returns in variable factors of production. After production, a fraction $\delta$ of the initial capital depreciates. Firms operate an investment technology that transforms the final consumption good into units of capital that can be used in subsequent periods, according to

$$
K_{t+1}=(1-\delta) K_{t}+X_{t}
$$

where $X_{t}$ denotes the firms' investment. Firms per-period profits are given by

$$
\Pi_{t}=P_{t}\left(A\left(K_{t}^{\alpha} h_{t}^{1-\alpha}\right)^{\nu}-F\right)-W_{t} h_{t}
$$

where $F$ is a fixed cost, and they face a borrowing constraint given by

$$
\frac{\tilde{B}_{t+1}^{p}}{P_{t+1}} \leq \phi\left(\frac{\Pi_{t+1}}{P_{t+1}}\right)^{\eta}
$$

where $\phi, \eta>0$.

A firm's problem is then given by

$$
V_{0} \equiv \max _{\left\{D_{t}, K_{t+1}, h_{t}, \tilde{B}_{t+1}^{p}, X_{t}\right\}_{t=0}^{\infty}} \sum_{t=0}^{\infty} \Lambda_{t} D_{t}
$$

subject to

$$
\begin{gathered}
D_{t} \leq P_{t}\left(A\left(K_{t}^{\alpha} h_{t}^{1-\alpha}\right)^{\nu}-F\right)-W_{t} h_{t}-\tilde{B}_{t}^{p}+\frac{\tilde{B}_{t+1}^{p}}{1+i_{t}}-P_{t} X_{t} \\
X_{t}=K_{t+1}-(1-\delta) K_{t} \\
\frac{\tilde{B}_{t+1}^{p}}{P_{t+1}} \leq \phi\left(A\left(K_{t+1}^{\alpha} h_{t+1}^{1-\alpha}\right)^{\nu}-F-w_{t+1} h_{t+1}\right)^{\eta}
\end{gathered}
$$

where $\Lambda_{t}$ is the household's stochastic discount factor. The firm will be active in $t$ if and only if 
$\Pi_{t} \geq 0$.

Noting that the choice of labor is a static problem, taking FOCs we get

$$
(1-\alpha) \nu A K_{t}^{\alpha \nu} h_{t}^{(1-\alpha) \nu-1}=w_{t}
$$

where $w_{t}$ denotes the real wage, so

$$
h_{t}=\left[\frac{(1-\alpha) \nu A_{t} K_{t}^{\alpha \nu}}{w_{t}}\right]^{\frac{1}{1-(1-\alpha) \nu}}
$$

Let $\tilde{\alpha} \equiv \alpha \nu$ and $\tilde{\gamma}=(1-\alpha) \nu$. Using above equation, we can rewrite the per-period profits as

$$
\frac{\Pi_{t}}{P_{t}}=\tilde{Z}_{t} K_{t}^{\frac{\tilde{\alpha}}{1-\tilde{\gamma}}}-F
$$

where $\tilde{Z}_{t} \equiv(1-\tilde{\gamma}) A_{t}\left(\frac{\tilde{\gamma} A_{t}}{w_{t}}\right)^{\frac{\tilde{\gamma}}{1-\tilde{\gamma}}}$.

Thus, the problem of the firm can be rewritten as

$$
\max _{\left\{K_{t+1}, B_{t+1}^{p}\right\}_{t=0}^{\infty}} \sum_{t=0}^{\infty} \Lambda_{t} P_{t}\left[\tilde{Z}_{t} K_{t}^{\frac{\alpha}{1-\gamma}}-F+\frac{1+\pi_{t+1}}{1+i_{t}} B_{t+1}^{p}-B_{t}^{p}-\left(K_{t+1}-(1-\delta) K_{t}\right)\right]
$$

subject to

$$
B_{t+1}^{p} \leq \phi\left(\tilde{Z}_{t+1} K_{t+1}^{\frac{\tilde{\alpha}}{1-\tilde{\gamma}}}-F\right)^{\eta}
$$

and $\Pi_{t} \geq 0 \forall t$.

Let $P_{t+1} \mu_{t}$ be the Lagrange multiplier associated with the borrowing constraint. The FOCs are

$$
\begin{gathered}
\left(K_{t+1}\right): \Lambda_{t+1} P_{t+1} \tilde{Z}_{t+1} \frac{\tilde{\alpha}}{1-\tilde{\gamma}} K_{t+1}^{\frac{\tilde{\alpha}}{1-\tilde{\gamma}}-1}-\Lambda_{t} P_{t}+\Lambda_{t+1} P_{t+1}(1-\delta)+ \\
P_{t} \mu_{t} \phi \eta \frac{\tilde{\alpha}}{1-\tilde{\gamma}}\left(\tilde{Z}_{t+1} K_{t+1}^{\frac{\tilde{\alpha}}{1-\tilde{\gamma}}}-F\right)^{\eta-1} \tilde{Z}_{t+1} K_{t+1}^{\frac{\tilde{\alpha}}{1-\tilde{\gamma}}-1}=0 \\
\left(B_{t+1}^{p}\right): \quad \Lambda_{t} P_{t} \frac{1+\pi_{t+1}}{1+i_{t}}-\Lambda_{t+1} P_{t+1}-P_{t} \mu_{t}=0
\end{gathered}
$$

Replacing $\Lambda_{t} P_{t}=\beta^{t} u^{\prime}\left(C_{t}^{w}\right)$, we can rewrite these equations as

$$
\begin{gathered}
1=\beta \frac{u^{\prime}\left(C_{t+1}^{w}\right)}{u^{\prime}\left(C_{t}^{w}\right)}\left(\tilde{Z}_{t+1} \frac{\tilde{\alpha}}{1-\tilde{\gamma}} K_{t+1}^{\frac{\tilde{\alpha}}{1-\tilde{\gamma}}-1}+(1-\delta)\right)+ \\
P_{t+1} \frac{\mu_{t}}{\Lambda_{t}} \phi \eta \frac{\tilde{\alpha}}{1-\tilde{\gamma}}\left(\tilde{Z}_{t+1} K_{t+1}^{\frac{\tilde{\alpha}}{1-\tilde{\gamma}}}-F\right)^{\eta-1} \tilde{Z}_{t+1} K_{t+1}^{\frac{\tilde{\alpha}}{1-\tilde{\gamma}}-1} \\
1=\frac{1+i_{t}}{1+\pi_{t+1}}\left[\beta \frac{u^{\prime}\left(C_{t+1}^{w}\right)}{u^{\prime}\left(C_{t}^{w}\right)}+P_{t+1} \frac{\mu_{t}}{\Lambda_{t}}\right]
\end{gathered}
$$


Comparing (9) and (27), it is immediately apparent that

$$
P_{t+1} \mu_{t}=\beta^{t+1} \chi\left[v^{\prime}\left(B_{t+1}-u^{\prime}\left(C_{t+1}^{w}\right)\right]\right.
$$

\section{G.1 Equilibrium Equations}

The equilibrium of the economy can be characterized by a system of 9 equations in the 9 unknowns $\left\{i_{t}, \pi_{t}, C_{t}^{w}, B_{t+1}^{p}, K_{t+1}, Y_{t}, h_{t}, w_{t}, \tilde{Z}_{t}\right\}$

$$
\begin{gathered}
1=\beta \frac{1+i_{t}}{1+\pi_{t+1}}\left[\frac{u^{\prime}\left(C_{t+1}^{w}\right)}{u^{\prime}\left(C_{t}^{w}\right)}+\chi \frac{v^{\prime}\left(B_{t+1}\right)-u^{\prime}\left(C_{t+1}^{w}\right)}{u^{\prime}\left(C_{t}^{w}\right)}\right] \\
C_{t}^{w}=Y_{t}-K_{t+1}+(1-\delta) K_{t}-\chi B_{t} \\
B_{t+1}=\phi\left[(1-\tilde{\gamma}) Y_{t+1}-F\right]^{\eta}+B_{t}^{g} \\
1=\beta \frac{u^{\prime}\left(C_{t+1}^{w}\right)}{u^{\prime}\left(C_{t}^{w}\right)}\left(\tilde{Z}_{t+1} \frac{\tilde{\alpha}}{1-\tilde{\gamma}} K_{t+1}^{\frac{\tilde{\alpha}}{1-\tilde{\gamma}}-1}+1-\delta\right)+\chi \frac{v^{\prime}\left(B_{t+1}\right)-u^{\prime}\left(C_{t+1}^{w}\right)}{u^{\prime}\left(C_{t}^{w}\right)} \phi \eta \\
\left(\tilde{Z}_{t+1} K_{t+1}^{\frac{\tilde{\alpha}}{1-\tilde{\gamma}}}-F\right)^{\eta-1} \tilde{Z}_{t+1} \frac{\tilde{\alpha}}{1-\tilde{\gamma}} K_{t+1}^{\frac{\tilde{\alpha}}{1-\tilde{\gamma}}-1} \\
Y_{t}=A K_{t}^{\tilde{\alpha}} h_{t}^{\tilde{\gamma}} \\
w_{t}=\frac{\tilde{\gamma} A_{t} K_{t}^{\tilde{\alpha}}}{h_{t}^{1-\tilde{\gamma}}} \\
\tilde{Z}_{t} \equiv(1-\tilde{\gamma}) A_{t}\left(\frac{\tilde{\gamma} A_{t}}{w_{t}}\right)^{\frac{\tilde{\gamma}}{1-\tilde{\gamma}}} \\
1+i_{t}=\max \left\{1, R_{t}^{*}+\phi_{y}\left(h_{t}-1\right)\right\} \\
w_{t} \geq \frac{\kappa+(1-\kappa) h_{t}^{\tilde{\gamma}}}{\pi_{t}} w_{t-1} ; \quad h_{t} \leq 1 ; \quad\left(\begin{array}{c}
\kappa+(1-\kappa) h_{t}^{\tilde{\gamma}} \\
\left.w_{t-1}-\frac{\kappa+\left(1-h_{t}\right)=0}{\pi_{t}}\right)
\end{array}\right.
\end{gathered}
$$

given initial capital $K_{0}$ and subject to the requirement that dividends be non-negative

$$
D_{t}=\tilde{Z}_{t} K_{t}^{\frac{\tilde{\alpha}}{1-\tilde{\gamma}}}-F+\frac{B_{t+1}^{p}\left(1+\pi_{t+1}\right)}{1+i_{t}}-B_{t}^{p}+(1-\delta) K_{t}-K_{t+1} .
$$




\section{G.2 Steady State}

A steady-state equilibrium of the economy solves the following system of equations:

$$
\begin{gathered}
1=\beta \frac{1+i}{\pi}\left[(1-\chi)+\chi \frac{B^{-\rho}}{u^{\prime}\left(C^{w}\right)}\right] \\
C^{w}=Y-\delta K-\chi B \\
B=\phi\left(\tilde{Z} K^{\left.\frac{\tilde{\alpha}}{1-\tilde{\gamma}}-F\right)^{\eta}+B^{g}}\right. \\
1=\beta\left[\left(\tilde{Z} \frac{\tilde{\alpha}}{1-\tilde{\gamma}} K^{\frac{\tilde{\alpha}}{1-\tilde{\gamma}}-1}+1-\delta\right)+\frac{\chi}{1-\chi} \frac{B^{-\rho}-u^{\prime}\left(C^{w}\right)}{u^{\prime}\left(C^{w}\right)} \phi \eta\left(\tilde{Z} K^{\frac{\tilde{\alpha}}{1-\tilde{\gamma}}}-F\right)^{\eta-1} \tilde{Z} \frac{\tilde{\alpha}}{1-\tilde{\gamma}} K^{\frac{\tilde{\alpha}}{1-\tilde{\gamma}}-1}\right] \\
Y=A K^{\tilde{\alpha}} h^{\tilde{\gamma}} \\
w=\frac{\tilde{\gamma} A K^{\tilde{\alpha}}}{h^{1-\tilde{\gamma}}} \\
\tilde{Z} \equiv(1-\tilde{\gamma}) A\left(\frac{\tilde{\gamma} A}{w}\right)^{\frac{\tilde{\gamma}}{1-\tilde{\gamma}}} \\
1+i=\max \left\{1,+\phi_{y}(h-1)\right\} \\
1 \geq \frac{\kappa+(1-\kappa) h^{\tilde{\gamma}}}{\pi} ; \quad h \leq 1 ; \quad\left(1-\frac{\kappa+(1-\kappa) h^{\tilde{\gamma}}}{\pi}\right)(1-h)=0
\end{gathered}
$$

subject to the requirement that dividends be non-negative, and given initial capital.

$$
D=\tilde{Z} K^{\frac{\tilde{\alpha}}{1-\tilde{\gamma}}}-F+\frac{B \pi}{1+i}-B-\delta K
$$




\section{H Unemployment Risk and Counter-Cyclical Demand for Safe Assets}

In this section we present an extension of the model in Section 3 that incorporates unemployment risk following Heathcote and Perri (2018). The model allows us to obtain a richer version of the GEE equation (10), and to show how different economic forces generate different cyclicalities in the demand for assets as well as the bond premium.

The economy is populated by a measure one of households. Households are comprised of a measure one of workers and a measure $\chi$ of retirees. Workers are endowed with one unit of time every period, which they supply inelastically in the labor market. Retirees cannot work, and they live for only one period. Every period a fraction $\chi$ of workers retires and a measure $\chi$ of workers is born. Thus, the composition of each household is constant over time.

At the beginning of every period, the workers of each household look for jobs in the labor market. In the presence of nominal wage rigidities, not all workers might be able to find a job, and a fraction $u_{t}$ will remain unemployed. When $u_{t}<1$ the economy is operating below potential and there is involuntary unemployment. Households are the owners of the firms, which distribute nominal dividends $D_{t}$. Finally, households can trade nominal assets $\tilde{B}_{t}$ at a nominal price $\frac{1}{1+i_{t}}$, where $i_{t}$ is the nominal interest rate.

Being employed, unemployed or retired determines how much of an agent's are resources available for consumption. In particular, we assume that intraperiod transfer of funds is not possible. To finance their consumption, agents have access to their savings, and only employed workers can use their wage income. At the end of the period, and after consumption takes place, the members of each household pool their resources and make the saving decisions for the following period.

Households maximize a utilitarian welfare function of their members' utility

$$
E_{0} \sum_{t=0}^{\infty} \beta^{t}\left[U_{t}\left(C_{t}^{w}, C_{t}^{u}\right)+\chi \log \left(C_{t}^{r}\right)\right]
$$

where $C_{t}^{w}, C_{t}^{u}$ and $C_{t}^{r}$ are the consumption of an employed worker, an unemployed worker and a retiree, respectively, and $\beta$ is the discount factor. The function $U_{t}(\cdot, \cdot)$ is an aggregator of the workers' consumption, which we assume takes the following functional form:

$$
U_{t}\left(C_{t}^{w}, C_{t}^{u}\right)=\frac{\left[\left(1-u_{t}\right)\left(C_{t}^{w}\right)^{\frac{\rho-1}{\rho}}+u_{t}\left(C_{t}^{u}\right)^{\frac{\rho-1}{\rho}}\right]^{\frac{(1-\sigma) \rho}{\rho-1}}}{1-\sigma}
$$

If we assume that $\rho \rightarrow \infty$ and $\sigma=1$, we get

$$
U_{t}\left(C_{t}^{w}, C_{t}^{u}\right)=\log \left(\left(1-u_{t}\right) C_{t}^{w}+u_{t} C_{t}^{u}\right)
$$

This specification corresponds to the case where employed and unemployed worker's consumption 
are perfect substitutes, so unemployment risk is irrelevant. ${ }^{34}$ This can be mapped onto the case we studied in Section 3. In this section, we will consider the case with $\rho=1$ and $\sigma=1$, so that equation (29) simplifies to

$$
U_{t}\left(C_{t}^{w}, C_{t}^{u}\right)=\left(1-u_{t}\right) \log \left(C_{t}^{w}\right)+u_{t} \log \left(C_{t}^{u}\right)
$$

This specification corresponds to the case where unemployment risk matters for intra-household allocations, as in Heathcote and Perri (2018).

Within a period, each member of the household makes their consumption decision based on their own portfolio holdings and income. The intra-period budget constraints faced by agents are given by

$$
\begin{aligned}
P_{t} C_{t}^{w} & \leq \tilde{B}_{t}+W_{t}+D_{t} \\
P_{t} C_{t}^{j} & \leq \tilde{B}_{t} \quad \text { for } j \in\{u, r\}
\end{aligned}
$$

where $P_{t}$ denotes the price level, $\tilde{B}_{t}$ denotes the holdings of nominal one period safe bonds, and $W_{t}$ is the nominal wage. At the end of the period, the household as a whole faces the following budget constraint:

$$
\left(1-u_{t}\right) P_{t} C_{t}^{w}+u_{t} P_{t} C_{t}^{u}+\chi P_{t} C_{t}^{r}+\frac{\tilde{B}_{t+1}}{1+i_{t}} \leq\left(1-u_{t}\right) W_{t}+D_{t}+\tilde{B}_{t}+T_{t}
$$

where $T_{t}$ are lump-sum transfers. The problem of the household consists of choosing $\left\{C_{t}^{w}, C_{t}^{u}, C_{t}^{r}, \tilde{B}_{t+1}\right\}_{t=0}^{\infty}$ in order to maximize (1) subject to the budget constraints (30), (31) and (32) for every $t \geq 0$, and a no-Ponzi condition. Since all households solve the same problem, we can treat the economy as populated by one representative household.

The firms' problem and wage rigidity constraint are isomorphic to those in Section 3. For the government, we assume that the central bank sets interest rates according to

$$
1+i_{t}=\max \left\{1, R_{t}^{*}+\phi_{Y}\left(1-u_{t}\right)\right\}
$$

where and $R_{t}^{*}$ is the real interest rate consistent with the zero-inflation full-employment equilibrium. The government's budget constraint is isomorphic to that in Section 3.

\footnotetext{
${ }^{34}$ Unemployment still matters because it reduces the household's income, but not for its effects on the distribution of consumption.
} 


\section{H.1 Equilibrium}

We will look for equilibria in which the intraperiod budget constraint of the unemployed workers and retirees is binding. The FOCs associated with the household's problem are

$$
\begin{aligned}
\left(C_{t}^{w}\right): & \beta^{t}\left(C_{t}^{w}\right)^{-1}=P_{t} \Lambda_{t} \\
\left(\tilde{B}_{t+1}\right): & \beta^{t+1}\left(u_{t+1} B_{t+1}^{-1}+\chi B_{t+1}^{-1}\right) \frac{1}{P_{t+1}}+\left(1-u_{t+1}-\chi\right) \Lambda_{t+1}=\frac{\Lambda_{t}}{1+i_{t}}
\end{aligned}
$$

where $\Lambda_{t}$ is the Lagrange multiplier associated with the household's budget constraint, and $B_{t} \equiv \frac{\tilde{B}_{t}}{P_{t}}$. Plugging (33) into (34), we get the following Generalized Euler Equation (GEE):

$$
\begin{aligned}
& 1=\frac{1+i_{t}}{1+\pi_{t+1}} \beta[\underbrace{\left(\frac{C_{t+1}^{w}}{C_{t}^{w}}\right)^{-1}}_{\text {intertemporal substitution motive }}+\underbrace{u_{t+1} \frac{\left(B_{t+1}\right)^{-1}-\left(C_{t+1}^{w}\right)^{-1}}{\left(C_{t}^{w}\right)^{-1}}}_{\text {self-insurance motive }}+ \\
& \underbrace{\chi \frac{\left(B_{t+1}\right)^{-1}-\left(C_{t+1}^{w}\right)^{-1}}{\left(C_{t}^{w}\right)^{-1}}}_{\text {retirement motive }}]
\end{aligned}
$$

We define the bond premium as

$$
b p \equiv u_{t+1} \frac{\left(B_{t+1}\right)^{-1}-\left(C_{t+1}^{w}\right)^{-1}}{\left(C_{t}^{w}\right)^{-1}}+\chi \frac{\left(B_{t+1}\right)^{-1}-\left(C_{t+1}^{w}\right)^{-1}}{\left(C_{t}^{w}\right)^{-1}} .
$$

The bond premium now has two terms: the retirement motive, as in Section 3, and the self-insurance motive arising from the unemployment risk, as in Heathcote and Perri (2018). Note that while the retirement motive is always pro-cyclical (increasing in $C_{t}^{W}$ and $C_{t+1}^{w}$ ), the self-insurance motive can be counter-cyclical since $u_{t+1}$ is decreasing in $Y_{t+1}$.

The rest of the economy can be characterized in a similar way as in Section 3. Focusing on steady-state equilibria, the characteristics of the economy depend on the cyclicality of the bond demand. If the bond demand is pro-cyclical (because the self-insurance motive is not sufficiently counter-cyclical), the economy is isomorphic to the economy in Section 3. In contrast, if the bond demand is counter-cyclical, the economy admits only two types of steady-state equilibria: a fullemployment steady state and a self-fulfilling liquidity trap. In particular, if the demand for safe assets is counter-cyclical, the economy does not admit (permanent) fundamental liquidity traps. 